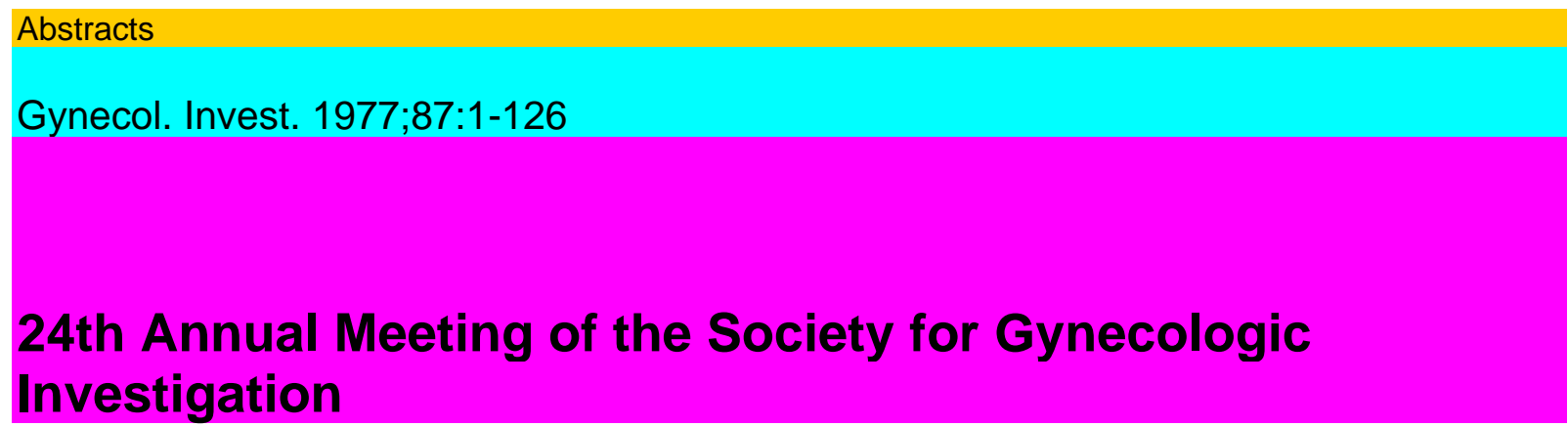

Scientific Abstracts

S. Karger · Basel $\cdot$ München $\cdot$ Paris $\cdot$ London $\cdot$ New York $\cdot$ Sydney

Society for Gynecologic Investigation

Officers, 1976-77

President

Kenneth J. Ryan, MD Immediate Past President

Robert L. Jaffe, MD President Elect

Paul C. MacDonald, MD Secretary-Treasurer

Thomas H. Kirschbaum, MD

Executive Council

W. Ann Reynolds, PhD (1977) DanielR. Mishell, MD (1977) Raymond L. VandeWiele, MD

(1978) Emanuel A. Friedman, MD (1978) James C. Warren, MD, PhD (1979) Samuel S.C. Yen, MD (1979)

Program Chairman

Mortimer Levitz, PhD

Local Arrangements Chairman

Donald C. Christian, PhD, MD

Publications Committee

Lawrence D. L·ongo, MD, Chairman Andre E. Hellegers, MD Carl J. Pauerstein, MD Charles A. Woolever, MD

All rights, including that of translation into other languages, reserved.

Photomechanic reproduction (photocopy, microcopy) of this volume or parts thereof

without special permission of the publishers is prohibited.

(C) Copyright 1977 by S. Karger AG, Basel (Switzerland), Arnold-Böcklin-Strasse 25 Printed in

Switzerland by Thür AG Offsetdruck, Pratteln

Program of Events

Registration

Wednesday, March 23, 1977, 4 p.m. Hotel Lobby Marriott Hotel

Hospitality Hour Wednesday, March 23,1977, 6 p.m.

Courtesy of Ross Laboratories Columbus, Ohio Marriott Hotel

Registration

Thursday, March 24, 1977, 7.30 a.m., and Friday, March 25, 1977, 7.30 a.m. Hotel Lobby

Marriott Hotel

Scientific Sessions Thursday, March 24,1977, 8 a.m. to 4.30 p.m. 
and Friday, March 25, 1977, 8.m. to 12.30 p.m. Mohave and Maricopa Rooms, Greenlee and Graham Rooms, Gila and Coconino Rooms or Cochise and Apache Rooms Marriott Hotel Introduction and President's Address First Plenary Session Concurrent Session A Concurrent Session B First Poster Session Concurrent Session C Concurrent Session D Concurrent Session E

Thursday, March 24, 1977

8 a.m.

8.30 a.m. to 10.15 a.m. 10.45 a.m. to 12.15 p.m. 10.45 a.m. to 12.15 p.m. 10.45 a.m. to 12.15 p.m. 1.45 p.m. to 4.30 p.m. 1.45 p.m. to 4.30 p.m. 1.45 p.m. to 4.30 p.m.

Mohave and Maricopa Rooms Mohave and Maricopa Rooms Mohave and Maricopa Rooms Greenlee and Graham Rooms Cochise and Apache Rooms Mohave and Maricopa Rooms Greenlee and Graham Rooms Gila and Coconino Rooms

Friday, March 25, 1977

Second Plenary Session Guest Lecture Concurrent Session A Concurrent Session B Second Poster Session

8 a.m. to 10.15 a.m. 8 a.m. to 9 a.m. 10.45 a.m. to 12.30 p.m. 10.45 a.m. to 12.30 p.m. 10.45 a.m. to 12.30 p.m.

Mohave and Maricopa Rooms Mohave and Maricopa Rooms Mohave and Maricopa Rooms Greenlee and Graham Rooms Cochise and Apache Rooms

Business Meeting Thursday, March 24, 1977, Mohave and Maricopa Rooms (members only) $\quad 4.30$ p.m.

Reception and Banquet Thursday, March 24, 1977, 7.00 p.m. Old Tucson

Charter buses will provide transportation from the Marriott Hotel to Old Tucson.

Reception and Banquet are supported, in part, by Ortho Pharmaceutical Corporation, Raritan, N.J., and by G.D. Searle and Company, Chicago, 111.

Coffee and Coke will be served in the Hotel lobby during intermissions on Thursday morning and afternoon and on Friday morning.

Contents

Program Scientific Sessions 9

Introduction, Thursday, March 24, 1977, 8 a.m 9

First Plenary Session, Thursday, March 24, 1977, 8.30 a.m 9

Concurrent Session A, Thursday, March 24, 1977,10.45 a.m 14

Concurrent Session B, Thursday, March 24,1977, 10.45 a.m 18

First Poster Session, Thursday, March 24, 1977,10.45 a.m 22

Concurrent Session C, Thursday, March 24, 1977, 1.45 p.m 28

Concurrent Session D, Thursday, March 24, 1977, 1.45 p.m 35

Concurrent Session E, Thursday, March 24, 1977, 1.45 p.m 41

Guest Lecture, Friday, March 25, 1977, 8 a.m 48

Second Plenary Session, Friday, March 25, 1977,9 a.m 48

Concurrent Session A, Friday, March 25, 1977, 10.45 a.m 52

Concurrent Session B, Friday, March 25, 1977, 10.45 a.m 56

Second Poster Session, Friday, March 25, 1977, 10.45 a.m 60

Abstracts 66

Membership List 114

Active Members $1977 \quad 114$

Emeritus Members 123 
Honorary Members 125

Author Index 127

Program Scientific Sessions

First Plenary Session

Thursday, March 24, 1977

Mohave and Maricopa Rooms - Marriott Hotel

8 a.m.

Introduction and President's Address: Kenneth J. Ryan

8.30 to 10.15 a.m.

Moderators: Robert B. Jaffe and Thomas H. Kirschbaum

8.30 a.m. 1 The Inhibition of PMN and Lymphocyte-Mediated RBC Lysis by Promethazine in an in vitro Erythroblastosis Model

John P. Gusdon, jr. and Glenn A. Herbst

Departments of Gynecology, Bowman Gray School of Medicine, Winston-Salem, N.C.

An in vitro method for the measurement of fetal red blood cell (RBC) destruction by FC receptor bearing polymorphonuclear leukocytes (PMNs) and lymphocytes has been developed. Bloods were obtained from infants who were Rh-D positive, and compatible with their mother, as well as infants who were Rh-D positive and incompatible with their Rh-D-sensitized mothers. RBCs, lymphocytes and PMN preparations were individually separated from each cord blood. Rh-D positive cord RBCs from compatible pregnancies were coated with anti-Rh-D. RBCs from babies whose mothers were sensitized to Rh-D and who had a positive direct Coombs were used without the further addition of antibody. All RBCs were labeled with $51 \mathrm{Cr}$, and cultured with autologous lymphocytes or PMNs at a 10:1 effec-tor:RBC ratio. Cultures contained varying amounts of promethazine- $\mathrm{HCl}(\mathrm{P}-\mathrm{HCl})$. Antibody alone did not cause red cell lysis. Both lymphocytes and PMNs were effective in causing the lysis of RBCs bearing antibody. Lysis of RBCs by PMNs or lymphocytes was inhibited in a linear fashion by increasing concentrations of P-HCl: correcting for spontaneous lysis, $5 \mu \mathrm{g} / \mathrm{ml}$ of P-HCl inhibited RBC lysis $10-20 \%$ over a 24-hour period, while $25 \mu \mathrm{g} / \mathrm{ml}$ decreased antibody dependent cell mediated lysis (ADCL) 70\%. Low doses of $\mathrm{P}-\mathrm{HCl}$ decreased spontaneous lysis by $50 \%$. $\mathrm{P}-\mathrm{HCl}$ was found to have two actions: (1) it inhibited ADCL of autologous RBC coated with antibody, and (2) it stabilized the RBC membranes so that even spontaneous lysis of RBC was significantly decreased. These data help to explain some of the: (1) possible mechanisms of fetal RBC destruction in erythroblastosis and, (2) mechanisms of action of $\mathrm{P}-\mathrm{HCl}$ in the treatment of the disease.

Society for Gynecologic Investigation

10

8.45 a.m. 2 Modulating Effects of Prostaglandins on the Uterine Vascular Bed

Robert Resnik and Gary W. Brink

Department of Reproductive Medicine, University of California, San Diego School of

Medicine, La Jolla, Calif.

Recent observations suggest that the prostaglandins (PG) of the E series may play an integral role in mediating estrogen-induced uterine blood flow (UBF), as well as increasing and maintaining UBF in pregnancy. The evidence to support this hypothesis is indirect, however, and data pertaining to the effect of PG on the uterine vascular bed following direct intra-arterial infusion is lacking. Accordingly, the vascular responses to uterine intra-arterial PG infusions were studied in 5 non-pregnant, castrated ewes, chronically equipped with square wave electromagnetic flow probes, and with catheters inserted into branches of the uterine arteries. 
$\mathrm{PGE}^{\wedge}$ at arterial concentrations of $0.7 \mu \mathrm{M}$, was found to be a potent uterine vasodilator which will rapidly increase UBF to levels achieved by maximal doses of estradiol-17/3. Conversely, PGF2Q has marked vasopressor properties and will decrease peak estrogen-induced UBF by $50 \%$ at uterine arterial concentrations of $0.1 \mu \mathrm{M}$. These findings demonstrate the vasoactive effects of prostaglandins in the uterine vascular bed, and support the hypothesis that the prostaglandins are involved in the auto-regulation of UBF.

(Supported by a grant from the National Foundation, March of Dimes.)

9 a.m. 3 Fetal Baboon Pulmonary Developmental Response to Intra-Amniotic Betamethasone R. V. Kotas, O.R. Kling, M.F. Block, J.F. Soodsma and R.D. Harlow University of Oklahoma College of Medicine, Department of Gynecology and Obstetrics, William K. Warren Medical Research Center, Tulsa, Okla.

The baboon pregnancy model was studied to test if intra-amniotic administration of $6 \mathrm{mg}$ betamethasone, at 4 and 3 days prior to premature delivery by cesarean section, effectively accelerated surfactant appearance in the fetal lung. Intra-amniotic betamethasone given to 6 fetal baboons between 147 and 152 days gestation (term $=180$ days) significantly increased ( $\mathrm{p}$ \&lt; 0.02 ) the amniotic fluid L/S ratio (control $1.35 \pm 0.18$; treatment $2.17 \pm 0.48$; mean $\pm \mathrm{SE}$ ). At delivery, treated animal lungs had a significantly increased deflation stability at $10 \mathrm{~cm} \mathrm{H} 2 \mathrm{OP}(\mathrm{p}$ \&lt; 0.001 ) to $54 \pm 3.4 \%$ as compared to the 5 controls of $31 \pm 1.9 \%$. The minimum surface tension was significantly decreased (p \&lt; 0.001$)$ in treated $(7.8 \pm 1.2$ dynes $/ \mathrm{cm} 2)$ versus controls $(23 \pm 2.2$ dynes $/ \mathrm{cm} 2)$. Changes in maximum air distensi-bility at $40 \mathrm{~cm}$ water pressure lagged about 10 days behind changes in deflation stability. The major molecular species of pulmonary phosphatidylcholine were analyzed by GLC as the diacylglycerol derivatives. The proportions of 14:0/16:0, 16:0/16:0 and 16:0/18:0 significantly increased over controls while unsaturated species decreased in animals exposed to intra-amniotic betamethasone. The fetal baboon pulmonary system does respond to intra-amniotic betamethasone with an increase in the $\mathrm{L} / \mathrm{S}$ ratio, improved pulmonary stability and a more mature pulmonary lecithin composition. Scientific Abstracts

11

9.15 a.m. 4 Ovarian Metabolism of Polycyclic Aromatic Hydrocarbons and Associated Ovotoxicity in the Mouse

Donald R. Mattison and Snorri S. Thorgeirsson NIH, Bethesda, Md.

The polycyclic aromatic hydrocarbons (PAH); benzo(a)pyrene (BP) and 3-methyl-cholanthrene (MC) are known initiators of ovarian granulosa cell tumors in mice. We have investigated PAHinduced ovarian aryl hydrocarbon hydroxylase $(\mathrm{AHH})$ activity and primordial oocyte destruction in responsive C57B1/6N(B6), nonresponsive DBA/2N(D2) and (D2xB6) FjXD2 backcross mice. Aromatic hydrocarbon responsiveness is known to segregate as an autosomal dominant trait in these two strains. Basal levels of ovarian $\mathrm{AHH}$ are similar in all mice; however, following MC treatment ovarian $\mathrm{AHH}$ increases 3-fold in $\mathrm{B} 6$ and responsive backcross mice but does not change in D2 and nonresponsive backcross mice. Time-response studies indicate that a single intraperitoneal injection of MC produces a $40 \%$ decrease in primordial oocyte number in $48 \mathrm{~h}$ in B6 mice and complete destruction in 4 days. In D2 mice however, little change in primordial oocyte number is observed until 5 days after MC treatment, and at 7 days $50 \%$ of the primordial oocytes remain. Ovotoxicity in backcross mice is similarly more pronounced in the responsive than nonresponsive pheno-type. The morphological changes in primordial oocytes following PAH treatment such as loss of oocyte nuclear architecture, disruption of nuclear membrane, pyknotic hyperchro-matic nuclei, increased eosinophilia and swollen oocytes are not reflected in 
other ovarian cells. These results show that ovarian PAH metabolism and ovotoxicity are expressed as an autosomal dominant trait in these mice. The high and rising incidence of human ovarian cancer in industrialized countries where PAH pollution is common, underscores the necessity of investigating ovarian metabolism of xenobiotics.

9.30 a.m. 5 Hypothalamic-Pituitary Vasculature: Evidence for Retrograde Blood Flow John C.

Porter and Charles Oliver

Department of Obstetrics-Gynecology, University of Texas Southwestern Medical School at Dallas, Dallas, Tex.

Does retrograde blood flow occur in the pituitary stalk? Do pituitary hormones reach the hypothalamus by retrograde flow? Does venous blood from the anterior pituitary reach the posterior pituitary? Do posterior pituitary hormones reach the anterior pituitary? Such questions imply that anterior pituitary hormones influence function of the posterior pituitary and vice versa, and that pituitary hormones may influence hypothalamic function. In order to address some of these questions, blood was collected from a long portal vessel of rats; and LH, TSH, prolactin (Pr), ACTH, $\alpha-\mathrm{MSH}$, and vasopressin (Vp) were determined in the plasma. The concentrations $(\mathrm{ng} / \mathrm{ml})$ of pituitary hormones in portal plasma from male rats with intact pituitaries were as follows: LH, 2,320 \pm 874 (mean \pm SE); TSH, 10,180 $\pm 1,471 ; \operatorname{Pr}, 5,430 \pm$ 1,176; ACTH, $82 \pm 17$; $\alpha$-MSH, $103 \pm 17.8$; and Vp, $2.4 \pm 1.0$. These values were 70-700 times that seen in arterial plasma from the same animals. After anterior lobectomy, LH, TSH, Pr, and ACTH levels in portal plasma were markedly reduced; $\alpha$-MSH was reduced to a lesser extent, and $\mathrm{Vp}$ was unaffected. Posterior lobectomy had no effect on portal plasma concentrations of LH and TSH, but did suppress $\operatorname{Pr}, \mathrm{ACTH}, \alpha \mathrm{MSH}$, and

Society for Gynecologic Investigation

12

Vp. These findings suggest that: (1) LH and TSH enter the retrograde channels in the stalk independent of the posterior pituitary; (2) $\mathrm{Pr}, \mathrm{ACTH}, \alpha-\mathrm{MSH}$, and $\mathrm{Vp}$ enter the retrograde channels via the posterior pituitary vasculature; (3) all pituitary hormones probably reach the hypothalamus in high concentrations and may affect brain function.

9.45 a.m. 6 Function of Progesterone (P) in Pregnancy Maintenance F. Febres, B. Gondos and

P.K. Siiteri

Departments of Obstetrics-Gynecology and Pathology, University of California, San Francisco School of Medicine, San Francisco, Calif.

On the basis of recent experiments that demonstrate marked antiinflammatory and immunosuppressive activity of $\mathrm{P}$ in vivo we have proposed that high local levels of $\mathrm{P}$ may protect the fetus from maternal immune attack. P-filled silastic tubes, previously used, had release rates of ca. $170 \mu \mathrm{g} / \mathrm{cm} /$ day. More recent results show that the granuloma response to cotton thread is blocked by using P-capsules with release rates of 10 or $2 \mu \mathrm{g} / \mathrm{cm} /$ day. Granuloma inhibition with the latter was observed in adrenalectomized rats suggesting that $\mathrm{P}$ effect is independent of corticosteroids. Other experiments have shown that: (1) Human trophoblasts from 15-20 week placentas survive for at least 28 days in the lungs of rats treated with silastic implants containing pregnenolone (PE) to increase trophoblastic $\mathrm{P}$ production. Marked inflammation of lungs observed at 8 and 13 days in controls was not found in Pe-treated animals. Survival of trophoblasts beyond 13 days has not been observed in untreated rats or those with subcutaneous implants of P. (2) Decidua obtained from pregnant (day 16) Sprague-Dawley rats implanted in the abdominal muscle of nonpregnant Long-Evans female rats remained histologically normal for 16 days if the recipients were treated with P implants $(n=5)$ whereas 
control implants $(n=5)$ were virtually destroyed. Peripheral progesterone levels were similar to those at mid pregnancy $(140-180 \mathrm{ng} / \mathrm{ml})$ in treated animals. These results indicate that $\mathrm{P}$ production by trophoblasts and/or P accumulation by the decidua may play an important role in prevention of fetal allograft rejection during pregnancy.

(Supported by NIH grant HD 8692.)

10 a.m. 7 The Membrane-Dependent Cleavage of the Human Placental Lactogen Precursor Irving Boime, Donna Smith and Elzbieta Szczesna Washington University School of Medicine, Department of Obstetrics-Gynecology, St. Louis, Mo.

In placenta, human placental lactogen (HPL, mol wt 22,000) is synthesized on the endoplasmic reticulum as a precursor (preHPL, mol wt 25,000). Since the processing of preHPL is a possible control point for the in vivo expression of HPL, this reaction was investigated in vitro. MRNA derived from term placenta directs the synthesis of preHPL in an ascites tumor system containing cytosol and ribosomes. The processing of preHPL to HPL required the addition of microsomal membranes to this system. Cleavage occurred only during synthesis of preHPL; completed chains of preHPL released from the ribosome were not cleaved. This accounts for the absence of preHPL in the circulation. Cleavage activity was inhibited $100 \%$ by $0.04 \%$ Triton, while protein synthesis was inhibited only $30 \%$. Using Triton to block cleavage at intervals after mRNA and membrane additions, it was shown

Scientific Abstracts

13

that cleavage required about $15 \mathrm{~min}$. This lag period probably reflects the synthesis of the chain to the appropriate length, the binding of the nascent chain ribosomal complex to the membrane and cleavage.

When the ascites system was incubated with charged initiator (35S) methionine-tRNA, labeled preHPL was formed. It was processed when membranes were added during the first few minutes of incubation, but no cleavage occurred when membranes were added after the complete protein was synthesized. Since only the primary gene product can be labeled with the initiator methionine, the data show that preHPL is the initial translation product from the placental genome and that it is not a cleavage product of a still larger protein.

10.15 to 10.45 a.m. Intermission

Concurrent Session A

Thursday, March 24, 1977

Mohave and Maricopa Rooms - Marriott Hotel

10.45 a.m. to 12.15 p.m.

Moderators: Girgis Mikhail and Norman F. Gant

10.45 a.m. 8 Androgen Insensitivity - a Cause of Oligospermia and Infertility in a Phenotypic Male

E. James Aiman, James E. Griffin, Jean D. Wilson and Paul C. MacDonald Department of Obstetrics-Gynecology, University of Texas Southwestern Medical School at Dallas, Dallas, Tex.

We have previously described the hormonal milieu and the magnitude of high-affinity specific binding of dihydrotestosterone (DHT) in genital skin fibroblasts in normal men and in genetic males with various androgen insensitivity syndromes. We have now studied a heretofore undescribed form of androgen resistance in a phenotypic male with severe oligospermia ( \&lt; $106 / \mathrm{ml}$ ) who had no somatic stigmata of androgen insensitivity. The plasma production rate of 
testosterone (PR-T) in this man was $11.9 \mathrm{mg} /$ day, a value twice that of normal men but similar to that of two men with Reifenstein's syndrome. Specific metabolic events, expected as a consequence of this increased PR-T, were not present; namely the plasma concentration of LH $($ mean $=49.5 \mathrm{ng} / \mathrm{ml}$ ) was significantly increased despite the increased PR-T and despite significant increases in the plasma concentration of testosterone (mean $=11.5 \mathrm{ng} / \mathrm{ml})$, the metabolic clearance rate of T $(1,043 \mathrm{~L} / \mathrm{D})$ was not low as expected with increased PR-T and binding capacity of the androgen binding plasma protein (396 fmol T/mg protein) was not low. No testicular secretion of estradiol occurred although LH concentrations were increased. The high affinity specific binding of DHT (B max) in genital skin fibroblasts was $7.8 \mathrm{fmol} \mathrm{DHT} / \mathrm{mg}$ protein in this oligospermic man, compared to $18-45$ in control subjects and 4-9 in males with Reinfenstein's syndrome. Finally, the occurrence of oligospermia and infertility may also constitute evidence for androgen insensitivity in view of testosterone action on the seminiferous epithelium to initiate and/or maintain spermatogenesis.

Scientific Abstracts

15

11 a.m. 9 Ovarian Failure Consistent with Aromatase Deficiency

Uwe Goebelsmann, Val Davajan, Jorge H. Mestman, Frank Z. Stanczyk and Miriam G. Wilson Departments of Obstetrics-Gynecology and Pediatrics, University of Southern California School of Medicine and Los Angeles County-USC Medical Center, Los Angeles, Calif.

A 24-year-old female presented with $1^{\circ}$ amenorrhea, hirsutism and clitoromegaly. Androgen excess became evident at puberty.' Menstruation occurred only after oral contraceptives. This normotensive, 157-cm tall, genetic female (46, XX) had elevated serum progesterone $(\mathrm{P}), 17-$ hydroxyprogesterone (170HP), androstenedione (A), testosterone (T), urinary 17-ketosteroids (17KS), normal serum cortisol (F) and dehydroepiandrosterone sulfate (DHEAS), and highly increased serum LH and FSH. Serum estrone ( $\mathrm{E}^{\wedge}$ and estradiol (E2) were only 13 and $21 \mathrm{pg} / \mathrm{ml}$, respectively. Dexamethasone suppressed F and DHEAS, lowered 17KS partially and failed to decrease serum P, 170HP, A and T. Enovid-E, however, suppressed serum LH, FSH, P, 170PH, $\mathrm{A}$ and T. ACTH caused appropriate rises in F, DHEAS, P, 170HP, A and T. Two-third wedge resection of both $6 \times 4 \mathrm{~cm}$ multicystic ovaries revealed multiple small follicle cysts, very few follicles and coUagenous or myxoid stroma with corpora albicantia-like structures. Ovarian chromosome analysis: right: 46, XX; left: 45, X (6\%)/46, XX (79\%)/47, XXX (15\%). No Y chromosome was detected. Incubation of 14C-pregnenolone with tissue from both ovaries resulted in extensive metabolism to neutral metabolites. T propionate intramuscularly raised serum T to $16 \mathrm{ng} / \mathrm{ml}$, but failed to increase serum E2 ( \&lt; $3 \mathrm{pg} / \mathrm{ml}$ ) and Ei ( \&lt; $5 \mathrm{pg} / \mathrm{ml}$ ) and to suppress serum LH and FSH. These findings are consistent with deficient aromatization. They supported the assumption that ovarian androgen excess and deficient E2 production prevented normal follicle maturation and caused premature follicle depletion. The unilateral ovarian mosaicism may or may not be causally related.

(Supported by NICHD grant 05932.)

11.15 a.m. 10 True Agonadism: a Variant of Testicular Dysgenesis

Robert E. Cleary, Robert L. Rosenfield and Peter CM. Young

Departments of Obstetrics-Gynecology, Indiana University School of Medicine, Indianapolis, Ind.

A 23-year-old phenotypic female with XY genotype presented with primary amenorrhea, minimal breast development, sparse pubic hair, fusion of the labia, and no clitoromegaly. Her vagina ended in a short blind pouch. Plasma FSH and LH were markedly elevated with FSH 
level being higher than LH. Plasma values of cortisol $(\mathrm{F})$, progesterone $(\mathrm{P})$, and dehydroepiandrosterone sulfate (DHA-SOJ were in the normal range for females. Plasma testosterone was $25 \mathrm{ng} / 100 \mathrm{ml}$, increased to $42 \mathrm{ng} / 100 \mathrm{ml}$ after ACTH, fell to $6 \mathrm{ng} / 100 \mathrm{ml}$ after dexamethasone, but did not change after administration of human chorionic gonadotropin. Following ACTH infusion, F increased from 20 to $48 \mu \mathrm{g} / 100 \mathrm{mg}$, estrone increased from 40 to 67 $\mathrm{pg} / \mathrm{ml}, \mathrm{P}$ increased from 140 to $880 \mathrm{ng} / 100 \mathrm{ml}$, DHA-S04 from 216 to $395 \mu \mathrm{g} / 100 \mathrm{mg}, 17-\mathrm{OHCS}$ from 5.9 to $17.3 \mathrm{mg} /$ day, and 17-KS from 3.3 to $4.3 \mathrm{mg} /$ day. At laparotomy, no uterus, only vestigial remnants of fallopian tube, and a very small 'steak' gonad was seen. Microscopic examination showed loose cellular gonadal stroma and no Society for Gynecologic Investigation

16

germinal elements. On the basis of the clinical, genotypic, and endocrine features of patients with 'true agonadism', a unified nomenclature is proposed in which 'true agonadism' is referred to as 'intersexual testicular dysgenesis' to distinguish it from Swyer syndrome and the syndrome of bilateral anorchia, both being variants of testicular dysgenesis.

11.30 a.m. 11 The Effect of an Oral Contraceptive on Plasma Concentrations of Dehydroisoandrosterone Sulfate and ACTH

James D. Madden, Leon Milewich, Celso Gomez-Sanchez, Bruce R. Carr, C. Richard Parker, jr., Norman F. Gant, John C. Porter and Paul C. MacDonald Department of Obstetrics and Gynecology, University of Texas Southwestern Medical School, Dallas, Tex.

Dehydroisoandrosterone sulfate (DS), the major C-19 steroid found in the human peripheral circulation, was measured daily $(08.00-10.00 \mathrm{~h})$ throughout the menstrual cycles of eight normal ovulatory women and four women on oral contraception (Norethindrone $1 \mathrm{mg}$ and mestranol 80 $\mu \mathrm{g})$. The concentrations of DS in the ovulatory women ranged from 1,025 to $4,200 \mathrm{ng} / \mathrm{ml}$ with a mean of 2,062 \pm 137 (mean \pm SEM). DS concentrations during the follicular and luteal phases of the cycle were not different. In women taking the oral contraceptive, the DS concentration ranged from 475 to $1,400 \mathrm{ng} / \mathrm{ml}$ with a mean of $895 \pm 83$. The decrease in the plasma concentration of DS is likely a result of a reduction in DS secretion since comparable differences in the urinary production rates of DS were found in one ovulatory women $(13.2 \mathrm{mg} /$ day $)$ and one women on the oral contraceptive $(7.2 \mathrm{mg} /$ day). Since DS secretion by the normal human ovary is negligible and ovarian dehydroisoandrosterone secretion is small, it is likely that the reduced plasma DS levels in women on this oral contraceptive is the consequence of reduced ACTH secretion. In studies of four normal ovulatory women whose plasma was sampled at 08.00-10.00 $\mathrm{h}$ the mean concentration of ACTH was $88 \pm 2 \mathrm{pg} / \mathrm{ml}$ whereas in four women on this oral contraceptive the concentration was $54 \pm 5 \mathrm{pg} / \mathrm{ml}$.

11.45 a.m. 12 The Use of a Rapid Corticosteroid-Binding Globulin Assay to Quantitate Potency of Exogenous and Endogenous Estrogens

Donald E. Moore, Shinnosuke Kawagoe, Daniel R. Mishell,jr., Val Davajan and Robert M.

Nakamura

Department of Obstetrics-Gynecology, University of Southern California School of Medicine, Los Angeles County Medical Center, Los Angeles, Calif.

A simple, precise and accurate charcoal adsorption method has been developed to assay the binding capacity of human corticosteroid-binding globulin (CBG-BC). 40 duplicate serum samples, each with a heat-inactivated blank, can be assayed per day. The interassay coefficient of variation is less than $6 \%$. CBG-BC levels remained constant throughout the cycle in 5 normal women despite fluctuating E2 levels which reached peaks of $190-430 \mathrm{pg} / \mathrm{ml}$. CBG-BC did not 
fall in postmenopausal women. In pregnancy there is a steady increase in CBG-BC beginning when E2 levels are greater than $1 \mathrm{ng} / \mathrm{ml}$ and $\mathrm{E}$, greater than $500 \mathrm{pg} / \mathrm{ml}$ (8-9 gestational weeks). This increase correlates well with both the increase in E2 ( $\mathrm{rs}=0.85, \mathrm{p} \& \mathrm{lt} ; 0.001)$ and $\mathrm{E}$, ( $\mathrm{rs}=$ 0.88 , p \& 1t; 0.001). Exogenous estrogens of various types, alone, or in combination with progestins also cause increases in CBG-BC. Oral conjugated estrogens

Scientific Abstracts

17

in dosages of $0.625 \mathrm{mg} /$ day or more are associated with a dose-response increase in CBG-BC (rs $=0.80, \mathrm{p} \& \mathrm{lt} ; 0.005$ ). This easily performed assay is of use in comparing the effects of various dosages of different exogenous estrogens upon one important metabolic parameter, the alteration of hepatic production of a serum protein.

12 a.m. 13 Variability as a Source of Sampling Error of Steroid Plasma Concentrations in Late Pregnancy

Paul J. Meis, John E. Buster, Calvin J. Hobel and John R. Marshall UCLA School of Medicine, Harbor General Hospital, Department of Obstetrics-Gynecology, Torrance, Calif.

Plasma from 5 normal 3rd trimester pregnant women drawn every $5 \min \times 7$ and every 15 min $\mathrm{X}$ 7 at similar times on 2 days, 2 days apart, was assayed in duplicate for estradiol (E2), estriol (E,), progesterone $(\mathrm{P}), 16 \alpha-\mathrm{OH}-$ progesterone $(16 \mathrm{P})$, and 17 $\alpha-\mathrm{OH}$-progesterone (17P). Data were analyzed using two-way analysis of variance. Single sampling carries a maximum error of \pm $100 \%$ and mean errors for the individual steroids ranging from $\pm 36 \%$ to $\pm 60 \%$. Although all pregnancies were uncomplicated and all mean values were within the normal range, variability differed between patients significantly ( $\mathrm{p}$ \&lt; 0.01) for E2, 17P, and P. Variability of 5-min sampling was not different from 15-min sampling.

Mean inter- Mean 5-min Mean 15-min Percent error at 95\% CI for N samplesassay CV variance variance

$\begin{array}{llllllllll}1 & 3 & 5 & 7 & 1020 & & & & & \\ \mathrm{E} 2 & 5.62 \% \pm 0.2815 .6 \% \pm 5.7 & 14.6 \% \pm 5.3 & \pm 36 & \pm 20 & \pm 16 & \pm 14 & \pm 12 & \pm 8 \\ \mathrm{E} 3 & 4.80 \% \pm 0.5919 .3 \% \pm 2.7 & 18.8 \% \pm 2.3 & \pm 42 & \pm 24 & \pm 19 & \pm 15 & \pm 12 & \pm 9.4 \\ \mathrm{P} & 5.54 \% \pm 0.2113 .4 \% \pm 6.2 & 16.5 \% \pm 5.6 & \pm 38 & \pm 22 & \pm 17 & \pm 14 & \pm 12 & \pm 8.5 \\ 16 \mathrm{P} & 5.36 \% \pm 0.0817 .9 \% \pm 2.5 & 17.4 \% \pm 3.8 & \pm 42 & \pm 24 & \pm 19 & \pm 16 & \pm 13 & \pm 9.4 \\ 17 \mathrm{P} & 6.62 \% \pm 0.5025 .2 \% \pm 3.1 & 21.3 \% \pm 3.6 & \pm 60 & \pm 35 & \pm 27 & \pm 23 & \pm 19 & \pm 13\end{array}$

Percent error at $95 \%$ confidence interval (CI) is determined by number of samples. Analysis of pooled aliquots of 5 samples obtained every 5 min by indwelling needle provides error at the $95 \%$ CI of from $\pm 16 \%$ to $\pm 27 \%$, a $55 \%$ reduction in error. Multiple sampling is required for the accurate study of steroid levels in individual subjects in late pregnancy.

12.15 to 1.45 p.m. Luncheon

Concurrent Session B

Thursday, March 24, 1977

Greenlee and Graham Rooms - Marriott Hotel

10.45 a.m. to 12.15 p.m. Moderator: Edward E. Wallach

10.45 a.m. 14 Enhancement of Growth of Herpes Virus by Crude Human Chorionic

Gonadotropin (HCG)

G.E. Knox, D. W. Reynolds and C.A. Alford

Departments of Obstetrics and Pediatrics, University of Alabama School of Medicine, Birmingham, Ala. 
Epidemiological studies establishing suppression of cervical CMV excretion during early gestation led to recently reported experiments demonstrating in vitro suppression of growth of cytomegalovirus by crude human chorionic gonadotropin (HCG). The effect was shown to: (1) require cellular protein synthesis; (2) occur early in the replicative cycle; (3) be accompanied by increased cell growth and number; (4) be caused by substances found in crude HCG other than immunochemically pure HCG. The experiments currently reported demonstrate: (1) enhancement of the growth of Herpes Simplex (HSV) by crude HCG, and (2) separation of the active molecule from HCG by physiochemical techniques. Using human fibroblasts grown to confluency followed by pretreatment with crude HCG or separated fractions of crude HCG, the growth of HSV was shown to be significantly enhanced in both plaque production and growth curve assays. Enhancement of rate of growth as well as absolute titer was shown to be dosedependent in both systems using a range of multiplicities of input. Fractionation of the crude HCG was accomplished stepwise by G-100 sephadex gel filtration followed by discontinuous polyacrylamide gel electrophoresis with demonstrated coelution of the protein (mol wt a, 30,000) responsible for suppression of CMV and enhancement of HSV. Pure HCG has no effect on HSV growth. These results suggest that first trimester pregnancy urine contains a substance capable of altering human fibroblasts such that suppression or enhancement of growth of members of the herpes virus family occur in vitro, the role of this naturally occurring protein with regard to other facets of growth and differentiation in normal pregnancy remains to be defined.

Scientific Abstracts

19

11 a.m. 15 Biochemical Characterization of the Vaginal Microenvironment and Its Relationship to Vaginal Bacterial Colonization

Bryan Larsen, Allen J. Markovetz and Rudolph P. Galask

Departments of Obstetrics-Gynecology and Microbiology, University of Iowa College

of Medicine, Iowa City, Iowa

Using the rat as a model of vaginal colonization we have demonstrated that the bacterial content of the vagina is influenced by estrogenic stimulation. Ultrastructural observations indicate that following estrogen treatment cytoproliferative changes occur and result in keratinization of the vaginal epithelium. Concomitant to this process, bacterial colonization of the epithelium is significantly increased. The increase is also demonstrable micro-biologically. It appears that changes in the vaginal tissue are stimulated by estrogen, and the estrogen-stimulated tissue contains a bacterial growth promoting substrate sufficient to cause the proliferation of the vaginal microflora. Ovariectomized rats were treated with $\alpha$-estradiol, $\varnothing$-estradiol or the suspending vehicle. On each of the following 5 days, vaginal lavage was performed on each rat and the material recovered was used for plate count determination of bacteria, and measurement of protein, carbohydrates, RNA, DNA, and amino acids. By the second estrogen post-treatment day increases were seen in the concentration of protein, amino acid and carbohydrates present in the vaginal washings from rats treated with $\varnothing$-estradiol. Rats treated with $\alpha$-estradiol showed increases in protein and carbohydrate but not amino acids. Bacterial counts increased in rats treated with $\beta$ - but not $\alpha$-estradiol and correlated with the amino acid content of the vaginal washings.

11.15 a.m. 16 Adhesiveness of Mouse Trophoblast to L1210 Cells and to Inert Particles Robert H. Glass, Akiko I. Spindle, Lynn M. Wiley and Roger A. Pedersen Department of Obstetrics-Gynecology and Laboratory of Radiobiology, University of California, San Francisco, Calif. 
The object of the current study was to identify areas of the implantation stage mouse embryo which have adhesive characteristics, and to determine the specificity or nonspeci-ficity of this property. Blastocysts were cultured in vitro in Eagle's basal medium modified to contain the amino acids optimal for blastocyst attachment and trophoblast outgrowth. The following cells or particles were added separately to the culture $24 \mathrm{~h}$ later: LI 210 leukemia cells; latex particles, diameter $5.6 \mu \mathrm{m}$; microspheres coated with a polymeric resin, diameter $10 \mu \mathrm{m}$. When the culture was terminated 6 days later all three were found to be adherent to trophoblast cells. The binding was so strong that it was not disrupted by vigorous washing, while the washing did dislodge the inner cell mass from the trophoblast. The adherence of cells and particles occurred over the entire exposed surface of the trophoblast, which indicates that the adhesive properties are not localized. In contrast, there was no adherence of cells or particles to the inner cell mass. Incubation of blastocysts in $0.1 \mathrm{M} \beta$-galactose which inhibits aggregation in the cellular slime mold did not prevent adherence of trophoblast to the plastic dish nor did it prevent adherence of LI210 cells to trophoblast.

The trophoblast of mouse embryos has the ability to attach not only to uterine epithelium, but also to ectopic sites in vivo and to glass or plastic in vitro. Our results demonstrate that the adhesive properties are expressed on the entire surface of the trophoblast cells when they are grown in vitro.

Society for Gynecologic Investigation

20

11.30 a.m. 17 In vitro Suppression of Human Lymphocyte Transformation by Progesterone L.E. Clemens, D. Stites and P.K. Siiteri

Departments of Obstetrics-Gynecology, Medicine and Laboratory of Medicine, University of California at San Francisco, School of Medicine, San Francisco, Calif.

Our recent studies have shown that locally administered progesterone $(\mathrm{P})$ blocks anti-genically stimulated inflammatory and/or immune responses. Characteristic of these reactions is the cellular division of activated lymphocytes. To elucidate the mechanism(s) of $\mathrm{P}$ action on these responses we compared its effect with that of other steroids on DNA synthesis in human mixed lymphocyte cultures (MLC). The hormones were added to the MLC at various times of the 5-day incubation period in order to determine which phase(s) of the activation sequence are inhibited. When present at 1-20 $\mu \mathrm{g} / \mathrm{ml}$ throughout the 5-day period, P, estradiol (E), testosterone (T), and cortisol (C) inhibited MLC response in a dose-related fashion; percent-inhibition at $20 \mu \mathrm{g} / \mathrm{ml}$ was $88,86,83$, and $78 \%$, respectively. The response to $\mathrm{C}$ was, however, highly variable, with an ID50 range of $0.05-20 \mu \mathrm{g} / \mathrm{ml}$. Preincubation of responding cells with P, E, or C for $12 \mathrm{~h}$ followed by washing prior to the addition of allogeneic cells, inhibited DNA synthesis by: $\mathrm{P}=$ $20 \%, \mathrm{E}=0 \%$ and $\mathrm{C}=93 \%$. However, when $\mathrm{P}, \mathrm{E}$, or $\mathrm{C}$ was added together with $5 / 8$ thymidine to activated cells (i.e. on day 5) inhibition was 92,70 , and $58 \%$, respectively. Furthermore $\mathrm{P}$, but not $\mathrm{C}$, inhibited the increase in $3 \mathrm{H}$-thymidine uptake by stimulated cells. The inhibition could be reversed by increasing $3 \mathrm{H}$-thymidine in the media. These results indicate that inhibition of MLC by $\mathrm{C}$ occurs at a specific early stage of transformation, whereas $\mathrm{P}$ blocks precursor uptake.

Nevertheless, our data suggest that maternal T-lymphocyte function may be suppressed during placental transit by the high concentration of $\mathrm{P}$ produced by their potential target cells, i.e. the trophoblast.

(Supported by NIH grants HD08692 and HD03939.)

11.45 a.m. 18 T and B Lymphocytes in the Early Human Fetus 
Jack Maidman, Virginia M. Anderson, Judy Faust and Virginia L. Swanson Department of Obstetrics-Gynecology, Charles R. Drew Postgraduate Medical School, Los Angeles, and Department of Pathology, Childrens Hospital of Los Angeles, Los Angeles, Calif.

The order of appearance of lymphocytes exhibiting typical $\mathrm{T}$ and $\mathrm{B}$ surface characteristics was studied in a series of aborted human fetus of 8 to 18 weeks gestation age. T cells were identified by E (sheep erythrocyte) rosette formation, and B cells by EAC (sheep erythrocyte + antibody + complement) rosette, and by surface immunoglobuüns. Typical T cells were found in the thymus as early as 8 weeks gestation and reached a peak proportion of $93-94 \%$ at $12-13$ weeks gestation and declined slightly toward 28 weeks gestation. A few B cells (2\%) appeared in the fetal thymus at 9 weeks gestation and gradually increased in proportion and in absolute numbers throughout the period of observation. Small numbers of T and B cells were observed in the 12 13 week spleen but did not reach significant numbers until 18 weeks gestational age. Lymphocytes from the liver did not exhibit typical T or B cell surface characteristics.

We have demonstrated the presence of typical T lymphocytes in the human fetal thymus as early as 8 weeks gestation and have documented the appearance of $\mathrm{T}$ and $\mathrm{B}$ lymphocytes in the thymus prior to this appearance in the spleen.

Scientific Abstracts

21

12 a.m. 19 Platelet Life-Span in Normal and Pathologic Pregnancy

Henk C.S. Wallenburg, Piet H. van Kessel, Edward Haddeman and Nel Rotmans Department of Obstetrics-Gynecology, Erasmus Universiteit AZR-Dijkzigt, Rotterdam

Morphologic studies have shown that thrombotic occlusion of uteroplacental arteries leading to a decreased maternal placental circulation and infarction is a frequent finding in pregnancies resulting in small-for-date babies. Increased platelet consumption due to platelet-mediated thrombotic disorders can be clinically diagnosed by measurement of $51 \mathrm{Cr}$ platelet survival time, a method which for obvious reasons has not been employed in pregnant women. Recently a nonisotope technique for determination of platelet life-span was developed (New Engl. J. Med. 292: 1310, 1975), based on the complete inhibition of platelet lipid peroxidation and formation of malonaldehyde in vivo by a single dose of acetylsalicylic acid. Platelet life span was determined by means of this technique between the 35-40th week of pregnancy in 17 women with clinically normal gestation (group I) and in 9 women with small-for-date babies (group II). Nine nonpregnant women were used as controls (group III). It was found that (1) platelet life span (days) in group I (mean $=9.2+0.30 \mathrm{SEM})$ was not different from that in group III (mean = $9.7 \pm 0.48 \mathrm{SEM}) ;(2)$ life span in group II (mean $=7.3 \pm 0.43 \mathrm{SEM})$ was significantly $(p=0.001)$ shortened as compared with that in group I. These data support the morphologic evidence that platelet-mediated arterial thrombosis contributes to placental insufficiency leading to intrauterine growth retardation. Determination of platelet life span might be a useful clinical procedure to distinguish between circulatory and other causes of placental insufficiency. 12.15 to 1.45 p.m. Luncheon

First Poster Session

Thursday, March 24, 1977

Cochise and Apache Rooms - Marriott Hotel

10.45 a.m. to 12.15 p.m.

20 Presence of Biologically Active ACTH in Normal Human Trophoblasts.

Rapin Osathanondh, Dorothy T. Krieger, Kenneth J. Ryan, Anthony S. Liotta and Dan Tulchinsky 
Department of Obstetrics-Gynecology and Laboratory of Human Reproduction and Reproductive Biology, Harvard Medical School, Boston, and Department of Medicine, Mount Sinai School of Medicine, New York, N.Y.

Extracts of extensively washed placental tissue and dispersed viable trophoblasts contained high ACTH activity as determined by radioimmunoassay (I) and bioassay (B). Serial dilutions of placental homogenate gave inhibition parallel to that of standard pACTH in I and B. I-ACTH content in mid-trimester placental tissue $(3.4 \pm \mathrm{SE} 0.1 \mathrm{ng} / \mathrm{g})$ obtained vaginally following intraamniotic prostaglandin infusion was significantly greater than that obtained via elective cesarean section at term $(1.7 \pm \mathrm{SE} 0.1 \mathrm{ng} / \mathrm{g})(\mathrm{n}=4)$. The ratios of B-ACTH over I-ACTH in placental extracts obtained at $12,15,18$, and 39 weeks of gestation ranged from 0.31 to 0.40 . Sephadex G50 filtration of placental homogenate obtained at term pregnancy revealed $29 \%$ of the total immunoreactivity to be in the void volume and 54\% in the authentic $125 \mathrm{I}$ ACTH peak. Dexamethasone given orally $(8-16 \mathrm{mg})$ in divided doses $10-48 \mathrm{~h}$ prior to elective cesarean section did not significantly alter placental ACTH content.

21 Amino Acid Transfer through the Human Placenta Studied by in vitro Perfusion Henning Schneider, Karlheinz Möhlen, Jean-Claude Challier and Joseph Dancis UniversitätsFrauenklinik, Marburg, BRD, Universitäts-Frauenklinik, Münster, BRD, Université de Paris, Biologie de la Reproduction, Paris, New York University School of Medicine, New York, N.Y. Amino acid transport in human term placenta has been studied with an in vitro perfusion technique in which separate maternal (MC) and fetal (FC) circulations are established. 12 of 15 amino acids were transferred from $\mathrm{MC}$ to $\mathrm{FC}$ at approximately the same rate, which was about one third the rate of antipyrine transfer. Glutamate, asparate and cysteine

\section{Scientific Abstracts}

23

were transferred at approximately half the rate of the other amino acids, consistent with the slow transfer rates reported in vivo, L-leucine and $i$-alanine are transferred considerably more rapidly than their respective $Z$ )-isomers, the difference being attributed to an active transport mechanism. However, D-glutamate is transferred more rapidly than its $i$-isomer. Studies were undertaken in which the fetal perfusate was recirculated permitting the establishment of gradients across the placenta. Of several amino acids studied, all except gluta-mate and asparate developed higher concentrations in the FC; the levels of asparate and glutamate in the FC fell progressively, reaching concentrations below those in MC. The $i$-dicarboxylic acids are rapidly metabolized by placenta explaining the preferential transfer of the Z)-isomer and the establishment of a transplacental gradient directed towards MC.

22 Lipid Transport and Metabolism in the Post-Term Rabbit

Martin I. Shapiro, Jacques F. Roux, Alice Harlow and Denise Masse

Department of Obstetrics-Gynecology, Hôtel-Dieu/St. Justine Hospitals, Pediatric

Research Center, St. Justine Hospital, University of Montreal, Montreal, P.Q.

APL-injected pregnant rabbits were delivered by cesarean section 27 and 30 days (d) near term (NT) and 3 and 4 days post-term (PT). Lipid metabolism of the PT fetus, NT fetus, and 3- and 4day-old newborns (NB) was compared. Pre and postnatal body and organ weights as well as lipid concentration in brain, liver, lung, brown adipose tissue and placenta were determined. The halftime ( $\left(\mathrm{t}^{\prime} / 2\right)$ of FFA in mother and fetus was calculated following a single maternal injection of $1-$ 14C-palmitate $(50 \mu \mathrm{Ci})$. Placental weight remains unchanged after 30NT. However, a significant positive correlation exists between fetal body weight (BW) and placental weight. The brain is spared - its weight increasing in a manner proportional to BW. Brain lipid concentration remains 
constant throughout the study period. Dramatic changes (greater than 50\% drop) in fetal lipid concentration occur in the liver when extending the PT period beyond 34 days (between 3PT and 4PT). The rate and time of peak appearance of radioactivity in fetal circulation indicate a peak shift in 4PT (peak appearance is at about $4 \mathrm{~min}$ [30NT] increasing to $8 \mathrm{~min}$ in the 4PT fetus) as well as a slower rate of entry, 4PT vs. 30NT. These changes imply some breakdown in placental transport ('placental insufficiency'). The concentration and tV2 of FFA in fetal plasma is maintained in spite of significantly slower placental transfer of FFA. Maternal 'attempts' at compensation include a diminished $t^{\prime} / 2$; this is evidently inadequate requiring in addition dramatic increases in fetal liver lipid mobilization.

(Supported by MRC grant No. DG111 and the University of Montreal.)

23 Stimulatory Effect of Soluble Supernatant on Hydroxylase Activity of Rat

TestisMicrosomes

G. Betz, P. Tsai and G. Olson

Departments of Obstetrics and Gynecology and Biochemistry. University Colorado

School of Medicine, Denver, Colo.

The stimulatory effect of $105,000 \mathrm{~g}$ supernatant (S) on the particulate enzymes which mediate cholesterol synthesis and further conversion to steroid hormones appears to be established as a unique and specific phenomenon. It has been proposed that the participation of steroid-carrier protein found in S may be a general case when enzymes interact with these insoluble substrates. These studies report the effect of $\mathrm{S}$ on the activities of $17 \alpha$-hydroxylase $(17-\mathrm{H})$ and 17,20-lyase $(17,20-\mathrm{L})$ of rat testis microsomes. When $\mathrm{S}$ is added to

Society for Gynecologic Investigation

24

the $17-\mathrm{H}$ assay, initial velocity increases to a maximum of $170 \%$ of the control. Exposure of S to $100^{\circ} \times 3$ min diminishes the enhancement to $135 \%$ of control but this effect is less resistant to heat (enhancement reduced to $110 \%$ of control). Exhaustive dialysis of S does not alter its effect. The possibility of NADPH generation is excluded by adding this nucleo-tide to ten times saturation in the presence of a generating system. No alteration in the products of the reaction was detected after addition of S. Purification of the stimulating factor of S has been undertaken by salt fractionation with 4-fold purification. A plot of vi of $17-\mathrm{H}$ or 17,20-L vs. micrograms of purified $\mathrm{S}$ added to the assay yields a hyperbolic curve, indicating that the stimulating factor is non-catalytic. The stimulatory activity of testis supernatant appears to be distinct from that involved in cholesterol synthesis (where $\mathrm{S}$ is requisite for activity) and in drug metabolism (S prevents $\mathrm{P}-450$ degradation). The effect of $\mathrm{S}$ on the kinetic parameters of both enzymes is being studied.

24 Stereoselective Activities of Aminoglutethimide Enantiomers

Hilton A. Salhanick, Carmen A lonso Whipple, Vytautas I. Uzgiris, Penelope E. Graves, E. Noel Mclntosh and Hugh R. Holtrop

Departments of Obstetrics-Gynecology and Popular Sciences, Harvard University, Boston, Mass. Aminoglutethimide is an important drug under investigation for the treatment of breast carcinoma, adrenal carcinoma and adenoma, and fertility control. Its therapeutic effectiveness is limited by its sedative side effects. The enantiomers have been individually examined in the following systems: affinity for the cytochrome P-450 associated with cholesterol side chain cleavage, enzymatic inhibition of cholesterol side chain cleavage in corpus luteum and adrenal mitochondria, inhibition of aromatization in placental microsomes and luteolytic activity in the rat, rabbit and human. In these systems, the dextrorotatory form is 2 to 25 times more active than 
its levo-enantiomer. Toxicity data in the rat and mouse indicate approximately equivalent neurological activity for the two isomers. In view of the enhanced therapeutic ratio, the clinical use of the dextroisomer appears to be indicated.

25 Effect of Cumene Hydroperoxide (CHP) on Placental Aromatase W. G. Kelly and Ann Stolee Departments of Obstetrics-Gynecology and Biochemistry, University of Minnesota Medical School, Minneapolis, Minn.

Hydroxylation of drugs by hepatic microsomes and aromatization of androstenedione $(\Delta)$ by placental microsomes are catalyzed by mixed function oxidases employing cytochrome P-450. Recently, several laboratories have reported that CHP and 10; support hydroxylation of drugs and steroids by hepatic microsomes in the absence of TPNH. To determine whether CHP and IO; also support aromatization of $\Delta$, lyophillized microsomes from human term placentae were incubated in $0.05 \mathrm{M}$ Tris-maleate buffer $(1.5 \mathrm{mg} / 10 \mathrm{ml})$ at $37^{\circ} \mathrm{C}$ with $1,2-3 \mathrm{H}-\Delta(0.3 \mu \mathrm{M})$ in the presence of CHP, IO; or TPNH. The rate of aromatization was determined by filtering aliquots taken at various times through charcoal and counting $3 \mathrm{H} » 20$ in the filtrate. Placental microsomes aromatized $\Delta$ rapidly at a constant rate for $30 \mathrm{~min}$ in the presence of TPNH. No reaction was observed in the presence of CHP $(0.1$

Scientific Abstracts

25

to $9 \mathrm{mM})$ or $10 ;(0.01$ to $80 \mathrm{mM})$. In the presence of both TPNH and CHP $(2 \mathrm{mM})$ the rate of aromatization was constant for only a few minutes and decreased thereafter. Dithio-threitol (10 $\mathrm{mM})$ and EDTA $(20 \mu \mathrm{M})$ together afforded protection against the effect of CHP. Neither CHP nor 10; support aromatization of $\Delta$ in placental microsomes and CHP destroys the activity of aromatase. In this respect, placental aromatase differs from the hepatic hydroxylases. It has been previously noted that $\mathrm{CO}$ inhibits hepatic hydroxylases but not aromatase. These differences suggest fundamental differences in the nature and operation of the respective cytochrome P-450. 26 Synthesis and Studies of the Human Placental Lactogen Gene

Irving Boime and Diana McWilliams

Department of Obstetrics-Gynecology, Washington University School of Medicine, St. Louis, Mo.

For examining the control of human placental lactogen (HPL) gene expression during pregnancy, it is necessary to have a sensitive assay for both HPL mRNA synthesis and its structural genes. To achieve this goal we have synthesized a radioactive complementary DNA (cDNA) from a purified fraction of HPL mRNA using reverse transcriptase. Based on the size of the cDNA it contains at least $80 \%$ of the HPL genome and there is evidence for a significant amount of complete gene transcripts in the cDNA population. Previously it was shown that 5 times more HPL was synthesized in cell-free extracts derived from term as compared to first trimester placentae. Employing hybridization techniques, the cDNA was used for assaying the levels of HPL mRNA in equivalent amounts of first trimester and term placenta. These studies showed that there was about a 4-fold greater population of HPL sequences in total RNA from term placenta than in a comparable quantity of total first trimester RNA. Only background hybridization was observed between the cDNA and total RNA derived from human kidney. Hybridization of the labeled cDNA with nuclear placental DNA revealed that the number of HPL genes (ca. 2) per haploid genome is the same in term and first trimester placenta. Thus, the enhanced synthesis of HPL mRNA per gram of placenta appears to be the result of a transcriptional activation rather than amplification of the HPL genes. The increase likely reflects placental differentiation in which the proportion of syncytium increases at term. 
27 Establishment of Two New Tissue Culture Lines from Human Squamous Cell Carcinoma of the Cervix and Vagina R.H. Nalick, P.C. MacDonald, F. Vellios and J.C. Porter Department of Obstetrics-Gynecology, University of Texas Southwestern Medical School at Dallas, Dallas, Tex.

This report describes the successful establishment in culture and characterization of two lines of squamous cell carcinoma derived from two patients, one with recurrent carcinoma of the cervix and the other with primary carcinoma of the vagina. Cells obtained from malignant ascitic fluid (cervical carcinoma) and tissue obtained by biopsy (vaginal carcinoma) were placed in primary culture, utilizing Weymouth's MB-7531/1 enriched medium containing 15\% fetal calf serum (heat inactivated). After 13th passage of the cervical cell line and 17th passage of the vaginal cell line, tumor cells were innoculated into cortisone-immunosuppressed hamsters. Examination of the resultant tumor nodules revealed histo-

Society for Gynecologic Investigation

26

logical patterns identical with the original human tumors. After the 70th and 72nd passage in culture of the vaginal and cervical cell lines, respectively, the cells were injected into nude (athymic) mice; and solid tumor masses developed rapidly. Chromosomal analysis revealed 6570 and 83-87 chromosomes for the cervical and vaginal tumor cell lines, respectively. Doubling time during the rapid growth phase in culture was $24 \mathrm{~h}$ for both lines. The vaginal cell line produced $40 \mathrm{fg}$ of HCG/day/cell. Tumor cells which maintain neoplastic potential in vivo, should facilitate investigation in such areas of research as sensitivity to radiation and chemotherapeutic agents, immunotherapy and immunodiagnosis, ectopic hormone production, specific cell receptors, and tumor-specific antigens.

28 Lysosomes and Corpus Luteum Function

George L. Flickinger and Jerome F. Strauss, III

Department of Obstetrics-Gynecology, University of Pennsylvania School of Medicine, Philadelphia, Pa.

Alterations in properties of ovarian lysosomes from superovulated rats were studied in relation to stages of luteal function - days 1, 4, 8 and 14 post HCG; 7 rats/group. Activity of N-acetyl-Øglucosaminidase (NAGase) in ovarian homogenates on day 1 was $2.8 \pm$ SE $0.3 \mathrm{mU} /$ ovary and $0.24 \pm 0.03 \mathrm{mU} / \mathrm{mg}$ protein. A 1.8 -fold increase (p \& $1 \mathrm{t} ; 0.01$ ) in total and specific activity (SA) of NAGase was associated with a 2.8 -fold rise in plasma progesterone $(\mathrm{P})$ on day 4 . On day 8 NAGase activity was 2.5 times greater than the levels of day 1 , but on day 14 , when plasma $P$ had declined to values similar to those on day $1(102 \pm 15 \mathrm{ng} / \mathrm{ml})$, NAGase remained at day 8 levels. Total and SA of NAGase in lysosome-enriched fractions prepared by differential centrifugation followed a similar temporal pattern between days 1-14. Furthermore, changes in B-galactosidase, acid phosphatase and acid phospholipase A, and A2 activities in both ovarian homogenates and lysosome-enriched fractions paralleled the pattern described for NAGase. Significant changes in latency of NAGase were not observed at any time. Lysosomal fractions, suspended in $47 \%$ sucrose, were layered between 42 and 52\% sucrose and centrifuged; $76 \pm 6 \%$ of membrane-bound NAGase in homogenates from day 1 ovaries sedimented to the heavier interface while $11 \pm 3 \%$ rose to the lighter zone. However, only $30 \pm 10 \%$ of the NAGase from day 8 ovaries sedimented while $43 \pm 1 \%$ appeared at the lighter interface. This finding suggests increased buoyancy of the lysosomes at this time which could have resulted from accumulation of lipids. Our data indicate that lysosomes may be involved in regulation of cell functions during the period of luteal development and increased steroidogenesis. 
29 Studies on the Activation of Sperm Proacrosin to Acrosin; a Process Required for Fertilization

Kenneth L. Polakoski and Richard F. Parrish

Department of Obstetrics-Gynecology, Washington University School of Medicine,

St. Louis, Mo.

Proacrosin is activated to acrosin (EC 3.4.21.10 - a sperm proteinase utilized by sperm to penetrate the ovum's zona pellucida) during the capacitation process. Since active acrosin is an absolute requirement for fertilization and the control of the activation process has contraceptive potential, we have recently isolated two forms of boar proacrosin to homo-

Scientific Abstracts

27

geneity and have used sodium dodecyl sulfate disc gel electrophoresis to characterize a mechanism of activation. The proacrosins are autoactivated sequentially to three different active species of acrosin $(a, \beta$, and $\gamma)$ :

Proacrosin I $\rightarrow$ Proacrosin II $\rightarrow \alpha$ Acrosin $\rightarrow$ Acrosin $\rightarrow 7$ Acrosin

(55,000 MW (53,000 MW (49,000 MW (34,000 MW (25,000 MWinactive) inactive) active) active) active)

The autoactivation is concentration-dependent and can be proteolytically induced with either a or $B$ acrosin and trypsin. These results indicate that activation of proacrosin can occur via a bimolecular mechanism. The process is stimulated by liposomes and is inhibited by physiological concentrations of spermine and spermidine, implicating intriguing possibilities for the regulation of this key enzyme system.

12.15 to 1.45 p.m.

Concurrent Session C

Thursday, March 24, 1977

Mohave and Maricopa Rooms - Marriott Hotel

1.45 to 4.30 p.m.

Moderators: Samuel Solomon and Raphael Jewelewicz

1.45 p.m. 30 Differential Feedback Regulation by 17/3-Estradiol of LH Release, Cellular LH

Content, and LHRH-Responsiveness in Pituitary Monolayer Cultures Loretta K. Tang

University of Rochester School of Medicine and Dentistry, Department of Obstetrics and Gynecology, Rochester, N.Y.

To evaluate the direct effects of 17/3-estradiol (E2) on pituitary LH release into medium, cellular $\mathrm{LH}$ content, and LHRH responsiveness, physiological doses of the steroid (10" $\left.{ }^{\circ}-10-8 \Lambda \mathrm{fE} 2\right)$ were tested in 4-hour incubation with pituitary monolayer cultures of female rats. The effects of E2 were dose-dependent: 10-9ME2 stimulated LH release to $176 \%$ of the control level; 10 "8 M E2 stimulated cellular LH content to $127 \%$ of the control level; 10 "9 M or 10"8 M E2 stimulated LH accumulation (sum of LH contents in medium and cells). Contrary to its stimulatory effect when given alone, 10"8 ME2 inhibited cellular LH content to 76\% of the control level in the presence of 10"8 M LHRH. Furthermore, preincubation with 10"8 M E2 (for $48 \mathrm{~h}$ or longer) decreased the subsequent LH release in response to 10"8 M LHRH stimulation with a coincident increase in cellular LH content. These data indicate that the initial effect after short-term exposure to E2 was stimulatory to the LH-producing cells. However, the latent effect after sustained exposure to E2 was inhibitory to the LHRH responsiveness of the LH-producing cells. The evid $5 / 8$ nce of multiple levels of E2 feedback, which may be regulated independently by E2, provides the means for biphasic E2 actions in LH secretion. 
(Supported by NIH grant BRSG-UR-5-27269.)

Scientific Abstracts

29

2 p.m.

31 Assessment of Progesterone-Induced LH-Release at a Test for theHypothalamicGonadotropin Function

J.S. Rakoff, L·A. Riggand S.S.C. Yen

Department of Reproductive Medicine, UCSD, School of Medicine, La Jolla, Calif.

It is well known that under estrogen $(\mathrm{E})$ primed conditions, progesterone $(\mathrm{P})$ induces a prompt release of LH. Our recent studies indicate that this $\mathrm{P}$ effect is due to a combined event of amplification of E-augmented pituitary sensitivity and an LRF-dependent LH release.

Administration of P (10 mg, intramuscularly), in subjects with high endogenous E (late follicular phase) or through enhancement by daily injection of intremental doses of EB for 5 days in early follicular phase, a mean of 4- to 5-fold increase in LH release within a mean time of $9 \mathrm{~h}$ was observed. In 12 hypothalamic amenorrhea (HA) patients with lower basal LH levels (p \&lt; 0.05) and the absence of pulsatile pattern, EB treatment alone induced at $200 \%$ increase in pituitary sensitivity to $10 \mu \mathrm{g}$ LRF stimulation without change in the basal levels $(11 \pm 1.4 \mathrm{vs} .9 .1 \pm 2.4$ $\mathrm{mlU} / \mathrm{ml}$ ). Thus, the functional capacity of the gonado-troph in HA is responsive to $\mathrm{E}$ augmentation but with no discernible increase in endogenous LRF. In another 15 patients with HA, following 5-7 days of EB priming, P induced a small but significant ( $p$ \&lt; 0.05) increase in LH release in only 3 and no response in 12. In contrast, all patients with hyperprolactinemic amenorrhea showed a small $(185 \pm 27 \%)$ but definite response to this EB-P stimulation.

Analyses of the relationship between basal LH and peak response to $\mathrm{P}$ revealed a significant positive logarithmic correlation $(\mathrm{r}=0.81)$, indicating a critical basal LH level at which the expression of P-induced LH release is manifested. Our findings implicate that: (1) the gonadotroph in HA patients is fully operational as evidenced by the functional augmentation by E; (2) HA is associated with a dysfunction of P-mediated LRF release, and (3) although present, the P-mediated LH release is impaired in hyperprolactinemic amenorrhea patients.

2.15 p.m.

32 Changes in Response to Gonadotrophin-Releasing Hormone (GnRH) in Male Fetal andInfant Rhesus Monkeys

Про T. Huhtaniemi, Carol C. Korenbrot, Maria Seron-Ferre, Julian T. Parer, Dallas B. Foster and Robert B. Jaffe

Department of Obstetrics-Gynecology and Reproductive Sciences, University of California, San Francisco, Calif.

17 fetal and infant male monkeys were challenged with GnRH between 130 days' gestation and 1 year postnatally, and pituitary and testicular responses measured. Responses of circulating LH and testosterone $(\mathrm{T})$ were observed at all ages; clear differences in response were seen between fetal, neonatal and infant stages of development. Intravenous administration of GnRH to the chronically catheterized fetus in utero resulted in a mean T increase of $110 \%$ in $\mathrm{lh}$ during the last third of gestation; doses of $50 \mu \mathrm{g} \mathrm{GnRH}$, but not $10 \mu \mathrm{g}$, consistently resulted in stimulation. In contrast, during the 4 days following delivery, 3-5 $\mu \mathrm{g}$ GnRH stimulated T increases of similar magnitude. From 18-89 days of age, an increased mean response (300\%) to $10 \mu \mathrm{g} \mathrm{GnRH}$ was seen. After this neonatal period, T responses following GnRH declined, and no effect of $10 \mu \mathrm{g}$ GnRH was seen by 1 year. Similarly, subcutaneous injections of GnRH in slow-release form $(500 \mu \mathrm{g} / 2$ weeks) maintained high $\mathrm{T}$ levels $(6-10 \mathrm{ng} / \mathrm{ml})$ until $65-80$ days of age. No stimulation 
was seen after this time. Circulating LH responses to GnRH, determined by Leydig cell in vitro bioassay, changed in a parallel fashion to $\mathrm{T}$ responses between fetal, neonatal and infant stages. It is

Society for Gynecologic Investigation

30

concluded that the male monkey perinatal pituitary-gonadal axis responds to GnRH. An increase in the sensitivity and magnitude occurs after birth and is maintained until about 90 days of age after which responsiveness gradually decreases during the first year of life. These findings correlate well with changes seen in pituitary-gonadal function in the human male infant. 2.30 p.m.

33 Delineation of the Significance of Falling E2 on Pituitary LH Sensitivity Prior to theMidCycle Surge

J.D. Hoff, B.L. Lasley and S.S.C. Yen

Department of Reproducive Medicine, UCSD, School of Medicine, La Jolla, Calif.

It has been observed that prior to the onset of mid-cycle surge of LH, E2 often exhibits a decline and that controversy exists concerning the role of this fall in E2 in the initiation of the midcycle surge. To resolve this question, the following experiment was performed. Increasing circulating E2 to late follicular levels was achieved by daily incremental estradiol benzoate (EB) injection over a period of 5-7 days during the early follicular (EB) phase of the menstrual cycle. Pituitary sensitivity (S) and reserve (R) were assessed by $10 \mu \mathrm{g}$ pulses of LRF and 2-hour intervals $\times 3$, given either immediately after the last dose of EB when E2 levels were highest (EB0) or at $36 \mathrm{~h}$ after discontinuation of EB when E2 levels had fallen significantly (EB36). LRF responses in six women in the EF phase without EB treatment served as controls. EB induced an increase in pituitary $\mathrm{S}$ and $\mathrm{R}$ in the EB0 group, and a further amplification of this increase for the $\mathrm{S}$ and $\mathrm{R}$ was observed after the fall in E2 (EB36). From EB0 to EB36, while basal levels are unchanged, the $\Delta \mathrm{LH}$ increased more than 2-fold $(78.8 \pm 31.9 \mathrm{vs} .171 \pm 38 \mathrm{mlU} / \mathrm{ml})$ and the percent rise increased 1.9 -fold $(380 \pm 56 \%$ vs. $726 \pm 59 \%$, p \& $\& 1$; 0.01$)$. Pituitary R (integrated $\Delta$ response X $6 \mathrm{~h})$ increased 2.7 -fold $(31.2 \pm 4.7$ vs. $86.5 \pm 22.4 \mathrm{IU}-\mathrm{min} / 6 \mathrm{~h}, \mathrm{p} \& \mathrm{lt} ; 0.04)$. Thus, the pituitary S and $\mathrm{R}$ are further augmented in the face of falling levels of E2; this may be related either to the continuous tissue action of E2 despite the fall in circulating levels or to the loss of E2 inhibition. The fall of circulating E2 at the late follicular phase is not temporally related to the timing of mid-cycle surge but it may contribute to the excursion and duration of the surge.

2.45 p.m.

34 Correlation of Hypothalamic LRF and Pituitary LH and FSH in the Human

Fetusthroughout Gestation

Theresa M. Siler-Khodr and Gabriel S. Khodr

Department of Obstetrics-Gynecology, American University of Beirut, Beirut

Hypothalamic and pituitary tissues were obtained from 50 human fetuses with no apparent endocrinopathies. These tissues were stored at $-20^{\circ} \mathrm{C}$ in acetone until extracted and analyzed for LRF, LH and FSH by RIA.

The hormonal patterns throughout gestation were distinctly different for male and female fetuses. In the female, hypothalamic LRF and pituitary LH and FSH attained peak content at 23 weeks' fetal age and thereafter declined. A second, lesser rise in LH and FSH occurred late in gestation (34 week fetal age to term); however, a concomitant increase in hypothalamic LRF was not observed. In the male, LRF, LH and FSH increased with progressing gestational age.

Hypothalamic LRF was significantly greater (p \&lt; 0.001) at 34 week fetal age to term than 
earlier in gestation. Pituitary LH increased exponentially with gestation and at a rate greater than the increase in pituitary size, while the increase of FSH paralleled the pituitary growth rate.

Scientific Abstracts

31

The ratio of LRF:LH and LRF:FSH in both male and female fetuses varied throughout gestation, suggesting that other factors in the fetus may also modulate gonadotrophin production and/or the effect of LRF on LH and FSH production. However, the finding that peak pituitary LH and FSH content correlated with the peak hypothalamic LRF content in both male and female fetuses indicates that fetal hypothalamic LRF is most hkely an important factor in regulating fetal gonadotrophin production and thus normal reproductive development.

3 to 3.15 p.m. Intermission

3.15 p.m. 35 Serial Determination of Maternal and Fetal C19 Steroids in Ovine Plasma during the Days Preceding Parturition

Antonio E. Colas and Luis B. Curet

Department of Obstetrics-Gynecology, University of Wisconsin Medical School,

Madison, Wise.

Cortisol-induced increases in placental aromatizing activity or in the supply of 4-androstene3,17-dione (A) synthesized from C21 steroids in the placenta have been proposed as possible explanations for the estrogen surge which occurs in the few hours before ovine parturition.

Another possibility is that the supply of extraplacental $\mathrm{Cl} 9$ precursors, perhaps from the fetal adrenal, increases concomitantly with the production of fetal cortisol. To investigate this possibility, we have repeatedly measured A, dehydroepiandrosterone (D) and testosterone (T) by RIA in plasma from blood drawn through catheters implanted in the maternal femoral artery (FA), uterine vein (UV), and umbilical vein and artery (UmV and UmA) of 12 ewes. For D there was a significant difference UV-FA, $1.35 \pm \mathrm{SE} 0.51 \mathrm{ng} / \mathrm{ml}$, which disappeared as parturition approached. There was a significant increase of $\mathrm{A}$ in $\mathrm{UmV}$ in the last day of gestation to $550 \pm$ $108(\mathrm{pg} / \mathrm{ml} \pm \mathrm{SE})$ compared to a mean of $288 \pm 21$ for the 6 preceding days. The levels of D were greater in UmA or UmV than in FA; the concentration of T in UmV was higher than in UmA or FA, and the levels of A were about the same in FA and UmV and significantly greater than in UmA. These results suggest that the conversion of extraplacental D to A and T (and presumably estrogens) increases during the last few days of pregnancy.

(Supported by NIH grants No. 1-RO1-HD-05387-05 and No. 5-TO1-HD-00104-10 and Ford Foundation grant No. 630-0505B.C.)

3.30 p.m. 36 Increased Metabolic Clearance (MCR) and Production (PR) of Cortisol (F) by Baboon Neonates (Papio papio) is Associated with Spontaneous Delivery Gerald J. Pepe and John D. Townsley Pregnancy Research Branch, NICHD, NIH, Bethesda, Md.

MCR, interconversion (p), PR, and secretion (SR) of F and cortisone (E) were determined in 9 newboms, 5 (4 3/8 1 + ) delivered by cesarean section (group 1, 164-179 days), and 4 (3 9 , Id) spontaneously (group 2, 166-180 days, term $=184$ days). $25 \mu \mathrm{Ci}(3 \mathrm{H}) \mathrm{F}$ and

Society for Gynecologic Investigation

32

$50 \mathrm{mCi}(14 \mathrm{C}) \mathrm{E}$ in $0.9 \% \mathrm{NaCl}$ were constantly infused $(0.1 \mathrm{ml} / \mathrm{min})$ via an antecubital vein.

Saphenous vein blood was obtained at $0,70,80$ and $90 \mathrm{~min}$. F and $\mathrm{E}$ were extracted from serum and purified chromatographically. Serum levels (jug/100 ml) were determined by radioimmunoassay. Results (mean $\pm \mathrm{SE}$ ): 
MCR-E exceeded ( $p$ \&lt; 0.001) that of F. Percent $F \rightarrow E$ was greater (p \&lt; 0.001) than \% $\mathrm{E} \rightarrow \mathrm{F}$, therefore, $\mathrm{F}-\mathrm{E}$ interconversion favors $\mathrm{E}$ formation. PR-E exceeded (p \& 1t; 0.001) PR-F with $83 \%$ E secreted. Since MCR-E was greater (p \&lt; 0.05) in group 2 than in group 1 but serum E was lower (p \&lt; 0.05) in group $2(26 \pm 4)$ than in group $1(36 \pm 2)$, PR-E was similar in both groups. MCR-F in group 2 was twice ( $\mathrm{p} \& 1 \mathrm{t} ; 0.001)$ that in group 1 and since serum F was similar in groups $1(32 \pm 7)$ and $2(34 \pm 8)$, PR-F was greater (p \&lt; 0.05) in spontaneously delivered newborns. About $65 \% \mathrm{~F}$ was secreted in both groups. The greater $\mathrm{F}$ synthesis associated with spontaneous delivery is compatible with the 4-fold greater adrenal 3(3hydroxysteroid dehydrogenase-isomerase activity in such animals (G.J.P., J.D.T., Soc. Study Reprod. Abstract 155,1976).

3.45 p.m. 37 Fetal ACTH Stimulation of Steroidogenesis and its Implications for Parturition in Chronically Prepared Rhesus Monkeys

Scott W. Walsh and Miles J. Novy

Perinatal Physiology, Oregon Regional Primate Research Center, Beaverton, Oreg.

Fetal carotid and jugular, maternal femoral and amniotic fluid catheters were placed in 5 rhesus monkeys at 125 days' gestation. The following experiments were performed: (l)Two animals received short-term (3-4 h) fetal ACTH infusions (5 IU injection plus $1 \mathrm{IU} / \mathrm{h}$ infusion) in conjunction with maternal dexamethasone infusion. Mean fetal plasma estrone (E,) increased $425 \%$ (55 to $289 \mathrm{pg} / \mathrm{ml}$ ) and fetal estradiol (E2) increased $216 \%(9.8$ to $31 \mathrm{pg} / \mathrm{ml}$ ) after $30 \mathrm{~min}$ of ACTH. Mean fetal progesterone (P) rose $39 \%(8.2$ to $11.4 \mathrm{ng} / \mathrm{ml})$ and cortisol increased from 5.0 to $12.0 \mu \mathrm{g} / 100 \mathrm{ml}$ after $2 \mathrm{~h}$. Maternal plasma steroids increased similarly but maximum levels were reached later and percent changes were not as great. (2) Three animals received short-term fetal ACTH without concurrent dexamethasone. Fetal and maternal plasma P and cortisol increased but plasma estrogens were

Scientific Abstracts

33

not substantially altered when endogenous ACTH was not first suppressed by dexametha-sone. (3) Three animals received long-term (1-9 days) fetal ACTH infusions which resulted in the onset of labor preceded by gradual increases of $\mathrm{E}$, in fetal plasma and of $\mathrm{E}$ ! and $\mathrm{E} 2$ in maternal plasma. Neither fetal nor maternal plasma $\mathrm{P}$ decreased prior to parturition. Amniotic fluid $\mathrm{E}[$, prostaglandin $\mathrm{E}$ and $\mathrm{F}$ also increased during ACTH treatment. These data suggest that the fetal adrenals play an important role in steroidogenesis and that increased release of fetal ACTH with subsequent increases of fetal and maternal plasma estrogens and amniotic fluid E, and prostaglandins may normally precede the onset of labor in primates.

4 p.m. 38 Dehydroepiandrosterone and not Dehydroepiandrosterone Sulfate is the Major Circulating Estrogen Precursor in Pregnant Baboons John D. Townsley, Herman A.J. Schut and Gerald J. Pepe Pregnancy Research Branch, NICHD, NIH, Bethesda, Md.

To examine whether Dehydroepiandrosterone (D) is quantitatively more important than dehydroepiandrosterone sulfate (DS) as an estrogen precursor in baboon pregnancy, the serum concentrations, metabolic clearance (MCR), conversion ratios (CR), intercon-version (p), production rates (PR), secretion rates (SR) and contributions of D and DS to serum estradiol-Пø (E2) were determined. At 11.00-12.00 h, 3 animals $(154-167$ days gestation, term $=184)$ weighing $18.4 \pm 0.6 \mathrm{~kg}$ were sedated with ketamine intravenously and $150 \mu \mathrm{Ci} 14 \mathrm{C}-\mathrm{D}$ and $1 \mathrm{mCi}$ $3 \mathrm{H}-\mathrm{DS}$ were infused constantly for $2 \mathrm{~h}$ via an antecubital vein. Saphenous vein blood was withdrawn after 100, 110 and $120 \mathrm{~min}$. Radio chemically pure serum D, DS and E2 were isolated by chromatography and crystallization. $\mathrm{D}$ and $\mathrm{DS}$ levels $(\mu \mathrm{g} / 100 \mathrm{ml})$ were determined by 
radioimmunoassay. Results (mean $\pm \mathrm{SE})$ : Serum D $(2.5 \pm 1.4)$ was \&lt; serum DS $(18.9 \pm 5.7)$ but MCR-D, $1 /$ day $/ \mathrm{kg}(35.0 \pm 2.5)$ was \&gt; MCR-DS $(2.6 \pm 0.4)$ making mean PR-D $\mu \mathrm{g} / \mathrm{h} / \mathrm{kg}$ (36) \&gt; PR-DS (20). Since CR-D $\rightarrow$ DS $(5.66 \pm 0.83)$ was $\& g t ; C R-D S \rightarrow D(0.005 \pm 0.001)$, $\mathrm{p}-\mathrm{D} \rightarrow \mathrm{DS}(42.7 \pm 4.5 \%)$ was $\& \mathrm{gt}$; $\mathrm{p}$-DS $\rightarrow \mathrm{D}(6.9 \pm 0.6 \%$. Therefore, mean SR-D was \&gt; mean SR-DS, 35 vs. $5 \mu \mathrm{g} / \mathrm{h} / \mathrm{kg}$, indicating that $95 \%$ D but only $25 \%$ DS was secreted. CR-D $\rightarrow$ E2 $(0.263 \pm 0.029)$ was $\& g t ;$ CR-DS $\rightarrow$ E2 $(0.002 \pm 0)$. Using these serum concentrations and conversion ratios, it was calculated that $91 \%$ serum E2 was derived from D directly and $4 \%$ from D via circulating DS, while only $1 \%$ E2 was derived directly from DS and $4 \%$ from DS via circulating D. Thus, despite the low serum D concentration resulting from a high MCR, the large SR-D and efficient conversion of D to E2 makes D the major circulating estrogen precursor in late baboon pregnancy.

4.15 p.m. 39 Fetal Contribution of Oxytocin in Human Parturition

M. YusoffDawood, Chun F. Wang, Rommel Gupta, and Fritz Fuchs Department of ObstetricsGynecology, Cornell University Medical College, New York, N.Y.

Recent evidence suggested that the fetus might contribute oxytocin to the mother during spontaneous labor. Oxytocin (OT) was measured by a specific and sensitive radio-immunoassay, requiring preliminary extraction with Fuller's earth and using oxytocin antibody raised in rabbits and rabbit anti- $\gamma$-globulin from goats to separate bound from free hormone. In 26 subjects with spontaneous labor and vaginal delivery (group I) and 18 subjects with cesarean section after labor (group II), umbilical arterial plasma (UA) levels

Society for Gynecologic Investigation 34 (means \pm SE: $116 \pm 17.2$ and $118.4 \pm 18.1 \mathrm{pg} / \mathrm{ml}$, respectively) were significantly higher than umbilical venous plasma (UV) $(38.0 \pm 5-6$ and $34.9 \pm 6.6 \mathrm{pg} / \mathrm{ml} ; \mathrm{p}=\& \mathrm{lt} ; 0.001$ and $\mathrm{p}=\& \mathrm{lt}$; 0.001 , respectively). With elective cesarean section (group III), UA OT was $29.8 \pm 7.5 \mathrm{pg} / \mathrm{ml}$ and UV OT was $16.1 \pm 5.9 \mathrm{pg} / \mathrm{ml}(\mathrm{n}=14)$. In contrast, UV levels $(69.9 \pm 18.6 \mathrm{pg} / \mathrm{ml})$ were higher than UA levels $(24.6 \pm 9.0 \mathrm{pg} / \mathrm{ml})(\mathrm{n}=7)$, when pitocin was given to the mother (group IV). The arteriovenous $(\mathrm{A}-\mathrm{V})$ difference in OT levels which were $73.3 \pm 13.3 \mathrm{pg} / \mathrm{ml}$ and $81.0 \pm 12.4 \mathrm{pg} / \mathrm{ml}$ in groups I and II were significantly higher than in group III $(13.8 \pm 5.1 \mathrm{pg} / \mathrm{ml} ; \mathrm{p}=\& \mathrm{lt} ; 0.005$ and $\mathrm{p}=\& \mathrm{lt} ; 0.001$, respectively). Amniotic fluid OT levels, which were $110.8 \pm 19.7 \mathrm{pg} / \mathrm{ml}$ in group I $(\mathrm{n}=3)$ and $48.1 \pm 12.4 \mathrm{pg} / \mathrm{ml}$ in group II $(\mathrm{n} \approx 11)$, were higher than in group HI $(13.6 \pm$ $6.7 \mathrm{pg} / \mathrm{ml}, \mathrm{n}=11)$. OT was also present in fetal urine. The findings indicate that during spontaneous labor, a substantial amount of oxytocin is produced by the fetus and transferred to the maternal circulation. (Supported by Ford Foundation grant No. 670-0455.)

4.30 p.m.

Business Meeting (members only)

Mohave and Maricopa Rooms - Marriott Hotel

7 p.m.

Reception, Banquet and Entertainment

Old Tucson

Charter buses are available for transportation from the Marriott Hotel to Old Tucson. Reception and Banquet are supported, in part, by the Ortho Pharmaceutical Corporation and the G.D. Searle Company.

Concurrent Session D

Thursday, March 24, 1977

Greenlee and Graham Rooms - Marriott Hotel

1.45 to 4.30 p.m. 
Moderators: Karlis Adamsons and Lawrence D. Longo

1.45 p.m. 40 In vivo Measurement of Regional Cerebral Metabolic Rate in Fetal Sheep in utero

R.M. Abrams, J.F. Clapp, III and M. Notelovitz

Department of Obstetrics-Gynecology, University of Florida, School of Medicine,

Gainesville, Fla.

Healthy fetal brain continually metabolizes energy, most of which is converted to heat and lost to the circulating blood. In preliminary studies in 5 fetal sheep in utero, brief total occlusion of the bracheocephalic artery (BC) prevented loss of fetal brain metabolic heat and led to a rise in brain temperature $\mathrm{C}^{1} / 8$ ). As the ischemia needed for the accurate estimation of fetal brain metabolic heat production may have been incomplete, the effect of simultaneous occlusion of the pulmonary artery and aorty (PA-A) on brain temperature was investigated in 10 near-term fetal sheep and the results compared with the alternate method of occlusion of the BC. Thermocouples (36 gauge) were implanted to a minimum depth of $1 \mathrm{~cm}$ in brain tissue, but their exact position was not verified. Rate of Tßr rise (Tßr) following PA-A occlusion $(0.144 \pm 0.018 \mathrm{SEM} \mathrm{C} / \mathrm{min})$ was significantly greater than $\mathrm{T} ß \mathrm{r}$ following $\mathrm{BC}$ occlusion $(0.130 \pm 0.014 \mathrm{SEM} \mathrm{C} / \mathrm{min})$. Brain specific heat (c) of 3 other fetal brains measured by the method of mixtures averaged 0.873 $\mathrm{cal} / \mathrm{g} / \mathrm{C}$. On this basis the fetal brain heat production $(\dagger \mathrm{gr} \times \mathrm{c}$ ) was $0.126 \mathrm{cal} / \mathrm{g} / \mathrm{min}$. Assuming brain metabolism to be completely aerobic and glucose to be the sole energy substrate, this estimated rate of fetal brain heat production was equivalent to a cerebral oxygen consumption of $2.5 \mathrm{~cm} 3 / 100 \mathrm{~g} / \mathrm{min}$ or about 4 times the oxygen uptake (per $100 \mathrm{~g}$ ) of the fetal body as studied in comparable acute experiments.

Society for Gynecologic Investigation

36

2 p.m. 41 Effect of Atropine on Fetal Cardiac Output during Hypoxemia

James R. Green, Robert K. Creasy, Michael A. Heymann and Abraham M. Rudolph

Cardiovascular Research Institute, University of California, School of Medicine, San Francisco, Calif.

It has been suggested by Cohn et al, that the decrease in fetal cardiac output during hypoxia is aggrevated by atropine blockade. We have investigated this question by continuous measurement of left cardiac output (LCO) or right cardiac output (RCO) during induced hypoxia with atropine blockade. An electromagnetic flow transducer was placed on the ascending aorta or the main pulmonary trunk of fetal lambs from 122 to 127 days' gestation. 2-7 days after operation fetal hypoxemia was induced by administration of a low 02 mixture ( $\rho \mathrm{I} 0253$ ) to the standing ewe. The mean fetal p02 decreased from $22.5 \mathrm{~mm} \mathrm{Hg}$ to $13.4 \mathrm{~mm} \mathrm{Hg}$. In 5 studies on 3 fetuses with aortic flow transducers the fetal heart rate (FHR) decreased to $86 \%$ of control after 5 min and the mean LCO decreased to $84 \%$ of control. Administration of $0.2 \mathrm{mg} / \mathrm{kg}$ atropine was followed by an increase in the FHR to $133 \%$ of control and a return of LCO to $98 \%$ of control. In 3 studies on 2 fetuses with main pulmonary trunk flow transducers the FHR decreased to $91 \%$ of control after 5 min of hypoxemia, but RCO decreased minimally to $98 \%$ of control. Administration of atropine caused a rise in the FHR to $160 \%$ of control and an increase in RCO to $15 \%$ above control values. The results indicate that atropine administration during moderate hypoxemia results in an increase in both left and right cardiac output and suggest that right cardiac output may be relatively maintained during moderate hypoxemia.

2.15 p.m. 42 Effects of 2- $\alpha$-Br-Ergocryptine on Prolactin Concentration and Mammary Blood Flow during Parturition in the Ewe

Laurence I. Burd 
Division of Fetal and Maternal Medicine, Michael Reese Hospital and Medical Center, Chicago, 111.

Previous studies in chronic sheep preparations with uterine vein sampling catheters and electromagnetic flow probes implanted around the mammary arteries, demonstrated that an increase in mammary blood flow (MBF), a rise in prolactin concentration and a decrease in progesterone concentration were early physiologic events during spontaneous and induced parturition, while an increase in estradiol-17|3 and onset of uterine contractions occurred later. This study was designed to examine the role of prolactin as a cause of the increase in MBF during parturition. In 3 ewes $1 \mathrm{mg}$ of 2 - $\alpha$-Br-ergocryptine was injected every $6 \mathrm{~h}$ to lower prolactin concentration. A control group of 3 animals received injections of the vehicle alone. In both groups, dexamethasone $(1 \mathrm{mg} / 24 \mathrm{~h})$ was infused into the fetus to initiate parturition. Prolactin concentration increased from $69 \pm$ SEM $19 \mathrm{ng} / \mathrm{ml}$ to $279 \pm$ SEM $90 \mathrm{ng} / \mathrm{ml}$ in the control group while it fell from $33 \pm$ SEM $4 \mathrm{ng} / \mathrm{ml}$ to $2 \pm$ SEM $0.1 \mathrm{ng} / \mathrm{ml}$ in the group receiving $2-\alpha$-Br-ergocryptine. Although prolactin concentration rose in the control group and decreased in the experimental group, a similar increase in MBF occurred in both groups (control, $61 \pm$ SEM $12 \mathrm{ml} / \mathrm{min}$ to $243 \pm \mathrm{SEM} 8 \mathrm{ml} / \mathrm{min}$; experimental, $68 \pm \mathrm{SEM} 16 \mathrm{ml} / \mathrm{min}$ to $265 \pm \mathrm{SEM} 59$ $\mathrm{ml} / \mathrm{min}$ ). This study seems to indicate that the increase in prolactin concentration and MBF which occur at the time of parturition in the ewe are not causally related.

Scientific Abstracts

37

2.30 p.m. 43 Cardiac Output and Uterine Blood Flow in the Pregnant Ewe

James F. Clapp, III

Department of Obstetrics-Gynecology, University of Vermont College of Medicine, Burlington, Vt.

15 chronically instrumented ewes were studied using the direct Fick technique for measurement of cardiac output and the diffusion equilibrium technique to measure uterine blood flow. The mean weight of the uterus and its tissue contents at term was $6.2 \pm 0.5 \mathrm{~kg}$ with mean rates of uterine blood flow and oxygen consumption of $1.62 \pm 0.151 / \mathrm{min}$ and $57 \pm 4 \mathrm{~cm} 3 / \mathrm{min}$, respectively. These data indicate that the uterus and its tissue contents at term utilize $24 \%$ of maternal oxygen consumption while accounting for only $13 \%$ of maternal weight. In 8 animals studied at term and again 3 months thereafter, uterine blood flow at term represented $79 \%$ of the increase in maternal cardiac output above the nonpregnant level. Likewise, uterine oxygen consumption at term represented $84 \%$ of the increase in maternal oxygen consumption above the nonpregnant level. The same relationship was noted throughout pregnancy in 4 animals studied repetitively from 60 days to term. When uterine blood flow and oxygen consumption at term were subtracted from maternal values there was no significant difference between maternal cardiac output and oxygen consumption at term and that found in the non-pregnant state.

(Supported by Vt. Heart Association grant No. 88.)

2.45 p.m. 44 The Effect of Systemic Infusions of Dehydroisoandrosterone on the Distribution of Uterine Blood Flow in the Ovine Pregnancy Charles R. Rosenfeld, Richard J. Worley and

Norman F. Gant

Departments of Obstetrics-Gynecology and Pediatrics, Southwestern Medical School at Dallas, Dallas, Tex.

Although estrogen is a potent vasodilator of the vascular beds of the ovine uterus, precursors of ovine estrogen remain unknown. Studies in our laboratories have shown significant increases in UBF and plasma estrone (Ei) and estradiol (E2) after a systemic infusion of 
dehydroisoandrosterone (D) in the pregnant ewe. To investigate the distribution of uterine blood flow (UBF), 4 pregnant ewes, 105 to 128 days of gestation, were studied with microspheres before and after a systemic infusion of $6 \mathrm{mg}$ D. Serial blood samples obtained from 3 ewes showed increases at $15 \mathrm{~min}$ in E1 from $27.3 \pm 2.23$ (mean $\pm \mathrm{SE}$ ) to $117 \pm 13.2 \mathrm{pg} / \mathrm{ml}$ and in E2 from $34.3 \pm 4.91$ to $71.7 \pm 5.21 \mathrm{pg} / \mathrm{ml}$ (p \&lt; 0.05 ). At $140 \mathrm{~min}$ neither UBF nor placental blood flow was significantly changed. Endometrial blood flow increased from $176 \pm 24$ to $242 \pm 32$ $\mathrm{ml} / \mathrm{min}(39 \%$, p \& lt; 0.005$)$ and myometrial blood flow rose from $35 \pm 6.1$ to $51 \pm 8.4 \mathrm{ml} / \mathrm{min}$ $(45 \%, \mathrm{p} \& \mathrm{lt} ; 0.01)$. Of interest were the responses in cervical blood flow, increasing from $3.18 \pm$ 0.6 to $15.6 \pm 2.0 \mathrm{ml} / \mathrm{min}(441 \%, \mathrm{p} \& \mathrm{lt} ; 0.005)$, and vaginal blood flow, increasing from $0.175 \pm$ 0.03 to $0.992 \pm 0.15 \mathrm{ml} / \mathrm{min} \cdot \mathrm{gm}(476 \%, \mathrm{p} \& 1 \mathrm{t} ; 0.01)$. These studies suggest that $\mathrm{D}$ may be an important precursor of E, and E2 and that the ovine estrogen surge at term may prepare the uterus, cervix and vagina for the process of parturition. Furthermore, they reveal that the increase in UBF following an infusion of D reflects increased perfusion of nonplacental tissues, supporting earlier observations that exogenous estrogens might have no beneficial effects for the fetus.

Society for Gynecologic Investigation

38

3.15 p.m. 45 A Pharmacokinetic Model Describing the Distribution and Elimination of Meperidine in the Maternal-Fetal Unit

Hazel H. Szeto, Charles E. Inturrisi, Amrutha Bhakthavathsalan, Maida Liu and Leon I. Mann Department of Pharmacology, Cornell University Medical College, New York, N.Y., and Department of Obstetrics-Gynecology, University of Vermont College of Medicine, Burlington, Vt.

Meperidine (M) pharmacokinetics were evaluated in the chronic pregnant ewe preparation. Plasma levels of M were measured (J. Chromat. 125: 503, 1976) in mother (MA) and fetus (FA) following intravenous bolus and continuous infusion of $\mathrm{M}$ to MA. After an intravenous bolus $(2.5 \mathrm{mg} / \mathrm{kg}), \mathrm{M}$ appears in FA within 2 min at levels approaching MA. Thereafter, FA and MA levels fall at approximately the same rate in a biexponential fashion. Pharmacokinetic analysis reveals that the fetus may be considered as part of the maternal central compartment, implying that there is rapid equilibration of $\mathrm{M}$ between mother and fetus. When $\mathrm{M}$ is infused at a rate of $0.06 \mathrm{mg} / \mathrm{kg} / \mathrm{min}$, steady state (SS) is achieved in MA in $30 \mathrm{~min}$ and in FA in $60 \mathrm{~min}$. At SS, the plasma $\mathrm{M}$ concentration ratio of $\mathrm{FA} / \mathrm{MA}$ is equal to 0.3 . Plasma protein binding of $\mathrm{M}$ averaged $54 \%$ for MA, and 28\% for FA. When differences between MA and FA in plasma binding and degree of ionization are taken into account the recalculated SS concentration ratio is still significantly less than 1 (approx. 0.26). These data suggest that there is either active transport of $\mathrm{M}$ from fetus to mother, or fetal elimination of $\mathrm{M}$. Data from the intravenous bolus study does not support active transport. Tehrefore we propose that $\mathrm{M}$ confers on the maternal-fetal unit the characteristics of a two-compartment open model with elimination from both maternal and fetal compartments. This model suggests that the elimination by the fetus makes an important contribution to the disposition of $\mathrm{M}$.

(Supported in part by DA-01457, UCP 237-71 and Hoffmann-La Roche.) 3.30 p.m. 46 Cardiovascular Reactivity of Sheep to Autonomic Stimuli during Adrenergic Depletion Adrien Dandavino, James R. Woods, jr., Bahij Nuwayhid, Charles R. Brinkman, III, Karen Blanchard, Kenneth E. Clark and Nicholas S. Assali Department of ObstetricsGynecology, UCLA School of Medicine, Los Angeles, Calif. 
Previous studies have shown that autonomic controls of cardiovascular functions change continuously throughout the perinatal period assuming adult pattern at 8 weeks of age. To further characterize intrinsic cardiovascular sensitivity to neurohumoral mediators, responses of chronically instrumented neonate and adult sheep to autonomic agonists and antagonists were investigated during neuronal adrenergic depletion. Effects on heart rate (HR) and arterial pressure (AP) of cholinergic stimulation (acetylcholine) and inhibition (atropine), $\alpha$-adrenergic stimulation (norepinephrine) and inhibition (phenoxybenzamine), ${ }^{\wedge}$-stimulation (isoproterenol) and inhibition (propranolol) and ganglionic stimulation (DMPP) and inhibition (Arfonad) were monitored in control periods and after adrenergic depletion with reserpine $(20 \mu \mathrm{g} / \mathrm{kg}$ intramuscularly daily for 5-7 days) using the same animals as its own control. Complete depletion was ascertained by abolition of response to tyramine. Adrenergic depletion produced: (1) marked bradycardia with insignificant AP changes; (2) increased reactivity of HR and AP to cholinergic receptor blockade and stimulation; (3) reversal of effects of $\alpha$-blockade and increased reactivity to a- and Ø-stimulation;

Scientific Abstracts

39

(4) reversal of ganglionic blocking action and diminished response to ganglionic stimulation. Conclusions: (a) neuronal adrenergic depletion with reserpine renders heart and blood vessels supersensitive to action of neurotransmitters and to atropine, and reverses action of ganglionic blockade; (b) neonate supersensitivity was not different from adult sheep.

3.45 p.m.

$47 \quad$ Vascular Compliance in the Fetal Sheep Placenta

Gordon G. Power and Raymond D. Gilbert

Loma Linda University School of Medicine, Loma Linda, Calif.

To explore the mechanical properties of umbilical vessels and to test the interaction between maternal and fetal vessels in the placenta we recorded pressure-volume curves from isolated in situ placentas of 17 sheep. We measured compliance at 3 rates of volume change and estimated true compliance by extrapolating to infinitely slow rates of volume change. We found control umbilical compliance averaged $0.218( \pm 0.020 \mathrm{SEM}) \mathrm{ml} / \mathrm{mm} \mathrm{Hg} / \mathrm{kg}$ fetal weight, a value that increased $28 \%$, a significant rise ( $\mathrm{p} \& \mathrm{lt} ; 0.001$ ), when maternal arterial pressure was lowered 85 $\mathrm{mm} \mathrm{Hg}$ (clamping aorta), but did not change significantly when venous pressure was raised 35 $\mathrm{mm} \mathrm{Hg}$ (clamping IVC). After replacing blood with kerosene which does not penetrate small vessels, we found arteries accounted for $22 \%$ and veins for $40 \%$ of total compliance, leaving $38 \%$ attributable to the placental unit. We conclude that umbilical vessels are about one half as compliant as adult vessels per body weight, but comparable to vessels elsewhere in the fetal body. We compared the observed interaction with predictions of mechanical and mathematical models, assuming that expanding fetal vessels would tend to stretch surrounding placental tissue and displace maternal blood. The observed interaction could be explained if maternal vessels operate on the linear part of their pressure-volume curve at normal and high pressures but become more compliant when maternal pressure falls. Thus, expanding fetal vessels could more easily displace maternal blood, and a higher umbilical compliance would be measured. 4 p.m.

48 Vasoreactivity to Angiotensin-II Infusion during Gestational Age 29-32 Weeks John P. O'Grady, Cynthia J. Hamilton and John A. Morris Department of Obstetrics-Gynecology, Charles R. Drew Postgraduate Medical School, Los Angeles, Calif. 
Reportedly (Gant N.F. et al, J. clin Invest. 52: 2682, 1973), healthy young primi-gravid patients at risk of developing pregnancy-induced hypertension (PIH) demonstrate an enhanced diastolic pressor response ( $\& \mathrm{gt}$; 20 torr) to \&lt; $8.0 \mathrm{ng} / \mathrm{kg}$ maternal body weight $/ \mathrm{min}$ infused A-II. We tested 26 such patients serially during a 4-week interval (29-32 weeks), maintained in the left lateral recumbency, with progressive increments in A-II dose $(2.0-15.0 \mathrm{ng} / \mathrm{kg} / \mathrm{min})$. Blood pressure was obtained with an ultrasound device. All patients were followed through delivery. 3 patients $(12 \%)$ developed PIH; only 1 of 3 demonstrated enhanced vasoreactivity. Conversely, 13 patients who did not develop PIH demonstrated enhanced vasoreactivity at least once during the testing interval. Comparison of results obtained from 1 week to the next was evaluated in 58 test pairs: discordant data, i.e. reactive to \&1t; $8 \mathrm{ng} / \mathrm{kg} / \mathrm{min}$ one week and unreactive the next, was observed in 18 pairs $(45 \%)$.

We conclude that assessment of PIH risk, utilizing the diastolic pressor response to infused A-II as reported, is unreliable.

Society for Gynecologic Investigation

40

4.15 p.m. 49 Hemodynamic Changes in Pregnant Rabbits

Bahij Nuwayhid

Department of Obstetrics-Gynecology, Washington University, School of Medicine,

St. Louis, Mo.

The hemodynamic changes during pregnancy have been controversial. Present data were obtained from 3 groups of rabbits: control nonpregnant (Gl), 10-20 day pregnancy (Gil) and 2030 day pregnancy (GUI). Under light pentobarbital anesthesia, jugular, carotid and femoral vessels were catheterized. Evans blue dye was used to measure plasma volume and $85 \mathrm{Sr}$ microspheres $15 \pm 5 \mathrm{~m} \mu$ were used to measure organ flow and cardiac output (CO). Parameters recorded were: arterial pressure (AP); heart rate (HR); plasma volume (PV); red blood cell volume (RBCV); reproductive flow (RF), including myometrial, tubal, ovarian, vaginal and placental flow; organ flow, including liver, lung, kidney, spleen and heart. Results showed: (1) HR increased 6 and 10\% in Gil and GUI, AP dropped 11 and 19\%; (2) total PV and RBCV increased by 45 and $28 \%$, CO increased $40 \%$ when these values were related to body weight; there was no difference between Gil and GUI; (3) systemic resistance dropped 18 and $27 \%$ in GM and GUI; (4) RP increased progressively but when measured per gram of tissue, there was a drop in myometrial and vaginal flow and an increase in placental and ovarian flows; (5) liver and spleen flows dropped, coronary flow increased. Conclusions: (1) the placenta is a low resistance structure implanted in parallel with the systemic circulation; (2) the BV and CO changes in pregnant rabbits reach a peak in mid-pregnancy; (3) pregnancy induces decreased vascularity in the vagina and myometrium but, in contrast, placental vascularity increases; (4) the liver and splenic flows decrease which may suggest increased sympathetic activity and venous return. 4.30 p.m.

Business Meeting (members only)

Mohave and Maricopa Rooms - Marriott Hotel

7.00 p.m.

Reception, Banquet and Entertainment

Old Tucson

Charter buses are available for transportation from the Marriott Hotel to Old Tucson. Reception and Banquet are supported, in part, by the Ortho Pharmaceutical Corporation and the G.D. Searle Company. 
Concurrent Session E

Thursday, March 24, 1977

Gila and Coconino Rooms - Marriott Hotel

1.45 to 4.30 p.m.

Moderators: William N. Spellacy and Walter G. Wiest

1.45 p.m. $50 \mathrm{ADH}$ and Oxytocin Content of Prolactin (PR) Powder

Helmuth W. Vorherr, Ute F. Vorherr and Sidney Solomon

Departments of Obstetrics-Gynecology, Pharmacology, and Physiology, University of

New Mexico, School of Medicine, Albuquerque, N. Mex.

Possible renal salt and water retaining effect of Pr in laboratory animals and humans has been

linked to premenstrual edema and to excessive water and salt retention in pregnant women. Since other pituitary hormones may be responsible for some renal effects attributed to Pr, rat (NIH-RP1), ovine (NIH-P-S-10, S-12), and bovine (NIH-P-B4), Pr preparations were examined for their content of $\mathrm{ADH}$ and oxytocin using rat antidiuresis, milk-ejection, and blood pressure assays. Blood pressure, antidiuretic, and milk-ejection activities were measured and identified as ADH or oxytocin or both by incubation of Pr solutions $(0.001$ to $2.0 \mathrm{mg} / \mathrm{ml})$ with ADH antiserum, oxytocin antiserum or pregnancy plasma.

Hormone RP-1 P-S-10 P-S-12 P-B4

ADH: $\mu \mathrm{U} / \mathrm{mgPr}$ powder $100,700 \pm 700^{\prime} \quad 2,540 \pm 207 \quad 1,582 \pm 94 \quad 1,578 \pm 450$

(3)2 (4) (4) (4)

Oxytocin: $\mu \mathrm{U} / \mathrm{mg}$ Pr powder 155,250 $\pm 3,500795 \pm 95 \quad 510 \pm 56 \quad 784 \pm 41$

(3) (4) (4) (4)

$1=$ mean $\pm \mathrm{SE}$;

$2=$ number of assay animals.

ADH (mainly) and oxytocin impurities of Pr powder exert renal effects falsely attributed to Pr. Pregnancy plasma or ADH and oxytocin antisera can inactivate Pr impurities of ADH and oxytocin allowing determination of the true renal effect of the Pr molecule.

Society for Gynecologic Investigation

42

2 p.m. 51 Further Evidence for the Specificity of Amnionic Osmoregulation by Prolactin Emilio A. Leontic, Barbara Andreassen, Beverly Smith and John E. Tyson Department of Obstetrics-Gynecology, The Johns Hopkins University School of Medicine, Baltimore, Md. Studies in this laboratory have shown that ovine prolactin (OPRL) significantly decreases fetal to maternal transport of tritiated water (THO) across human term amnion in vitro (Am. J. Physiol., in press). Since extracts of OPRL are known to be contaminated with vasopressin, studies were performed where vasopressin $(20-200 \mu \mathrm{U} / \mathrm{ml})$ was added to the fetal side of the membrane suspended in an Ussing chamber. No influence of vasopressin was observed on membrane permeability. When equimolar concentrations of HPL or HGH were substituted for OPRL (10 $\mu \mathrm{g} / \mathrm{ml}$ ), no changes in permeability constants were observed. That is, these substances failed to decrease permeability. Furthermore, the addition of an excess of antibody to OPRL abolished the OPRL effect on membrane permeability, yet it had no effect in control preparations which did not contain OPRL. Further substantiation of OPRL effect on amnion permeability was obtained when amniotic membranes were pre-incubated with a specific antiprolactin receptor antibody. The antireceptor sera added in a concentration of $200 \mu \mathrm{l}$ (1:50 dilution) nullified the OPRL effect. Others have shown that a 1:100 dilution of a similar antisera causes $50 \%$ of inhibition in the binding of radiolabeled prolactin to specific tissue receptors. These results add to the growing 
body of evidence suggesting that prolactin plays a specific role in the regulation of water transport across the human amnion at term.

2.15 p.m. 52 The Influence of Gonadotropins on Ovulation in vitro

Yasuo Hamada, Karen H. Wright and Edward E. Wallach

Department of Obstetrics-Gynecology, Pennsylvania Hospital, and University of

Pennsylvania School of Medicine, Philadelphia, Pa.

The purpose of the present investigation was to determine both temporal and qualitative requirements for gonadotropins to bring about ovulation in the isolated in vitro perfused rabbit ovary. Three experimental approaches were used: (1) administration of an ovulation-inducing dose of HCG (50 IU) to the intact rabbit and initiation of ovarian perfusion at various time intervals thereafter (1, 2, and $4 \mathrm{~h}$, post HCG administration); (2) addition of HCG (100 IU) to the perfusion fluid following ovarian removal from the untreated, isolated rabbit; (3) removal and perfusion of both ovaries from the rabbit which has received PMS alone for follicular maturation to determine the effects on ovulation of PGF2Ö added to the perfusate. A significant reduction in numbers of ovulations occurred in vitro when the ovary for perfusion was removed $2 \mathrm{~h}$ or less after HCG administration to the intact animal. Addition of HCG to the perfusate achieved ovulation in vitro with the same frequency as in perfused ovaries from animals which had received systemic HCG prior to ovarian removal and perfusion. In rabbits treated with PMS alone (100 IU intramuscularly, $80 \mathrm{~h}$ before beginning perfusion), addition of PGF2 $\alpha(1 \mathrm{mg})$ to the perfusion system resulted in an increase in ovaries ovulating as compared to the contralateral perfused ovaries without added PGF2 $\alpha$.

Scientific Abstracts

43

2.30 ค.m. 53 Effect of Ampullary Isthmic Junction Resection on Estrogen-Induced Tube Locking of Ova in the Rabbit

Canton A. Eddy, Jose P. Balmaceda and Carl J. Pauerstein

Department of Obstetrics and Gynecology, The University of Texas Health Science

Center, San Antonio, Tex.

The pattern of tubal ovum transport in most mammalian species is dominated by a pause at the ampullary isthmic junction (AIJ) prior to entrance of ova into the uterus. In the rabbit the administration of $250 \mu \mathrm{g}$ estradiol cypionate (EC) on the day of ovulation significantly prolongs retention of ova in the oviduct. Recent findings (Pauerstein et al.: Gynecol. Invest. 5: 121, 1974) suggest that estrogen in 'tube locking 1 doses causes constriction of the AIJ and that after this junction is negotiated, progress through the isthmus is probably normal. Advances in tuboplastic microsurgery allow us to examine tubal function by altering tubal anatomy (Eddy et al.:

Experientia 32: 1194, 1976). The present experiment examines the mechanism of estrogeninduced retardation of tubal ovum transport. Rabbits underwent unilateral microsurgical excision or transection of the AIJ followed by end-to-end tubal anastomosis. Following recovery, animals were given an ovulatory dose of $100 \mathrm{U}$ HCG followed by $250 \mu \mathrm{g}$ EC. $72 \mathrm{~h}$ post HCG animals were killed. Oviducts were excised, dehydrated and cleared (Orsini: J. Reprod. Fert. 3: 283, 1962) and the location of ova determined. Only those oviducts demonstrating patency of the anastomosis site were retained. Resection of the AIJ did not prevent estrogen-induced retardation of ovum transport. These results indicate that estrogen retards transport by acting upon the tubal isthmus rather than through selective action upon the AIJ.

2.45 p.m. 54 Qualitative transition in the Luteotropic Mechanism of Early Pregnancy

David $\mathrm{H}$. Wu and Walter G. Wiest 
Department of Obstetrics-Gynecology, Washington University School of Medicine, St. Louis, Mo.

Ergocarnine blockade of prolactin secretion induces abortion in rats prior to day 7 of pregnancy but is ineffective thereafter. Assuming that changes in gonadotropic requirements for support of the corpus luteum are responsible, we have perifused dispersed luteal cells with luteinizing hormone (LH) and prolactin (PRL) alone and in combination. Progesterone secretion by luteal cells gradually declined during $5 \mathrm{~h}$ perfusion under conditions simulating tonic in vivo PRL-LH levels. Initial rates of progesterone secretion from cells obtained from days 5 and 8 of pregnancy were double that from day 2. Using day 5 cells, supplementation of tonic gonadotropin levels with a simulated PRL surge maintained initial progesterone secretion, and PRL withdrawal markedly reduced progesterone secretion while supplemental LH was ineffectual. Conversely, using day 8 cells, progesterone secretion could be maintained undiminished with supplemental LH, but PRL was ineffectual. Total deprivation of LH from day 8 cells resulted in acute decline of progesterone secretion. Thus, the dispersed cell model successfully visualizes and more completely defines the qualitative transition in the luteotropic mechanism occurring between days 5-8 of pregnancy and parallels observations in vivo.

Society for Gynecologic Investigation

44

3 to 3.15 p.m. Intermission

3.15 p.m. 55 Regulation of Placental Growth and Choriaonic Somatomammotropin (MCS) in the Rhesus Monkey: Effects of Protein Deprivation, Fetal Anencephaly and Placental Ligation Miles J. Novy, Michel L. Aubert and Melvin M. Grumbach

Perinatal Physiology, Oregon Regional Primate Research Center, Beaverton, Oreg., and Department of Pediatrics, University of California School of Medicine, San Francisco, Calif.

A protein deficient diet (50\% of estimated requirements) was administered prior to conception and throughout pregnancy (group I, $n=11$ ). Experimental fetal anencephaly (group II, $n=7$ ) and ligation of the interplacental bridging vessels (group HI, $n=6$ ) were performed at 75-80 days' gestation. MCS was measured serially in maternal plasma and in fetal plasma at cesarean section. Fetal weight, stripped placental weight and placental DNA content were also determined near term in the three experimental groups and in appropriately timed controls.

MCS levels were not affected by protein deprivation, fetal anencephaly or placental ligation. MCS rose steadily until term paralleling trie increase in placental weight (MCS at term $=16.5 \pm$ $0.90 \mu \mathrm{g} / \mathrm{ml}$ in maternal and $24 \pm 1.2 \mathrm{ng} / \mathrm{ml}$ in fetal plasma). At term MCS correlated with placental DNA $(r=0.71, p \& 1 t ; 0.01)$ but not placental or fetal weight. Moderate protein deprivation had a negative effect on maternal weight gain but no effect on placental DNA, placental or fetal weight. Fetal anencephaly resulted in a $25 \%$ reduction in placental weight (p \&lt; 0.05) and a proportionately greater reduction in fetal carcass weight. Ligation of bridging vessels resulted in atrophy of the secondary placenta, an increase in weight and DNA content of the primary placenta (compensatory hypertrophy) and normal fetal weight. We conclude that placental growth is regulated by vascular and fetal pituitary trophic factors.

3.30 p.m. 56 Glucagon Response to Oral Alanine in Normal and Diabetic Pregnancies John L. Kitzmiller, Robert Tanenberg, Thomas T. Aoki and John Hare Harvard Medical School, Boston Hospital for Women, Joslin Clinic and Research Laboratory, Boston, Mass.

The role of glucagon in metabolic homeostasis of pregnancy and hyperglycemia of diabetes is uncertain. The concentration of glucagon was determined in the basal state and after the stimulus 
of alanine in late pregnancy and the puerperium. Seven nonobese normo-glycemic pregnant women and 16 insulin-dependent diabetic women were studied at 32-34 weeks' gestation and at 6-8 weeks' postpartum. After a 10-hour fast, blood samples were drawn at baseline and 30, 60, 90, and 120 min after ingestion of $10 \mathrm{~g}$ L-alanine. In the

Scientific Abstracts

45

normal subjects basal glucagon levels tended to be higher during pregnancy as compared to postpartum, and showed a significantly greater response to alanine. The rise in glucagon after alanine was

Glucagon, pg/ml Mean \pm SEM $\quad$ Basal 30 min 60 min 90 min 120 min

7 Controls 34 weeks $\quad 41 \pm 4$

6 weeks postpartum $22 \pm 5$

16 Diabetics 34 weeks $\quad 31 \pm 463 \pm 984+1160 \pm 748+7$

6 weeks postpartum $35 \pm 368 \pm 966 \pm 851 \pm 741 \pm 5$

similar in diabetics and controls during pregnancy. Diabetic subjects showed no evidence of fasting hyperglucagonemia and basal glucagon concentration was not related to the fasting blood glucose level. Blood glucose did not change significantly during the tests in controls but rose 28 $\mathrm{mg} / \mathrm{dl}$ at $60 \mathrm{~min}$ (antepartum) and $36 \mathrm{mg} / \mathrm{dl}$ at $90 \mathrm{~min}$ (postpartum) in the diabetics. Seven diabetic patients were also studied before and 3-5 days after delivery, and the glucagon response to alanine was the same or greater than the response approximately 1 week prior to the delivery. 3.45 p.m. 57 Studies of Glucagon Secretion in Normal and Insulin-Dependent Diabetic Pregnant Women

William N. Spellacy, William C. Buhi and Sharon A. Birk

Department of Obstetrics-Gynecology, University of Florida School of Medicine, Gainesville, Fla.

An assessment of glucagon secretion during basal and oral glucose $(100 \mathrm{~g}$ Пnduced hyperglycemic periods was made in normal women and in women whose pregnancy was complicated by insulin-dependent diabetes mellitus (White's Classes B-D). The glucagon was measured by a radioimmunoassay method using a nearly specific $\alpha$-cell antibody (Unger K30). Measurements of glucose, insulin and human placental lactogen were also made. The results show that basal glucagon levels are elevated in all pregnant women, but the rise is not correlated with the concentration of HPL. Normally, hyperglycemia suppresses the plasma glucagon levels. In the diabetic patients ( $31.8 \pm 2.1$ weeks' gestation) the glucagon was not suppressed with hyperglycemia as is shown in the table $(\mathrm{n}=8)$ :

Time,hFasting $0.5 \quad 1 \quad 2 \quad 3$

Glucose, $\mathrm{mg} / 100 \mathrm{ml}$

mean + SEM $111.5+11.1173 .0 \pm 18.9207 .4 \pm 12.4222 .3 \pm 18.6230 .9 \pm 22.2$

Glucagon, $\mathrm{pg} / \mathrm{ml}$

mean \pm SEM $242.3 \pm 38.2263 .1 \pm 35.4320 .6 \pm 41.3272 .5 \pm 28.3227 .7 \pm 34.3$

$\begin{array}{lllll}\mathrm{t} & 0.4 & 1.5 & 0.9 & 0.04\end{array}$

Society for Gynecologic Investigation

46

The failure of glucagon to suppress in the pregnant diabetic may contribute to the difficulty in controlling their blood glucose levels during the gestational period and may partially explain the increased insulin requirement of the pregnant diabetic.

4 p.m. 58 Placental Transfer and Fetal Toxicity of Sodium Nitroprusside 
Paul E. Lewis, Robert C. Cefalo, John S. Naulty and F. Lee Rodkey

Department of Obstetrics-Gynecology, National Naval Medical Center, Bethesda, Md.

Sodium nitroprusside has been used in preeclampsia for the treatment of severe arterial hypertension. We studied maternal and fetal nitroprusside and cyanide levels in 8 near-term normotensive ewe preparations under intravenous ketamine anesthesia and controlled ventilation. Electromagnetic flow meters were applied to the umbilical and uterine circulations. Baseline maternal and fetal blood pressures, respiratory gases, blood cyanide and nitroprusside levels were obtained during the 30-min postoperative stabilization period. A maternal intravenous infusion of $0.005 \%$ solution of nitroprusside was maintained at a rate sufficient to decrease the mean blood pressure by $20 \%$ for a period of $1 \mathrm{~h}$. Maternal and fetal levels of nitroprusside were at equilibrium at the 20-min sample. Fetal cyanide levels were not significantly elevated in 4 animals which required only a low rate of nitroprusside infusion to maintain the desired decrease in maternal blood pressure. In 4 animals who required a steadily increasing dose of nitroprusside to maintain the decreased blood pressure there was a marked accumulation of maternal and fetal cyanide with fetal levels significantly higher than the maternal level. These 4 fetuses expired in utero. In this preparation the placenta appears to be readily permeable to the nitroprusside molecule and increasing fetal cyanide levels appeared to be dose-related to maternal nitroprusside levels. The significantly higher fetal cyanide levels may be due to rapid formation of cyanide or a slower rate of detoxification and/or excretion. No significant changes were noted in umbilical or uterine flow.

4.15 p.m. 59 Cadmium Uptake in the Rat Embryo as a Function of Gestational Age Robert A. Ahokas and P. V. Dilts, jr.

Department of Obstetrics-Gynecology, University of Tennessee Center for the Health Sciences, Memphis, Tenn.

Maternal tissue distribution, placental transfer and fetal accumulation of cadmium $(\mathrm{Cd})$, a known embryotoxic trace element, was investigated following a single oral dose of $100 \mu \mathrm{g} \mathrm{Cd} / \mathrm{rat}$ as $\mathrm{Cd}$ Cl2-containing $109 \mathrm{Cd}$ at days 6, 10, 14 and 17 of gestation. At 24 and $96 \mathrm{~h}$ post $\mathrm{Cd}$ administration the rats were killed and the fetuses or embryos, placentas, and maternal tissues removed for determination of $109 \mathrm{Cd}$ activity. Maternal liver and kidneys were the main target organs of $\mathrm{Cd}$ accumulation at all stages of gestation. At $24 \mathrm{~h}$, livers had accumulated 0.039 $0.386 \%$ dose $/ g$ tissue and kidney $0.053-0.203 \%$ dose $/ g$ tissue. A gradual redistribution occurs after the initial $24 \mathrm{~h}$ since 96-hour levels of Cd in liver were slightly decreased and kidney levels were slightly increased. Maternal blood concentrations were low $(0.0001-0.0026 \% \mathrm{dose} / \mathrm{g}$ whole blood) at all stages of gestation. Embryo levels of Cd were highest prior to formation of the functional placenta ( 0.0081 and $0.0043 \%$ dose/g at days 6 and 10 , respectively). The embryo to maternal blood Cd ratios were 51.6 and 42.3, respectively, indicating that the embryo accumulates $\mathrm{Cd}$. After formation of the

Scientific Abstracts

47

functional placenta, fetal Cd levels were decreased $(0.00034$ and $0.00019 \%$ dose $/ \mathrm{g}$ at days 14 and 17 , respectively) while the placenta accumulated $\mathrm{Cd}(0.033$ and $0.092 \%$ dose/g at days 14 and 17, respectively). The placenta apparently protects the fetus from exposure to this element during the last third of gestation. The results indicate that the embryotoxic manifestations of large amounts of $\mathrm{Cd}$ administered to pregnant rats on days 14-17 may not result from direct action on the fetus but from maternal and/or placental effects. 4.30 p.m. 
Business Meeting (members only)

Mohave and Maricopa Rooms - Marriott Hotel

7 p.m.

Reception, Banquet and Entertainment

Old Tucson

Charter buses are available for transportation from the Marriott Hotel to Old Tucson. Reception and Banquet are supported, in part, by the Ortho Pharmaceutical Corporation and the G.D. Searle Company.

Second Plenary Session

Friday, March 25, 1977

Mohave and Maricopa Rooms - Marriott Hotel

8 to 9 a.m.

Distinguished Guest Lecture (made possible by a continuing grant from Ross Laboratories, Columbus, Ohio). 'New Aspects of Mechanisms of Steroid Hormone Action: Somatic vs. Germ Cell', Etienne-Emile Baulieu, MD, PhD, Professor of Biochemistry, Université de Paris Sud, Bicêtre, France

9 to 10.15 a.m.

Moderators: W. Ann Reynolds and Pentti K. Siiteri

9 a.m. 60 The Isolation from Human Amniotic Fluid and Characterization of Lamellated

Structures Derived from Fetal Lungs

Sergio Fabro, Linda B. Gilmore, Mark J. Reasor, Diane Y. Bell and Gary E.R. Hook NIEHS, Pharmacology and Toxicology Branch, N.C., and Department of Obstetrics-Gynecology, George Washington University, Washington, D.C.

Synthesis and storage of fetal lung surfactant is initiated in cytoplasmic inclusion bodies of alveolar type II cells in the latter part of pregnancy. In this paper we wish to report the presence, at term, in human amniotic fluid of lamellated structures resembling lamellar inclusion bodies of the pulmonary alveolar type II cell. These structures were isolated by differential centrifugation at $10,000 \mathrm{~g}$ per $10 \mathrm{~min}$ and morphologically identified by electro microscopy. This fraction contained 2.8 and $47.8 \%$ of the total protein and phospholipids of the amniotic fluid, respectively. The limiting membrane of the intracellular organelle was absent, however, from these lamellated structures. Tubular myelin structures, which are normally found only within the airways of the lung, were also found in amniotic fluid. The lamellated structures were associated with high concentrations of acid hydrolases (e.g. (3-N-acetylglucosaminidase, $\alpha$-mannosidase, /3-glucuronidase, and acid phosphatase) and alkaline phosphatase. Isopycnic centrifugation on continuous density sucrose gradient showed the acid hydrolases were not a contaminant from lysosomes. Although secretion of pulmonary surfactant in the form of lamellated structures by the type II cells has been observed morphologically in fetal animals near birth, this is the first report describing the presence of lamellar bodies free in the human amniotic fluid. Furthermore, the results indicate the lamellar bodies secreted by pulmonary type II cells are carried into the amniotic fluid along with associated hydrolytic enzymes.

Scientific Abstracts

49

9.15 a.m. 61 Factors Affecting Biologic Action of Progestins in Human Endometrium

William J. Mann, Peter D. Feil, Laurence Demers, Rodrigue Mortel and

C. Wayne Bardin

Departments of Obstetrics-Gynecology, Biological Chemistry, Medicine and Pathology, 
The Milton S. Hershey Medical Center, The Pennsylvania State University, Hershey, Pa. Several studies suggested that the greater potency of medroxyprogesterone acetate (MPA) vs. progesterone could depend upon either differential whole body metabolism of progestins, or factors enhancing the local activity of MPA on the endometrium. In order to distinguish between these two possibilities, we first studied MPA and progesterone metabolic clearance rates (MCR), and binding to serum proteins. When $3 \mathrm{H}$-progesterone and $3 \mathrm{H}-\mathrm{MPA}$ binding to plasma proteins were analyzed by polyacrylamide gel electrophoresis, only progesterone bound to cortisol binding globulin. The MCR of MPA (2,100 liter/day) was high but still less than progesterone (2,500 liter/day), even though MPA did not bind to serum proteins. We next examined the direct cellular action of progestins. Using an organ culture of human endometrium, MPA stimulated glycogen synthesis to a greater extent than progesterone. The kinetics of progesterone and MPA binding to endometrial progestin receptors was also investigated. The dissociation rate (tV2) for MPA (24 h) was much slower than progesterone ( $2 \mathrm{~h})$. Summary: (1) MPA is not bound by serum proteins; (2) MPA clearance rate is high but less than progesterone; (3) MPA has a more potent direct action on endometrium than progesterone, and (4) MPA dissociates slower than progesterone from the cytoplasmic receptor. Conclusion: in women, the increased biologic activity of MPA over progesterone is determined primarily at end organ rather than by differential rates of steroid clearance.

9.30 a.m. 62 The Biosynthesis of the Phosphatidylglycerol Component of Lung Surfactant John M. Johnston, Gary E. Reynolds and Mary B. Wylie

Departments of Obstetrics-Gynecology and Biochemistry, University of Texas

Southwestern Medical School at Dallas, Dallas, Tex.

The type II alveolar cell is the site of synthesis of surfactant, the lipoprotein that lines the alveolar spaces and prevents their collapse. The phospholipids of surfactant are characterized by high concentrations of dipalmitoylphosphatidylcholine (DP-PC) and phosphatidylglycerol (PG). It has been suggested that PG functions to stabilize the surfactant lipoprotein complex. We have shown that the lamellar bodies (LB) of the type II cells are the site of PC biosynthesis and that the increase in DP-PC biosynthesis during fetal development may be the result of an increase in phosphatidic acid phosphohydrolase (PAPase) activity. In this study we have demonstrated the formation of PG from its precursor, phosphatidylglycerol-phosphate (PGP) in LB. The hydrolytic release of P04 from phosphatidic acid (PA) and PGP was shown to be catalyzed by the same enzyme in LB by demonstrating that: (1) the substrates are competitive; (2) an identical inactivation for the hydrolysis of the two substrates is obtained by the addition of $\mathrm{Hg} 2+$, and (3) heat inactivation profiles are similar for both substrates. The Km and Vmax for PA and PGP hydrolysis are similar. These findings are consistent with the observed increase in DP-PC and PG in surfactant, the decrease in phosphatidylinositol concentration found in surfactant obtained during the latter stages of gestation, and the increased incidence of hyaline membrane disease of the newborn when the PG concentration in surfactant is relatively low.

Society for Gynecologic Investigation

50

9.45 a.m. 63 Extraglandular Aromatization - Primarily an Extrahepatic Metabolic Process

Clare D. Edman and Paul C. MacDonald

Department of Obstetrics-Gynecology, University of Texas Southwestern Medical

School at Dallas, Dallas, Tex.

Extraglandular aromatization increases with aging, obesity, and liver disease. It has also been shown that extraglandular aromatization increases during postoperative recovery, in 
hyperthyroidism, compensated congestive heart failure and acute starvation. A common finding in these metabolic disorders is a relative increase in extrahepatic metabolism of plasma androstenedione (A). For this reason, we sought to ascertain if the extent of extraglandular aromatization was inversely related to the hepatic clearance of A. First, we found that only $5 \%$ of total extraglandular aromatization could be accounted for by trans-splanchnic-transhepatic metabolism. Second, an inverse relationship exists between hepatic extraction of plasma androstenedione and the transfer constant of conversion of A to estrone (El) $\left[\mathrm{pl}^{\wedge} \mathrm{g}^{7} / 81\right.$ - When the hepatic extraction of $\mathrm{A}$ is $90 \%$, the conversion of $\mathrm{A}$ to $\mathrm{El}$ is 0.015 ; but when the hepatic extraction is $10 \%$, the $\left[\mathrm{pl}^{\wedge} \beta^{3} / 41\right.$ is 0.16 . Modest reductions in hepatic clearance of A (e.g. $65 \%$ ) are associated with an increase of the $[\mathrm{p}] \mathrm{g}^{3 / 4}$ to 0.06 . We envision that a decreased hepatic extraction of plasma A results in relatively greater extrahepatic metabolism favoring aromatization. Reduced hepatic clearance of A may occur in early hepatocellular damage, before extensive scarring and fibrosis, and thus account for the increased extraglandular aromatization observed with aging, obesity, congestive heart failure, postoperative convalescence, starvation, and liver disease.

10 a.m. 64 Effect of Atropine on Heart Rate and Oxygen Consumption of the Hypoxic Fetus Julian T. Parer

Department of Obstetrics-Gynecology and Reproductive Science and Cardiovascular Research Institute, University of California, San Francisco, Calif.

To determine if vagal blockade during hypoxic bradycardia improves fetal oxygenation(Vq ), 10 studies were carried out on 5 chronically instrumented sheep, after 0.8 of gestation, with mean fetal weight of 2,674 g. Catheters were placed in the maternal and fetaldistal aorta, common umbilical vein, and amniotic cavity. An electromagnetic flow probewas placed around the common portion of the umbilical artery. After control sampling, hypoxic gas mixtures were administered by face mask to achieve a mean maternal arterialp02 of $32.5 \pm 3.7 \mathrm{~mm} \mathrm{Hg}$ but no change in maternal arterial $\rho \mathrm{C} 02$ or $\mathrm{pH}$. This produced a20\% decrease in FHR $(171 \pm 30 \mathrm{SD}$ to $137 \pm 19 \mathrm{bpm}, \mathrm{p} \& \mathrm{lt} ; 0.001)$ and fetal Vq2 decreasedfrom $7.9 \pm 1.9$ to $4.6 \pm 1.5 \mathrm{ml} / \mathrm{min} / \mathrm{kg}$ fetus (p \&1t; 0.001) 27 min after institution of hypoxia. The umbilical blood flow (mean $219 \pm 57$ $\mathrm{ml} / \mathrm{min} / \mathrm{kg}$ fetus) was unchanged but the $\mathrm{Cy} 0-\mathrm{Ca} 0 ; \mathrm{i}$ decreased from $3.5 \pm 0.9$ to $2.1 \pm 0.5 \mathrm{ml}$ $\mathrm{O} 2 / 100 \mathrm{ml}$ (p \&lt; 0.01). $\quad 2$

There was an immediate increase in FHR to $249 \pm 26 \mathrm{bpm}$ after atropine (mean dose $190 \mu \mathrm{g}$ ) was infused rapidly into the umbilical vein. At sampling, 8 min after atropine, FHR was $209 \pm 44$ bpm (p \&lt; 0.001), but umbilical blood flow and fetal Vq were not significantly changed. Atropine caused only a $25 \mathrm{bpm}$ increase in fetal heart rate in the normoxic fetus.

Scientific Abstracts

51

It is concluded that during hypoxia there is a substantial increase in vagal activity. Other studies have shown that there is also an augmented sympathetic chronotropic effect, unmasked by atropine blockade. These investigations show that atropine is of no benefit to fetal oxygenation during hypoxic bradycardia.

(Supported by NIH grant No. HD 09980.)

10.15 to 10.45 a.m. Intermission

Concurrent Session A

Friday, March 25, 1977

Mohave and Maricopa Rooms - Marriott Hotel

10.45 a.m. to 12.30 p.m. 
Moderators: Hilton A. Salhanick and Eric Block

10.45 a.m. 65 Isolation of $\alpha H C G$ Subunit mRNA

Thomas Landefeld and Irving Boime

Department of Obstetrics-Gynecology, Washington University School of Medicine,

St. Louis, Mo.

To examine the factors controlling the synthesis of human chorionic gonadotropin (HCG) during pregnancy it is important to isolate the mRNAs encoding the hormone. Purified first trimester placental mRNA, when translated in wheat germ, or ascites tumor extracts directed the synthesis of a major protein with a molecular weight of about 14,000. A similar protein was synthesized in partially purified placental extracts. Both proteins contained tryptic peptides corresponding to those of the $\alpha \mathrm{HCG}$ subunit. Since the molecular weight of the protein portion of native $\alpha$-subunit is 11,000 , the data suggest that the cell-free product is a precursor.

No detectable synthesis of the $\varnothing$-subunit was observed. When first trimester RNA was translated in the presence of a variety of labeled amino acids only the $\alpha$-subunit was detected. Similar results were obtained when mRNA was isolated from the whole placenta, post-nuclear, or postmitochondrial supernates, and translated in the wheat germ cell-free system.

These results suggest that (a) the $\alpha$-subunit is synthesized as a precursor protein and (b) the mRNA encoding the /3-subunit turns over very rapidly and thus is under stringent control; its levels perhaps constituting a rate-limiting step in the expression of HCG in vivo.

11 a.m. 66 Study of the Steroid Binding Site of Human Placental Estradiol 17/3-Dehydrogenase with 12/3-Bromoacetoxy-4-estrene-3,17-dione

James C. Warren and Chang-Chen Chin

Department of Obstetrics-Gynecology, Washington University School of Medicine,

St. Louis, Mo.

We have recently crystallized human placental estradiol 170-dehydrogenase and identified a histidine residue in the catalytic region of the active site by affinity labeling with $16 \alpha-$ bromoacetoxyestradiol 3-methyl ether. Presuming that this histidine might actually

Scientific Abstracts

53

proximate the steroid $17 \alpha$-hydrogen (which is removed during dehydrogenation) and thus be directly involved in the catalytic step, we sought to further pinpoint its location. Examination of molecular models reveals that if a $12 \varnothing$-bromoacetoxysteroid also affinity labels this residue, it must be so located, as the rotomers of the two reagent arms (12/3-bromo-acetoxy and $16 \alpha-$ bromoacetoxy) overlap only in the region of the 17 $\alpha-\mathrm{H}$. Accordingly, 4-estrene-3,17-dione was incubated with Colletotrichum derridis and the resulting 120-hydroxy-4-estrene-3,17-dione was reacted with $(2-3 \mathrm{H})$ bromoacetic acid and dicyclohexyl-carbodiimide in pyridine. The product was recrystallized from ethanol and structure assured by IR spectroscopy and elemental analysis as 12 í3-bromo $(3 \mathrm{H})$ acetoxy-4-estrene-3,17-dione (120-BAE). This steroid is a substrate, proving that it binds at the active site. Enzyme incubated with a 150-fold molar excess of 12/3-BAE in $0.5 \mathrm{M}$ potassium phosphate buffer at $\mathrm{pH} 7.0$, is inactivated in a time dependent, irreversible manner. Inactivation follows pseudo first order kinetics with $\mathrm{t}^{\prime} / 2=18 \mathrm{~h}$. Amino acid analysis of a hydrolysate of the 12/3-BAE enzyme inactivated revealed tritiated 1,3-

dicarboxymethylhistidine. Affinity labeling of the histidine residue by both $16 \alpha$ - and 120 bromoacetoxy steroids localizes it at the point of catalysis and identifies it as a catalytic residue. 11.15 a.m. 67 Biological Testing and Receptor Binding of Medroxyprogesterone 17Bromoacetate 
Frederick Sweet and Bhaskar Samant

Department of Obstetrics-Gynecology, Washington University Medical School, St. Louis, Mo.

Previously we reported that intrauterine release of $1-2 \mathrm{mg}$ of $16 \alpha$-bromoacetoxy-progesterone (16 $\alpha$-BAP) or 16 $\alpha$-bromoacetoxymedroxyprogesterone (16 $\alpha$-BAMP) in 7-day pregnant rats causes resorption of over $50 \%$ of the fetuses by day 14 . The present work was undertaken to further investigate the relationships among the position of the bromoacetoxy reagent group on the steroid, interceptive activity, and progesterone receptor binding. For this purpose we synthesized medroxyprogesterone 17-bromoacetate (MPBA), an affinity labeling analog of Provera. Treatment of 7-day pregnant rats with 2-3 mg of MPBA caused no observable interruption of pregnancy. The biological activities of ló-BAP, 16 $\alpha$-BAMP and MPBA were correlated with competitive binding against $3 \mathrm{H}$-progesterone of the steroids for crude rabbit uterine progesterone receptor. 16 $\alpha$-BAP and 16 $\alpha$-BAMP had relative affinity constants (RAC) of 0.5 , while MPBA had an RAC value of over 100, similar to medroxyprogesterone acetate. These results suggest that the position of the bromoacetoxy reagent group on the progesterone D-ring critically determines antiprogestational and thus interceptive activity, and also the degree of progesterone receptor binding.

11.30 a.m. 68 Danazol - 17 $\alpha$-Pregn-4-en-20-yno-(2,3-d) isoxazol-17-ol - Inhibits Gonadal Steroidogenesis

Robert L. Barbieri, Jacob A. Canick and Kenneth J. Ryan

Harvard Medical School, Laboratory of Human Reproduction and Reproductive

Biology, Department of Obstetrics-Gynecology, Boston, Mass.

Danazol is being used in the management of endometriosis, chronic cystic mastitis, and precocious puberty. Parenteral administration of danazol to castrated immature rats can suppress their high levels of serum LH and FSH (Biol. Reprod. 10: 438, 1974). Based on

Society for Gynecologic Investigation

54

these findings it has been repeatedly stated that danazol exerts its pharmacologic effects by acting as an antigonadotropin. However, oral administration of danazol to humans significantly suppresses serum gonadal steroids without significantly altering serum LH or FSH levels (J. clin. Endocr. Metab. 32: 522, 1971; Obstet. Gynec, N.Y. 45: 302, 1975; Johns Hopkins med. J. 137: $265,1975)$. These clinical observations suggest that danazol exerts its pharmacologic effects by directly inhibiting gonadal steroidogenesis. Concentrations of danazol as low as $1 \mu \mathrm{M}$ significantly inhibit LH stirnulated testosterone and androstenedione production in cultured rat Leydig cells. Danazol binds to rat testis microsomal cytochrome P-450, eliciting a type I binding spectrum $(\mathrm{Kg}=3.0 \mu \mathrm{M})$, which implies that danazol binds to the active enzymatic site. Danazol competitively inhibits rat testis $17 \alpha$-hydroxylase with an inhibition constant (Ki) of $2.5 \mu \mathrm{M}$ and $17 / 3$-hydroxysteroid dehydrogenase with a $\mathrm{Ki}$ of $2.8 \mu \mathrm{M}$. These inhibition constants are similar to the concentration of danazol in the serum of human females taking $800 \mathrm{mg} /$ day of danazol for two days. Given these experimental findings and the clinical observations cited above, it is likely that danazol exerts its primary pharmacologic effect by directly inhibiting gonadal steroidogenesis.

11.45 a.m.

69 Leucine-3H Incorporation into the Proteins of Hypothalamus and Pituitary and LHRelease following Estrogen Treatment

Satya P. Kalra and Eugene O. Mitchell 
Department of Obstetrics-Gynecology, College of Medicine, University of Florida, Gainesville, Fla.

Single injections of estradiol benzoate (EB, $10 \mu \mathrm{g} / \mathrm{rat}$ ) to ovariectomized rats significantly suppressed serum LH levels 2, 4, 8 and 24 h later; serum LH-RH (methanol extracted) levels were unaltered but the LH-RH content in the medial basal hypothalamus (MBH) was significantly elevated at $24 \mathrm{~h}$. This treatment also has been shown to modify the sensitivity of the pituitary to LH-RH administration: a rapid decrease (up to $4 \mathrm{~h}$ ) followed by an augmentation in LH release. To study whether new protein synthesis is the common underlying mechanism in the estrogen feedback action at the hypothalamo-pituitary axis, the incorporation of leucine- $3 \mathrm{H}(80$ $\mu \mathrm{c} /$ rat s.c.) into proteins of the preoptic area, $\mathrm{MBH}$, cortex and the pituitary was examined at intervals after EB injection. Leucine-3H incorporation was unaffected in these tissues for $4 \mathrm{~h}$ following EB treatment at the time when serum LH and the responsiveness of the pituitary to LH-RH were clearly depressed. However, a marked increase in leucine-3H incorporation into the proteins of the pituitary only occurred at 8, 16 and $24 \mathrm{~h}$ after EB administration, coincident with the enhanced pituitary sensitivity to LH-RH. These studies show that estrogen promotes storage of LH-RH in the MBH and that new protein synthesis may be an important initial step in the estrogen-induced augmentation of the pituitary responsiveness to LH-RH.

(Supported by NIH grant HD-08364.)

12 p.m.

$70 \quad$ Prostaglandins - Calcium Ionophores?

Mary E. Carsten and Jordan D. Miller

Department of Obstetrics-Gynecology and Anesthesiology, University of California

School of Medicine, Los Angeles, Calif.

The concentration of free calcium in the myometrial cell determines contraction and relaxation of the uterus with an increase in free calcium causing contraction. Previous

Scientific Abstracts

55

studies have demonstrated that prostaglandins (PG) and oxytocin are able to regulate calcium accumulation in a microsomal fraction derived from bovine myometrium. In this in vitro model, the change in calcium accumulation can be brought about by inhibition of ATP-dependent calcium binding or by enhancing calcium release.

Experiments were designed to separate these two processes. Microsomal preparations were allowed to take up calcium in the presence of limited amounts of ATP. When the ATP was exhausted, a steady level of calcium was attained. Addition of PGE2, PGFja, but not PGFjø, partially released the calcium previously taken up. Calcium release was measured by the $45 \mathrm{Ca}$ Millipore filtration method. Exchange of $45 \mathrm{Ca}$ with intrinsic calcium was determined in separate experiments and corrected for. The antibiotic ionophores X537A and A23183, as well as oxytocin, also released calcium previously accumulated under ATP stimulation. None of these agents with the exception of oxytocin released intrinsic calcium. Thus, the effect of the PGs resembles that of the ionophores, suggesting an ionophoretic action of these prostaglandins. The release of calcium conforms with the in vivo smooth muscle contracting action of these agents.

12.15 p.m. 71 Human Placental Lactogen (HPL) Concentration and Pools in the Placenta Clifford Ermshar and David Gusseck

Departments of Perinatal Research and Biochemistry, Loma Linda University School of Medicine, Loma Linda, Calif. 
Other studies of the regulation of HPL synthesis by the placenta require that we know the placental content of HPL, the fraction of HPL in readily secretable storage granules and the rate of HPL turnover within the placenta. Changes in these parameters as a function of gestational age or trophoblastic disease could, in themselves, serve as regulatory mechanisms. Conflicting reports of placental HPL levels in the literature probably stem from the rapid loss of HPL from tissue into extracellular fluid as a function of time after delivery or into wash medium during rinsing of the tissue. We have optimized the rapid extraction of HPL from placental tissue with a process utilizing detergents. Over $93 \%$ of total tissue HPL is obtained in one extraction to yield an average term placental content of $660( \pm 67 \mathrm{SEM}) \mu \mathrm{g} \mathrm{HPL} / \mathrm{g}$ tissue. In a flow-through apparatus utilizing placental fragments, we have resolved the rate of extracellular fluid washout from the secretion rate and the rate of synthesis. We have found that $87 \%$ of placental HPL appears to be packaged for secretion and can be readily washed from the tissue. When this readily secreted fraction is depleted, a steady state level $(86 \mu \mathrm{g} / \mathrm{g})$ is reached which appears to be limited by the rate of synthesis. This steady state level can be maintained for over $13 \mathrm{~h}$, reflects an initial rate of HPL synthesis of 10-12 $\mu \mathrm{g}$ HPL/g tissue, is slowly decreased by tissue death $\left(t^{\prime} / 2=8 \mathrm{~h}\right)$, and is interrupted by the addition of inhibitors of protein synthesis. HPL turnover rate measurements are in progress and will be reported.

(Supported by NIH grant No. HD 09440.)

12.30 p.m. Adjournment

Concurrent Session B

Friday, March 25, 1977

Greenlee and Graham Rooms - Marriott Hotel

10.45 a.m. to 12.30 p.m.

Moderators: Guy M. Harbert, Jr. and Frank C. Greiss, jr.

10.45 a.m. 72 The Effect of Progesterone (P) and/or Estradiol (E) on Uterine Contractility and (3-Adrenergic Receptor (/3-AR) Number

James M. Roberts, P.A. Insel, R. Goldfien and Alan Goldfien

Department of Obstetrics-Gynecology and Reproductive Sciences, Medicine and Cardiovascular Research Institute, University of California, San Francisco, Calif.

In some species adrenergic stimulation causes contraction $(\alpha-A R)$ or relaxation (Ø-AR) depending on the hormonal milieu. We examined the contractile response to norepinephrine and (3-AR in uteri of immature rabbits treated with $\mathrm{P}$ and/or $\mathrm{E}$ to determine the relationship between changes in contractility and (3-AR sites. Norepinephrine $(5 \times 10$ " $6 \mathrm{M})$ increased uterine contractility in $\mathrm{E}$ treated rabbits and the increase was blocked by phentolamine. After $\mathrm{E}+\mathrm{P}$, spontaneous uterine activity was inhibited by the same concentration of norepinephrine. The effect was blocked by propranolol. Particulate fractions of myo-metrium with isoproterenol responsive adenylate cyclase (with added guanyl nucleotide) were assayed for Ø-AR activity with 12SI-hydroxybenzylpindolol (I-HYP). We have shown that I-HYP, a potent /3-adrenergic antagonist, binds specifically, rapidly, reversibly and stereoselectively to uterus with high affinity (Krj $=70-360 \mathrm{pM})$ and low capacity (5-20 fm/mg protein) and competes with $/ 3$ agonists in a rank order characteristic of the $/ 3 \mathrm{j}-\mathrm{AR}$. We found $20 \pm 5 \mathrm{fm}$ of sites/uterus in $\mathrm{E}$ treated animals and $16 \pm 3 \mathrm{fm} /$ uterus in those recieving $\mathrm{E}+\mathrm{P}$. We conclude that the $\mathrm{P}$ induced predominance of $\varnothing$-AR activity is not associated with an increase in number of $/ 3$-AR/uterus. 11 a.m. 73 Reactivity of Uterine Vasculature to Dopamine Karen Blanchard, Charles R. Brinkman, HI, Adrien Dandavino, Kenneth E. Clark and Nicholas S. Assali 
Department of Obstetrics-Gynecology, UCLA School of Medicine, Los Angeles, Calif. The use of dopamine in the management of various forms of circulatory shock has received increasing attention in recent years; very little is known about its effects on the uterine circulation. The present report deals with data on uterine hemodynamic response to i.v. dopamine in pregnant and nonpregnant sheep. Pregnant and nonpregnant sheep were Scientific Abstracts

57

chronically instrumented for measurement of heart rate (HR), arterial pressure (AP), central venous pressure (CVP) and uterine blood flow (QU). Uterine vascular resistance (UVR) was calculated from the ratio of AP and QU. Dose response curves were developed to both bolus injections and constant infusions in doses ranging from $2-80 \mu \mathrm{g} / \mathrm{kg}$. Results show: (a) AP progressively increased with doses above $10 \mu \mathrm{g} / \mathrm{kg}$ to a maximal increase of $90 \%$ in both groups of animals; (b) progressive and sustained increases in CVP were noted above doses of $10 \mu \mathrm{g} / \mathrm{kg}$; (c) HR progressively increased in the nonpregnant animals while it decreased in the pregnant; these responses were present at $5 \mu \mathrm{g} / \mathrm{kg}$; (d) QU increased linearly with increasing doses reaching a maximal increase of $25 \%$ in both groups of animals; the QU response was also noted at a lower dose level than the AP response. Conclusions: (1) dopa-mine has a paradoxical effect upon the heart rate of pregnant sheep; (2) pregnant and nonpregnant animals are equally sensitive to the vasopressor effects of dopamine; (3) UVR increases less than other regional vascular resistances, and (4) increased QU may be related to increased cardiac output.

11.15 a.m.

74 Biorhythms in the Dynamics of a Pregnant Uterus

Guy M. Harbert

Department of Obstetrics-Gynecology, University of Virginia School of Medicine, Charlottesville, Va.

Rhesus monkeys were used in chronic experiments to delineate the existence and influencing factors of biorhythms in the dynamics of the uterus during pregnancy. Part 1 of the study established the biorhythms of spontaneous uterine activity, uterine artery blood flow, and aortic blood pressure. During a 24-hour period, all measured functions varied in patterns conforming to significant Fourier curves. Amplitude of variation was as great as $59 \%$ for intraamniotic pressure and $63 \%$ for uterine blood flow. These patterns were compounded by labor. Parturition produced inversely related exponential changes in uterine pressure and blood flow values and a linear increase in mean blood pressure. In part 2, the effect of adrenergic blockade and prostaglandin inhibition on the biorhythms was investigated. $\alpha$-Blockade (phentolamine) abolished the circadian rhythm of uterine pressure but not the exponential pattern of labor. Uterine blood flow increased. /3-Blockade (propranolol) decreased uterine blood flow without significantly altering the basic rhythms. Inhibition of prostaglandin synthesis (indomethacin) decreased the amplitude but did not abolish the circadian pattern of uterine activity. Uterine blood flow exhibited -disproportionate changes. Labor was inhibited. Differences in chronology and amplitude of the curves suggest adrenergic factors may act independently on the myometrium and uterine vascular bed to modulate these rhythms.

(Supported in part by USPHS grant HD 02798.)

11.30 a.m.

75 A Uterine Vasoactive Property of Glucosamine

Frank C. Greiss, jr. and J. Gordon Still

Department of Obstetrics-Gynecology, Bowman Gray School of Medicine, Wake Forest 
University, Winston-Salem, N.C.

Barcroft described a relatively constant concentration of glucosamine in the ovine cotyledon after 50 days of gestation which he associated with the ingrowth of Wharton's jelly. The present experiment was designed to evaluate possible vasoactive properyties of

Society for Gynecologic Investigation $\quad 58$

this amino sugar. Ewes were oophorectomized, an electromagnetic flow-probe was implanted on one uterine artery and its first branch was cannulated for drug infusions as described by Killam et al. (Am. J. Obstet. Gynec. 115: 1045, 1973). When daily intravenous estradiol-17j3 (E2), 1 $\mu \mathrm{g} / \mathrm{kg}$, produced consistent increases in uterine blood flow (UBF), 5-min uterine arterial infusions of a 1-mol solution of glucosamine- $\mathrm{HCl}(\mathrm{pH} 2.9)$ were given prior to E2 stimulation. These infusions produced control arterial glucosamine concentrations from 2.6 to $77 \mathrm{mg} / \mathrm{ml}$. Above $2 \mathrm{mg} / \mathrm{ml}$, an immediate sustained increase in UBF occurred which generally decreased rapidly to control levels when the infusion was discontinued. UBF responses were expressed as a percentage of the subsequent response induced by E2 on the same day. Within the doses tested, the dose-response curves were linear attaining $75-95 \%$ of the E2 response at doses between 40 and $77 \mathrm{mg} / \mathrm{ml}$. In a few experiments where the glucosamine solution was buffered to $\mathrm{pH} 7.0$, comparable vascular responses occurred.

We believe this observation of a vasoactive property of an amino sugar is unique and may explain, in part at least, the marked distributional shift of UBF to the ovine cotyledon during definitive placentation.

(Supported by USPHS grant No. HL-03941 from the National Heart and Lung Institute.) 11.45 a.m.

76 Changes in Cervical Compliance at Parturition Independent of Uterine Activity

Stanley J. Stys, William H. Clewell and Giacomo Meschia

Division of Perinatal Medicine, University of Colorado Medical Center, Denver, Colo.

Cervical compliance changes at spontaneous and dexamethasone-induced parturition were studied in 6 pregnant ewes. At 111-124 days of gestation, small balloons were placed within the cervical os and amniotic cavity to measure cervical compliance and intracervical and intrauterine pressures. The internal os was purse-stringed to mechanically isolate the cervix from the uterus; a catheter was placed into the fetal femoral vein for dexamethasone infusion. Continuous recordings of intracervical and intrauterine pressures and daily intermittent measurements of cervical compliance were made for at least 2 weeks prior to parturition. Up to fivefold increases in cervical compliance were noted in several animals $48 \mathrm{~h}$ following surgery, with a gradual return to baseline values.

Cervical compliance changed abruptly at parturition, increasing tenfold or more within $12 \mathrm{~h}$. The abruptness and magnitude of the compliance change was similar in spontaneous and dexamethasone-induced parturition, and occurred before the onset of uterine activity. In the 3 dexamethasone-induced ( $1 \mathrm{mg} / 24 \mathrm{~h}$ ) ewes, cervical compliance remained unchanged for approximately $48 \mathrm{~h}$ after the dexamethasone infusion was begun. In all 6 animals, the abrupt increase in cervical compliance was followed within hours by uterine activity characteristic of early labor. We conclude that uterine contractions dilate the cervix only after it has become compliant by another mechanism.

12 p.m.

77 Stimulus Summation and Tachyphylaxis in Estrogen Response

William H. Clewell, Stanley J. Stys and Giacomo Meschia

Division of Perinatal Medicine, University of Colorado Medical Center, Denver, Colo. 
Previous studies in ovariectomized, nonpregnant ewes have shown that the injection of $1 \mu \mathrm{g}$ of estradiol-17/3 (E2) over 1 min into the lumen of the uterine artery causes a maximal local increase in uterine blood flow and that this response can be reproduced daily for 1

Scientific Abstracts

59

month or more. We now report that by dividing the dose, temporal summation of the stimulus can be demonstrated. Five 1 -min doses of $0.2 \mu \mathrm{g}$ injected at 5 -min intervals, or $0.04 \mu \mathrm{g} / \mathrm{min}$ infused over $25 \mathrm{~min}$, have an effect virtually identical to that of a $1-\mu \mathrm{g}$ bolus. However, a comparison of submaximal doses shows that there is a threshold for temporal summation of the stimulus and that above this threshold there is a dose range in which temporal summation is incomplete; i.e., the bolus causes greater response than divided doses. Tachyphylaxis to estrogens was induced by continuous infusion of $8 \mu \mathrm{g} / \mathrm{h}$ of E2 into one uterine artery. Following the initial response, the flow returned to baseline and was refractory to stimulation by a systemic dose of E2 (which caused the expected maximal vasodilatation in the contralateral uterine horn). The tachyphylaxis to E2 did not prevent vasodilatation by bradykinin and adenosine. Following discontinuation of the E2 infusion, responsiveness to the vasodilatory effect of estrogen returned to normal in approximately $24 \mathrm{~h}$.

12.15 p.m. 78 Isolation of Human Placental Myosin

Gabor Huszar

Department of Obstetrics-Gynecology, Yale University School of Medicine, New Haven, Conn.

As a part of our study on the contractile proteins of the utero-placental unit the isolation and characterization of myosin in human placenta was carried out. Human placentas were previously shown to contain an actomyosin like protein with ATPase activity and the amounts of this actomyosin increase with the gestational age. The actomyosin is thought to arise from the anchoring villi which are composed substantially of smooth muscle and bridge the fetal and maternal surface of the placenta \{Michael, C: J. Obstet. Gynec. Br. Commonw. 81: 307, 1974 and ref. herein). In the present work the placentas were subjected to high salt extraction and purification and the placental myosin was further studied by Sepharose-column chromatography, SDS-gel electrophoresis, amino acid analysis, and ATPase enzymatic assays. High salt extracts yield about $0.2 \%$ of myosin of the wet placental tissue. The myosin has an apparent molec. wt of 480,000 , with heavy chains of about 200,000 and light chains of about 24,000 and 20,000 molec. wt which are present in equal ratios. The ATPase of myosin is activated by K-EDTA and calcium (80-100 $\mu \mathrm{mol} \mathrm{Pi} / \mathrm{mg}$ myosin/min) and it is inhibited by magnesium. Magnesium activates the placental myosin ATPase in presence of actin. Amino acid composition of placental myosin is not remarkably different from that of myosins of other sources, only the amounts of methylated amino acids are lower than in skeletal or cardiac muscle myosin (Huszar, G.: J. molec. Biol. 94: 311, 1975). The study of placental contractile proteins seems to be important because contraction-relaxation of the anchoring villi is implicated in the regulation of placental hemodynamics by changing the volume of the intervillous space.

12.30 p.m. Adjournment

Second Poster Session

Friday, March 25, 1977

Cochise and Apache Rooms - Marriott Hotel

10.45 a.m. to 12.30 p.m.

79 Calcium Metabolism during the Human Menstrual Cycle 
Roy M. Pitkin, W. Ann Reynolds, Gerald A. Williams, Gary K. Hargis and Wanda

Kawahara

Department of Obstetrics-Gynecology, University of Iowa College of Medicine, Iowa

City, Iowa, and Departments of Anatomy and Medicine, University of Illinois College

of Medicine and West Side VA Hospital, Chicago, 111.

Fasting blood samples were obtained at 0800 every day or every other day throughout ovulatory menstrual cycles (as indicated by plasma progesterone \&gt; $2 \mathrm{ng} / \mathrm{ml}$ ) in 6 women.

Total calcium $(\mathrm{Ca})$ and magnesium $(\mathrm{Mg})$ were measured by atomic absorption spec-trometry, ionic calcium $(\mathrm{Ca}+\mathrm{t})$ by flow-through electrode and phosphorus $(\mathrm{P})$ by a colori-metric method. Parathyroid hormone (PTH) and calcitonin (CT) were determined by radio-immunoassay. The most striking finding was a consistent cyclicity of PTH with progressive increase during the follicular phase to a peak slightly after mid-cycle and then a decrease during the luteal phase. The peak PTH level, which followed the LH 'surge' by 1-3 days, was 20-55\% above the early follicular level and 20-68\% above the late luteal value. CT exhibited a similar, though somewhat more attenuated and less precise cyclic pattern with peak levels reaching values $15-70 \%$ above early follicular levels and 22-59\% above luteal levels. In each subject, PTH and CT correlated significantly, as did $\mathrm{CT}$ and $\mathrm{Ca}++$. This represents the first reported variation with the menstrual cycle in calcium-regulating hormones. These findings suggest an effect (presumably of estrogen) on $\mathrm{Ca}++$ levels in extracellular fluid with a resultant stimulation of PTH and CT which regulate calcium metabolism. On the other hand, a direct response to other hormones regulating ovulation and menstruation cannot be ruled out.

Scientific Abstracts

61

80 Secretion of Progesterone and Relaxin by the Human Pregnancy Corpus luteum

Gerson Weiss, E. Milikin O’Byrne, Joseph A. Hochman, Laura T. Goldsmith and Bernard G. Steinetz

Department of Obstetrics-Gynecology, New York University School of Medicine, New York, N.Y., and Ciba-Geigy Corp., Ardsley, N.Y.

The function of the corpus luteum at midtrimester and at term was studied in 19 pregnant women. Six women had their pregnancies terminated by hysterotomy at 14-18 weeks. The remaining 13 women were delivered by cesarean section at term. Luteectomies were also performed on six women at the time of cesarean section. Progesterone and relaxin levels in peripheral blood serum were used as indices of luteal activity. Relaxin is a product of the human pregnancy corpus luteum. Relaxin secretion correlates well with luteal progesterone secretion (Science, N.Y. 194: in press).

After cesarean section at term the decline in serum progesterone was parallel to that observed after hysterotomy at midtrimester, although the absolute levels were much higher at term. On the other hand, the actual relaxin concentrations, as well as the decrease in relaxin levels seen after evacuation of the uterus, were similar at midtrimester and at term. After luteectomy there was a more precipitous decrease in serum levels of both progesterone and relaxin than seen in nonluteectomized patients.

Thus, in contrast to previous findings in lower primates, the corpus luteum of human beings does not regress in midpregnancy but instead, remains functional throughout pregnancy. There is continued secretion of luteal progesterone and relaxin in the puerperium. The corpus luteum appears to be the only source of these hormones in the puerperium.

81 Polyamines in Amniotic Fluid as Potential Indicators of Fetal Growth 
Harlan R. Giles, Diane H. Russell and C.D. Christian

Departments of Obstetrics-Gynecology and Pharmacology, The University of Arizona

Health Sciences Center, Tucson, Ariz.

Polyamines are a group of small, low molecular weight cations that are ubiquitous in nature. Although originally relegated to a role in putrefaction, polyamines have become integrally associated with normal and abnormal RNA and DNA replication in vitro and in vivo. Recent work has raised the possibility that polyamines may be valuable markers for tumor cell depletion and replication in patients undergoing therapy for malignancies.

Concentrations of four polyamines - putrescine, cadaverine, spermidine, and spermine - were determined by amnio acid analysis of amniotic fluid samples. Control values were obtained from patients undergoing elective termination of pregnancy, from Rh sensitized mothers who subsequently delivered $\mathrm{Rh}$ negative infants, or from elective repeat cesarean sections. Eleven patients with intrauterine fetal demise (IUFD) were noted to have significant elevations of cadaverine ( $\mathrm{p} \& \mathrm{lt}$; 0.001) in amniotic fluid when compared to controls matched for gestational age. Eight patients with intrauterine growth retardation (IUGR) exhibited similar elevations in cadaverine and a less marked, but statistically significant increase in amniotic fluid spermidine. Eight other patients with significant pregnancy complications but without growth retardation exhibited amniotic fluid polyamine profiles which were not significantly different from the normal controls. The question is thus raised as to whether amniotic fluid concentration of certain polyamines, notably cadaverine and spermidine may be clinically useful as an indicator of fetal growth.

Society for Gynecologic Investigation

62

82 Effects of Fasting on Ovine Uterine Blood Flow and Substrate Uptake

Frank H. Morriss, Eugene W. Adcock, Arlyn H. Hartfiel and Sharon S. Crandell Departments of Pediatrics and Obstetrics-Gynecology, University of Texas Medical School at Houston, Houston, Tex.

To determine the effect of maternal nutrition during pregnancy on uterine blood flow (UBF) and uptake (Q) of 02, glucose (glue) and 21 amino acids (aa), 7 ewes 92-126 days gestation (GA) were prepared with uterine artery flow transducers; 4 of these received catheters in uterine veins and femoral artery. After recovery and during adequate nutritional intake, control studies of UBF and substrate uptake were made. Each ewe was then fasted, but allowed water, and restudied after 3-4 days and after 5-7 days. Whole blood glue was determined by the glue oxidase method, 02 with a Lex02Con analyzer, and aa by ion-exchange column chromatography.

During fasting maternal arterial whole blood glue and 7 aa decreased while lysine and 1-methyl histidine increased. When all fasting studies are compared with 27 studies of $Q$ aa in 5 additional well-fed ewes at similar GA, Q ornithine and Q lysine were decreased (p \&lt; 0.025).

Conclusions: (1) fasting is accompanied by significant decreases in uterine consumption of 02 , glue and 3 aa which are major fetal sources of N2; (2) both a 25\% decrease in UBF and decreased (substrate) contribute to decreased Q; (3) whole blood lysine increases with GA in well-fed ewes as well as during fasting, suggesting that a maternal aa metabolic alteration similar to fasting develops during pregnancy.

(Aided by a Basil O'Connor Starter Research grant from The National Foundation-March of Dimes.)

83 The Control of Vascular Reactivity to Angiotensin II (A-II) in Human Pregnancy 
Royice Everett, Richard Worley, Kenneth Leveno, Paul MacDonald and Norman Gant Department of Obstetrics-Gynecology, University of Texas Southwestern Medical School, Dallas, Tex.

Gravidas destined to develop pregnancy-induced hypertension (PIH) lose resistance to the pressor effects of A-II several weeks before the onset of hypertension. Moreover this loss of resistance to A-II is apparently unrelated to plasma renin activity or A-II levels. The present study was designed to ascertain if prostaglandin(s) or related substances are involved in the control of vascular reactivity during human pregnancy. In six normal gravidas beyond the 28th week of gestation, the administration of $25 \mathrm{mg}$ of indomethacin on two occasions $6 \mathrm{~h}$ apart was associated with a marked loss in A-II resistance. The dose of A-II required to evoke a pressor response of a $20 \mathrm{~mm}$ of rise in diastolic pressure before treatment in these Scientific Abstracts

63

six women was $25.84 \pm 6.04$ (mean $\pm \mathrm{SEM}$ ) whereas the dose required after treatment was 9.71 \pm 1.77 (p \&lt; 0.025). Resistance to A-II is regained by $24 \mathrm{~h}$ after discontinuation of indomethacin administration. These findings are consistent with the view that a generalized inhibition of the synthesis of prostaglandin(s) or related substances is associated with a loss in the pregnancy acquired resistance to the pressor effects of infused angiotensin II.

84 Failure of Glucocorticoid Administration in Inducing the Production of a Mature L/SRatio

F. Arias and J. Pineda

Department of Obstetrics-Gynecology, Washington University School of Medicine, St. Louis, Mo.

It has been reported that antepartum glucocorticoid administration is useful in the prevention of neonatal respiratory distress syndrome but estimations of the amniotic fluid $\mathrm{L} / \mathrm{S}$ ratio (as an objective index of fetal pulmonary surfactant production) after corticoid administration have produced discrepant findings. In an attempt to reconcile the controversy, the effect of glucocorticoids (Ø-methasone phosphate $6 \mathrm{mg}$ and $\varnothing$-methasone acetate $6 \mathrm{mg}$, given together intramuscularly on each of two consecutive days) on amniotic fluid L/S ratio was measured in 15 patients, all between 28 and 32 weeks of gestation (as determined by clinical estimation and serial ultrasonic cephalometry) where induction of fetal pulmonary surfactant was considered desirable in view of fetal or maternal complications. Determination of amniotic fluid L/S ratio was carried out before, and 3-5 days after as well as $7^{\wedge} 14$ days after corticoid administration. There was a trend toward increased L/S ratios, but in no single case were corticoids capable of inducing the production of a mature L/S ratio within 1 week and only one patient responded with L/S maturation within 2 weeks after administration of the medication. These findings suggest that glucocorticoids lack any immediate effect on the biochemical indicator of fetal lung maturation and generate doubts about the advantages of their widespread use for the purpose of accelerating fetal surfactant production.

85 Failure of Severe Distress to Stimulate Aspiration of Amnionic Fluid by the ImmatureHuman Fetus

Johann H. Duenhoelter and Jack A. Pritchard

Department of Obstetrics-Gynecology, University of Texas Southwestern Medical School at Dallas, Dallas, Tex.

Studies have been previously presented before this Society which were interpreted to indicate that even the very young fetus normally inspires appreciable volumes of amnionic fluid. An 
alternative explanation raised was that the aspiration was the consequence of the severe distress induced by the termination of the pregnancy rather than a physiologic event. Observations summarized below preclude severe fetal distress as the major stimulus for aspirating amnionic fluid.

Amnionic fluid was labeled as in previous studies with radiochromium $(51 \cdot \mathrm{Cr})$ tagged red cells shortly before spontaneous fetal death in 2 cases of severe hypertension, the injection of prostaglandin F2 $\alpha$ and subsequent fetal death in 3 cases, shortly before hysterectomy in 3 cases, and immediately after hysterectomy but with the fetal heart beat persisting for more than $1 \mathrm{~h}$ after so labeling in 1 case. $51 \cdot \mathrm{Cr}$ accumulated in the lungs

Society for Gynecologic Investigation

64

equivalent to amnionic fluid volumes no greater than \%o of those found in lungs of fetuses of comparable weights in which the label had been introduced $19-48 \mathrm{~h}$ before terminating the pregnancy by hysterectomy.

Conclusions: (1) even the very immature human fetus normally inspires amnionic fluid, and (2) fetal distress, at least under the conditions of these studies, does not markedly intensify the aspiration of amnionic fluid.

86 Effects of PGF2 $\alpha$ and PGE2 on Sheep Umbilical and Uterine Circulation

Margaret K. McLaughlin, Susan C. Brennan, Lewis A. Hamilton and Ronald A. Chez Pregnancy Research Branch, NICHD, NIH, Bethesda, Md.

We studied changes in calculated vascular resistance (VR $=$ arterial - venous pressure/ flow) after intraaortic injection of PGE2 or PGF2 $\mathrm{u}$, to the fetus $(0.1-100 \mu \mathrm{g} / \mathrm{kg}$ estimated body weight, $\mathrm{n}=5)$, and of PGF $2 \alpha$ to the ewe $(0.5-50 \mu \mathrm{g} / \mathrm{kg}$ body weight, $\mathrm{n}=4)$. Uterine and umbilical blood flow (UtBF, UmBF), maternal and fetal arterial pressures (MAP, FAP), and maternal and fetal heart rates (MHR, FHR) were measured in chronically instrumented sheep at 120-132 days. All responses were dose related and peaked by 3 min postinjection. Statistically significant maximal changes ( $\mathrm{p}$ at least \&lt; 0.02) from control levels were:

Conclusions: (1) Acute vascular changes induced on one side of the sheep placenta by exogenous PGE2 and PGF2 $\alpha$ are associated with acute changes on the other side of the placenta. Whether these changes are or are not in the same direction is a function of the agent injected. (2) Thus, the resultant umbilical/uterine perfusion ratio is variably altered. (3) We do not know whether similar changes occur when endogenous prostaglandin levels increase physiologically. 87 Role of HCG in the Regulation of the Fetal Zone of the Human Fetal Adrenal Gland Maria Seron-Ferre, Christina C. Lawrence and Robert B. Jaffe Department of Obstetrics-Gynecology and Reproductive Sciences, University of California at San Francisco, San Francisco, Calif. It has been suggested that human chorionic gonadotropin (HCG) is a trophic hormone for the fetal zone of the human fetal adrenal gland. To test this hypothesis, the isolated fetal zone of adrenals from 5 fetuses 12-17 weeks gestational age were superfused in the presence or absence of HCG $(250 \mathrm{ng} / \mathrm{ml})$. Dehydroepiandrosterone sulfate (DHAS) was measured in the superfusion effluent. No difference was observed between control and experimental superfusions during the first $60 \mathrm{~min}, 65 \pm 7.8 \mathrm{vs} 72 \pm 8.0 \mathrm{ng} / \mathrm{ml}$ (mean $\pm \mathrm{SE}$ ) respectively. In the presence of HCG, DHAS secretion rose significantly to $122 \pm 7.6 \mathrm{ng} / \mathrm{ml}$, while in the control secretion remained at $76.0 \pm 5.32 \mathrm{ng} / \mathrm{ml}$. This difference was main-

Scientific Abstracts 
65

tained for the duration of the experiment. These results support the hypothesis that HCG regulates DHAS production by the human fetal adrenal gland early in gestation. As we have found that ACTH stimulated DHAS secretion in some experiments in a previous study, and as there is indirect evidence for a role of ACTH in DHAS regulation late in pregnancy, these observations suggest that a transition from HCG to ACTH regulation of the fetal zone of the human fetal adrenal occurs after midgestation.

(Supported by NIH grant HD 08478 and the Rockefeller Foundation.)

88 Androgen Dynamics in Normal and Castrate Male Rhesus Monkeys

Torn Tabei, Kenneth Burry, Pearl Namkung, Robert A. Steiner, Philip Petra, Harvey Schiller, John Resko and W. LeRoy Heinrichs

Departments of Obstetrics-Gynecology, Physiology, Biochemistry and Laboratory Medicine, University of Washington, Seattle, Wash., and Washington and Oregon Regional Primate Research Center, Seattle, Wash., and Beaverton, Oreg.

To assess the regulatory roles of adrenal and testicular hormones on androgen dynamics in adulthood we measured the metabolic clearance rate (MCR) and production rate (PR) of dehydroepiandrosterone (DHA) and of testosterone (T) in four normal adult male rhesus monkeys and six castrates. The MCR $\gamma j$ ha oi* intact males, $165 \pm 23$ liter/day $(x \pm \mathrm{SD})$ was significantly less than that of the castrates, $334 \pm 58$, but this difference seemed to be related to body weight. Since the plasma concentration of DHA was similar in both groups (15.6 $\pm 3.4 \mathrm{vs.}$ $13.4 \pm 8.5 \mathrm{ng} / \mathrm{ml})$, the mean PRrjHA m castrates $(5-7 \pm 3.4 \mathrm{mg} /$ day) was greater than that of intact males $(2.7 \pm 1.0)$. The MCRj of intact males, $55 \pm 14$ liter/ day was similar in the castrate group, $68 \pm 7$, and no weight relationship was apparent. Despite great differences in plasma concentrations of T $(6.0 \pm 3.7$ vs. $0.3 \pm 0.1 \mathrm{ng} / \mathrm{ml})$ and PRy $(1,082 \pm 932 \mathrm{vs} .25 \pm 20 \mu \mathrm{g} /$ day $)$, the plasma binding capacities of dihydrotestosterone and corticosterone were similar in both groups; plasma estradiol levels were also similar. $5 \alpha$-Reduction of $\mathrm{T}$ by abdominal skin was the same in both groups, but this transformation in scrotal skin of the castrates exceeded by twofold the rate observed in skin from normal animals.

These data indicate that testosterone produced by the testis is not essential for regulating androgen clearance in adulthood.

(Supported by PHS grants No. HD 08736, and HD 00272.)

12.30 p.m. Adjournment

Abstracts

89 Amino Acid Concentration in the Sheep Placenta

Luis B. Curet

Department of Obstetrics-Gynecology, University of Wisconsin Center for Health

Sciences, Madison, Wise.

Previous work in our laboratory suggested that amino acids are transported across the sheep placenta in three stages. Amino acids would leave the uterine circulation in the first stage to be concentrated in the placenta during the second stage and eventually appear in the umbilical circulation during the third stage. The concentration gradients shown in figure 1 are consistent with a step-wise transport.

The present study was designed to study the tissue stage of transport. Six ewes were studied at 50,80 and 140 days of gestation. Three ewes in each group received an intravenous infusion of $\alpha$-amino isobutyric acid. All animals were sacrificed and fetal and maternal cotyledons were analyzed for amino acid concentration. 
Figure 2 summarizes the regression over the three periods studied of each amino acid concentration in maternal and fetal cotyledons. The concentration of amino acids decreases in the maternal cotyledons while that in the fetal cotyledons increases.

Figures 3 and 4 show the regression of the difference in concentration between fetal and maternal cotyledon for all amino acids. As expected the regressions have a positive slope. It would appear from these observations that the fetal cotyledon is capable of concentrating amino acids during the course of gestation and provide some degree of safety for the fetus. Current studies underway in our laboratory are aimed at determinmg how quickly these amino acids become depleted upon reducing the maternal intake of protein.

Scientific Abstracts

\section{7}

90 Behavior of Cardiac Output and Systemic Vascular Resistance during Neonatal Growth James R, Woods, jr. , Adrien Dandavino, Charles R. Brinkman, HI and

Nicholas S. Assali

Department of Obstetrics-Gynecology, UCLA School of Medicine, Los Angeles, Calif.

We have previously shown in sheep that: (a) resting heart rate (HR) decreases progressively during neonatal growth and the changes are independent of autonomic nervous activities; (b) parasympathetic tone rises considerably after birth while sympathetic tone decreases; ratio of both remains constant throughout neonatal period and similar to adult. Present studies deal with behavior of cardiac output (CO), stroke volume (SV) and systemic resistance (SR) during neonatal growth. Two groups of newborn lambs were chronically instrumented for measurements of arterial pressure (AP), SV and CO; in one group CO was monitored with electromagnetic flow transducer around pulmonary artery while in the other, indicator dilution was used. Same lamb was studied from 1-5 weeks and its response to cholinergic and $\beta-$ adrenergic stimulation and blockade was tested weekly. Results show: (1) during neonatal growth, changes in HR, AP, SV, CO and SR were comparable in both groups, indicating pulmonary artery instrumentation had no deleterious effects on cardiovascular functions; (2) $\mathrm{CO} / \mathrm{kg}$ declined $34 \%$, SV remained unchanged and SR increased $50 \%$ during first 5 weeks of life; (3) cholinergic blockade resulted in 7-12\% increase in $\mathrm{CO}$, whereas $\mathrm{j} 3$-adrenergic blockade had minimal effects; (4) /3-adrenergic stimulation produced 30\% increase in CO. Conclusions: (1) CO decreases, SR increases and SV remains unaltered during neonatal growth; (2) neonatal heart is capable of exhibiting adult-like inotropic effects in response to autonomic stimuli.

91 In vitro Quantitation of Uterine Inhibitors

Harold Schulman

Department of Obstetrics-Gynecology, Albert Einstein College of Medicine, Bronx, New York, N.Y.

Currently there is not an in vitro or in vivo method of quantitating the potency of uterine inhibiting drugs. Electric field stimulation (EFS) of pregnant and parturient rabbit myometrial strips has been effectively used to assay oxytocic potency of prostaglandins and it is shown in this study to be useful in assaying potency of /3-sympathomimetic compounds.

Decreasing electric field stimulation (DEFS) provides 3 measurable endpoints: tension, excitability, and threshold voltage. Three compounds were tested for these parameters; isoproterenol, ritodrine and isoxsuprine.

Tension Excitability Voltage

$\%$ control contractions $/$ min threshold, $\mathrm{V} / 5 \mathrm{~cm}$

Isoproterenol $81.6 \pm 3.3 \quad 0 \quad 6$ 


$\begin{array}{llll}\text { Ritodrine } & 68.3+5.1 & 2.0 & \text { \&lt; } 3 \\ \text { Isoxsuprine } & 42.2+3.8 & 2.3 & \text { \&lt; } 3\end{array}$

It is concluded that in this system isoxsuprine is the more potent inhibitor of uterine tension evoked by EFS. It is also revealed that so-called uterine inhibition by these compounds represents the creation of a chaotic fibrillating muscle which is unable to respond in a synchronous way to produce a contraction of maximal tension.

Society for Gynecologic Investigation

68

92 The Changes in Fetal Red Cell Oxygen Affinity in Relation to Gestational Age: the Role of 2,3-Diphosphoglycerate and Adult Hemoglobin

Harry Bard, Ann Comet and Francois Teasdale

Perinatal Service, University of Montreal, Hôpital Sainte-Justine, Montreal, P.Q.

To reflect the in utero changes in fetal oxygen affinity in relation to gestational age along with the factors that control oxygen affinity, fresh heparinized cord blood obtained at delivery from nonstressed normal fetuses ranging from 28 to 42 weeks of gestation had the following parameters determined simultaneously; P50 by gas mixing tonometry, 2,3-diphos-phoglycerate (2,3-DPG) according to the method of Keitt, and the proportions of adult ( $\mathrm{HbA})$ and fetal hemoglobin $(\mathrm{HbF})$ by eluting $\mathrm{HbF}$ and $\mathrm{HbA}$ from DEAE Sephadex A-50. There was a significant positive correlation between Ps0 and gestational age $(r=0.62, p \& 1 t ; 0.001)$. The linear regression increased from 17.8 to $22.5 \mathrm{~mm} \mathrm{Hg}$. There was a significant positive correlation between Pso and the percentage to $\mathrm{HbA}(\mathrm{r}=0.56, \mathrm{p} \& \mathrm{lt} ; 0.01)$. Gestational age had no effect on fetal 2,3-DPG levels. The mean and SD was $15.1874 \pm 2.1786 \mu \mathrm{mol} / \mathrm{g} \mathrm{Hb}$. Contrary to what is expected during postnatal life, there was no significant correlation found between the percentage of $\mathrm{HbA}$ and 2,3-DPG nor between Pso and 2,3-DPG. The fetus gradually decreases red cell oxygen affinity during the last trimester of gestation by increasing $\mathrm{HbA}$, while the 2,3-DPG levels remain stable.

93 Predictability of Gestational Hypertension

Shailaja M. Didolkar, Milo B. Sampson, Patrick J. Carmody, Wayne L. Johnson and L·oren P. Petersen

Department of Obstetrics-Gynecology, State University of New York at Buffalo, Buffalo, N.Y. To assess the predictability of various factors for gestational hypertension, 85 patients were studied prospectively. Gestational ages ranged from 28 to 37 weeks. $60 \%$ were primigravidas. Patients were admitted to a Clinical Research Center and put on a balanced diet and bedrest the evening before studies began. Next day they were studied for $1 \mathrm{~h}$ in the left lateral position and 1 $\mathrm{h}$ supine. Blood pressure measurements were done every $10 \mathrm{~min}$ and fetal heart rate was monitored continuously. Sodium balance, creatinine clearance, hematocrit HPL, E3 and urine output were measured. Seventeen (20\%) developed gestational hypertension, 15 of the 17 were primigravidas. Patients were grouped according to mean diastolic blood pressure (BP) change from left lateral to recumbent position.

Mean diastolic BP $\quad \downarrow \& \mathrm{gt} ; 4 \mathrm{~mm}$ No $\quad \uparrow 5$ - til- $\uparrow \& \mathrm{gt} ; 20 \mathrm{~mm}$ Total

change $10 \mathrm{~mm} 19 \mathrm{~mm}$

$\pm 4$

$\begin{array}{llllll}\text { No. patients } 12 & 23 & 14 & 27 & 9 & 85 \\ \text { Gestational hypertension } 5 & 50 & 6 & 1 & 17 \\ \text { (41.6\%) (21.7\%) } & (0 \%) & (22.2 \%) & (11.1 \%) \\ + \text { Rollover (Gant) } 0 & 02 & 12 & 6 & 20 & \end{array}$




\section{+ Gestational hypertension $\begin{array}{llllll}0 & 0 & 0 & 2 & 1 & 3\end{array}$ Scientific Abstracts \\ 69}

Gestational hypertension patient\&were scattered in all four groups, $41 \%$ being in the group where blood pressure actually decreased. Only 3 of the 20 patients $(15 \%)$ who had a positive rollover test developed gestational hypertension. There was no correlation between creatinine clearance, sodium balance, serum creatinine, hematocrit, urine output and development of gestational hypertension.

94 Nicotine and Breathing Movements in the Fetal Lamb

Frank A. Manning and David Walker

Department of Obstetrics-Gynecology, University of Southern California School of

Medicine, LAC/USC Medical Center, Los Angeles, Calif.

Nicotine is responsible for the decrease in fetal breathing movements (FBM) associated with smoking; the mechanism of action is unclear. The effect of nicotine on maternal and fetal heart rate (MHR, FHR), blood pressure (MBP, FBP), blood gas and acid-base status, intrauterine pressure (IUP), and FBM was studied in six chronically catheterized pregnant ewes. In nine experiments, nicotine (10-20 mg) was given by maternal intravascular injection. Nicotine injection produced maternal hypertension maximal at $1 \mathrm{~min}(130 \pm 7.3 \%$ of control, $\mathrm{p} \& \mathrm{lt} ; 0.05)$. MHR changes were biphasic, an initial bradycardia followed by sustained tachycardia $(126 \pm 4 \%$ of control at 10 min, p \&lt; 0.05). Changes in FBP and FHR were similar but delayed in onset and of lesser magnitude. The maximal rise in FBP occurred at 2 min $(117 \pm 9 \%$ of control). FHR fell $(83 \pm 2.1 \%$ of control at $2 \mathrm{~min}, \mathrm{p} \& 1 \mathrm{lt} ; 0.05)$, then rose to a maximum at $40 \mathrm{~min}(118 \pm 9.5 \%$ of control). IUP remained unchanged. No significant changes in maternal $\mathrm{Pa} 02, \mathrm{~Pa} . \mathrm{C} 02$, or $\mathrm{pH}$ were observed. In contrast, fetal Paø2 fell within $5 \mathrm{~min}(\Delta=5.11 \pm 1.03 \mathrm{~mm} \mathrm{Hg}, \mathrm{p} \& \mathrm{lt} ; 0.01)$, and the decrease persisted for up to $30 \mathrm{~min}$. No significant changes were observed in $\mathrm{PaC} 02$ or pH. FBM were present for $31.2 \pm 6.75 \%$ of the time during the control period $(1 \mathrm{~h})$. Nicotine injection caused a fall in FBM evident by $15 \min (17 \pm 11 \%$ of the time, $p$ \&lt; 0.05$)$ and persistent for up to $45 \mathrm{~min}$. The fall in FBM was related to the fall in fetal PA02 ( $\mathrm{r}=0.58$, p \& $1 \mathrm{t}$; $0.001)$.

These observations suggest that fetal hypoxemia is the mechanism by which nicotine causes a reduction in the incidence of FBM.

95 Effect of Progesterone on the Pituitary's Response to LHRH

Virendra B. Mahesh and James C. McPherson

Department of Endocrinology, Medical College of Georgia, Augusta, Ga.

In a previous study it was shown that 26-day-old castrated female rats treated with $0.1 \mu \mathrm{g} / \mathrm{kg}$ body wt. of estradiol and various doses of progesterone for 5 days starting with the day of castration, showed stimulation or suppression of tonic FSH and LH secretion, depending on the dose of progesterone used (Endocrinology 97: 111, 1975). The current study confirms these findings in the immature rat treated with $0.1 \mu \mathrm{g} / \mathrm{kg}$ body wt. of estradiol for 4 days, and given a single injection of progesterone. Progesterone in doses of $0.2 \mathrm{mg}$ and $0.8 \mathrm{mg} / \mathrm{kg}$ body wt. injected at 9.30 a.m. resulted in a 7-fold increase in LH and 2-fold increase in FSH by 4.00 p.m. whereas the $0.4 \mathrm{mg}$ and $3.2 \mathrm{mg} / \mathrm{kg}$ body wt. dose levels had either no effect or were suppressive. In the castrated rat various doses of progesterone did not have any effect on gonadotropin secretion in the absence of estradiol priming. In order to examine whether the effect of progesterone on the estradiol-primed rat was manifested at least in part at the level of the pituitary, and whether such an effect was dependent 


\section{Society for Gynecologic Investigation \\ 70}

on the dose of progesterone used, groups of animals were castrated and treated with $0.1 \mu \mathrm{g} / \mathrm{kg}$ body wt. of estradiol for 4 days starting on the day of castration. On the 4th day post castration they were injected with vehicle or 0.8 or $3.2 \mathrm{mg} / \mathrm{kg}$ body wt. of progesterone. After serum LH levels stabilized for the evening at 6.00 p.m., the rats were either given saline or $10 \mathrm{ng}$, LHRH at 2-hour intervals and multiple samples collected for assay. The $0.8 \mathrm{mg} / \mathrm{kg}$ body wt. dose of progesterone was stimulatory for pituitary content and release of LH while the $3.2 \mathrm{mg} / \mathrm{kg}$ dose was inhibitory as compared to estrogen primed controls.

96 The Relation of Gestational Age to Microviscosity of Amniotic Fluid (AF) Lipids Measured by Fluorescence Polarization (FP)

Thomas Blumenfeld, Raymond I. Stark, Vincent J. Freda and L. Stanley James Division of Perinatal Medicine, College of Physicians and Surgeons, Columbia University, New York, N.Y. FP techniques are used to study the microviscosity of lipid dispersions. FP measurements are rapid, easy to perform and precise (coeff. of var. $0.48 \%$ ). The microviscosity of lipid micelles in $\mathrm{AF}$ is related to the relative concentrations of various micellar lipids and is a good approximation of $\mathrm{L} / \mathrm{S}$ ratio. The phospholipid composition of AF changes during gestation and reflects fetal lung maturation. To determine if a similar change occurs in AF microviscosity, FP values were determined on serial AF samples obtained during 19 isoim-munized pregnancies. Patients were grouped by the interval in gestation of sequential samples.

Group Gestational ageNo. of No. of FP value - mean (range)

patients samples

$\begin{array}{clll}\text { \&lt; 33wks } & 4 & 17 & 0.372(0.386-0.333) \\ \text { \&gt; 33wks } & 4 & 14 & 0.334(0.345-0.301) \\ \text { 26to38wks } & 11 & 66 & 0.368(0.385-0.353) \text { before change }\end{array}$

$0.345(0.368-0.328)$ after change

There was a significant change in slope of FP values vs. gestational age in group III, occurring between 29 to 35 weeks (mean $=31.5$ weeks). This study establishes a definite relation between FP values of AF and gestational age. Changes in FP occur over the same interval as changes in AF phospholipids. The precision, rapidity and ease of FP measurements of AF lipid microviscosity may facilitate and enhance the ability to predict fetal lung maturity. 97 Interrelationship between Risk Factors of Pregnancy, Perinatal Events and Outcome Henry R. Rey, Jean D. Joseph, Raymond Stark, R. Vande Wiele and L. Stanley James Division of Perinatal Medicine, College of Physicians and Surgeons, Columbia University, New York, N.Y.

Analysis of perinatal data in 665 patients has shown a statistically significant inverse relationship between the Hobel antepartum and intrapartum risk scores and neonatal complications ( $p$ \&lt; 0.01). Risk scores were inversely related to Apgar scores at both 1 and

Scientific Abstracts

71

5 min when controlling for severity of neonatal complications. For fetuses of gestational age (GA) \&gt; 32 weeks, a significant positive correlation was found between risk scores and abnormalities in heart rate-uterine pressure patterns during labor ( $\mathrm{p} \& 1 \mathrm{t} ; 0.01)$. For high risk mothers (Hobel A.P. score \&gt; 10 and Hobel I.P. score \&gt; 20), several unexpected relationships were found between type of delivery and outcome. For infants \&lt; 32 weeks, the incidence of mortality and morbidity was $50 \%$ lower in those delivered by cesarian section (CS) 
than in those delivered by mid-forceps (MF), breech (BR), or vacuum extraction (Vac). At 32-36 weeks, mortality was 5 times greater in those delivered by MF, BR and Vac than in those delivered spontaneously or by low forceps, and twice that found in the CS group. At 36 weeks or more however, that relationship was reversed with $75 \%$ of the mortality and $50 \%$ of the morbidity associated with cesarian section. This study demonstrates the importance of controlling for GA if outcome is to be related to mode of delivery. It appears that the immature fetus has a poor tolerance of labor and vaginal delivery irrespective of risk.

98 Fetal Vasopressin (AVP) Levels during Adrenocorticotrophin (ACTH) Induced Parturition in the Lamb

Raymond I. Stark, Kazim Husain, Jacques M. Milliez, Salha S. Daniel, Hisayo O. Morishima and Raymond L. Vande Wiele

Division of Perinatal Medicine, College of Physicians and Surgeons, Columbia University, New York, N.Y.

Activation of the fetal neurohypophysis during labor has been documented and implicated as a potential trigger for the initiation of labor. To investigate the relation of AVP measured by a sensitive radioimmunoassay to the onset of parturition, 9 fetal lambs were instrumented at 121 days of gestation. At 129 days, 7 fetuses were infused with ACTH $(1 \mathrm{O} \mu \mathrm{g} / \mathrm{kg} / \mathrm{h}), 2$ with saline. During infusion fetal $\mathrm{pH}(7.36 \pm 0.002)$ and $\mathrm{pC} 02(42 \pm 2 \mathrm{~mm} \mathrm{Hg})$ were constant, p02 decreased $(22 \pm 2$ to $18 \pm 2 \mathrm{~mm} \mathrm{Hg}, \mathrm{r}=0.96)$. Delivery occurred after a mean of $74 \mathrm{~h}$ infusion. Fetal AVP levels during infusion prior to labor $(1.8 \pm 1.8 \mathrm{pg} / \mathrm{ml})$ were not different from controls $(1.85 \pm$ $1.1 \mathrm{pg} / \mathrm{ml}$ ). Levels rose progressively only after the onset of labor to a mean peak at delivery of $720 \pm 1,470 \mathrm{pg} / \mathrm{ml}$. Fetal AVP during active labor $(40 \pm 73 \mathrm{pg} / \mathrm{ml})$, pushing $(173 \pm 404 \mathrm{pg} / \mathrm{ml})$ and $30 \mathrm{~min}$ after delivery $(360 \pm 340 \mathrm{pg} / \mathrm{ml})$ were predictive of AVP levels in cord blood $(\mathrm{r}=$ $0.955,0.985$ and 0.992 ). Fetal levels of AVP prior to labor and during early labor were not predictive of levels at birth. Maternal AVP rose only during the pushing phase $(2.1 \pm 1.4$ to $6 \pm 4$ $\mathrm{pg} / \mathrm{ml}$ ) and never exceeded fetal levels. We conclude that in parturition induced by ACTH, fetal AVP rises only after the onset of labor, reaches a peak at delivery and is unrelated to maternal levels.

Fetal vasopressin does not appear to be related to the initiation of labor, but could be related to the maintenance of labor or fetal cardiovascular adjustments during labor.

99 Quantitative Classification of Baseline Variability

Bruce K. Young, Howard M. Weinstein, Howard M. Hochberg and Michael E.D. George

Department of Obstetrics-Gynecology, New York University School of Medicine, New York, N.Y., and Roche Medical Electronics, Cranbury, N.J.

Simultaneous tape recordings of fetal scalp ECG, or cardiac Doppler, maternal ECG, and uterine contractions were obtained from 32 patients in labor. Neonatal ECG and instantaneous heart rate were recorded at birth and $24 \mathrm{~h}$. Computer-derived distributions of

Society for Gynecologic Investigation

72

beat-to-beat changes were used to develop a simple numerical and graphical description of the long- and short-term variability patterns. The visually observed variability may be described by the R-R interval change (beat-to-beat change) which is greater than $90 \%$ of the beat-to-beat changes. Thus the 90th percentile of R-R interval changes quantitatively describes the baseline variability. The variability may be classified as fixed, minimal, moderate, or marked, based on this simple calculation. The effects of meperidine $\mathrm{HC} 1$ on the observed maternal and fetal variability were described clearly by this method. Maternal and fetal baseline heart rates and 
variability often moved in the same direction. Newborn heart rates showed marked baseline variability and were unrelated to fetal heart rate variability.

100 Obstetrical Intensive Care: 3 Years' Results

Bruce K. Young, Howard M. Weimtein, Jon R. Snyder, Howard M. Hochberg and Michael E.D.

George

Department of Obstetrics-Gynecology, New York University School of Medicine, New York, N.Y., and Roche Medical Electronics, Cranbury, N.J.

An obstetrical intensive care unit (OBICU) utilizing fetal and maternal monitoring equipment was used for monitoring during labor in the highest risk patients. Continuous maternal ECG, respiration, blood pressure, and beat to beat heart rate were recorded with fetal heart rate and uterine contractions. In selected cases central venous pressure was monitored. In the first 401 patients, there were 5 perinatal deaths. Corrected perinatal mortality was $10 / 1,000$, below the $15.5 / 1,000$ of our general obstetrical population over the same period. There were 2 maternal deaths, both due to catastrophic hemorrhage, compared with none in the general obstetrical population. The maternal deaths were due to carotid artery laceration and ruptured spleen respectively. The favorable perinatal results in these parturients with the most serious medical, surgical, and obstetrical complications demonstrated that the OBICU is practical, and may have a favorable impact on patient care in the high risk category.

101 Effects of Magnesium Sulfate on Toxemic Patients in Labor

Bruce K. Young and Howard M. Weimtein

Department of Obstetrics-Gynecology, New York University School of Medicine, New York, N.Y.

144 toxemic patients in labor were treated with magnesium sulfate. 97 patients, including 4 eclamptics, received intermittent intravenous 'pushes' of $2 \mathrm{~g}$ every 1-2 h. 47 including 3 eclamptics, received a continuous intravenous infusion of $1 \mathrm{~g} / \mathrm{h}$. All patients had continuous electronic monitoring of maternal respiration, electrocardiogram, blood pressure, uterine contractions, and fetal heart rate. In the patients treated by i.v. push, maternal blood pressure fell briefly in $93 \%$, transient respiratory depression was seen in $79 \%$, and nausea, flushing, and occasional vomiting was often encountered. No hypotension, respiratory depression, or side effects, were seen in patients treated by continuous infusion. Neither series showed a significant inhibition of uterine contractions, or changes in maternal or fetal ECG. Intravenous magnesium sulfate should be given by continuous infusion.

Scientific Abstracts

73

102 The Variability of Uterine Blood Flow, Arterio-Venous 02 Content and 02 Consumption in Pregnant Sheep during 24 Hours Egon Lanz, Donald Caton, Helene Schlereth and Donald H. Barron Department of Obstetrics-Gynecology and Anesthesia, University of Florida, Gainesville, Fla.

Four sheep (90-140 days pregnant) were prepared with an electromagnetic flow probe around one uterine artery and with catheters in a femoral artery (A) and in both uterine veins (UV). UBF and arterial pressure were recorded continuously, A and UV-02 contents and partial pressures were measured every $4 \mathrm{~h}$.

The variations between lowest and highest values during $24 \mathrm{~h}$ were in $\%$ :

AnimalUBF A-UV C02 Q02

(140 days) $\quad 33 \quad 69 \quad 43$

(120 days) $\quad 23 \quad 43 \quad 36$


$\begin{array}{llll}\text { (105 days) } & 44 & 81 & 55 \\ \text { (90 days) } & 14 & 36 & 34\end{array}$

02 consumption was highest between midnight and 4.00. Variations of Q02 correlated primarily with A-UV C02. Data suggest there may be a diurnal pattern in the Gyconsump-tion of the pregnant uterus and its contents.

103 Fetal Brain Function, Metabolism and Neuropathology following Acute Hypoxia L.I. Mann, N. Peress, A. Bhakthavathsalan, H. Szeto and M. Liu Department of Obstetrics-Gynecology, University of Vermont College of Medicine, Burlington, Vt., and Department of Pathology, State University of New York Medical School, Stony Brook, N.Y.

Fetal brain function and metabolism were correlated with neuropathology following acute hypoxia in nine fetal sheep preparations. The brains of experimental animals and age-matched controls were perfused and fixed in situ. Fetal brain function was studied in terms of the fetal electroencephalogram (EEG) and fetal brain metabolism in terms of carotid arterial (FA) minus sagittal vein (SV) differences of blood gases and substrate. The length of hypoxia was altered by specifically prolonging the state of isoelectricity (Flat) of the fetal EEG. The isoelectric stage of the EEG appeared at a mean p02 of approximately $5 \mathrm{mmHg}(\mathrm{FA} ; 1 \mathrm{vol} \%$ ) and was always preceded by fetal bradycardia or irregularity. Brief periods of hypoxia lasting less than $11 \mathrm{~min}$ with an isoelectric stage of less than 2 min were associated with a rapid recovery of the EEG following reintroduction of oxygen and no significant neuropathology. Longer periods of hypoxia and isoelectric EEG resulted in a severe metabolic acidosis during recovery, a longer period to recovery or no recovery of the EEG, and more frequent pathologic involvement of the cerebral white matter on light and electron microscopic evaluation. Nonmyelinated fibers and poorly myelinated regions appeared more vulnerable and brain stem lesions were not observed. The neuropathology was similar to that found in human infants dying with developmental disabilities. The observations suggest that hypoxia with lactacidemia and metabolic acidosis in contrast to hypoxia without acidosis leads to irreversible brain damage.

(Supported by UCPREF and MMERF.)

Society for Gynecologic Investigation

74

104 Comparison of Cardiovascular Responses to Hypovolemia in Fetal and Immediate Neonatal Periods

B. Nuwayhid, D. Vaughn, A. Dandavino, K. Blanchard, C.R. Brinkman, III and

N.S. Assali

Department of Obstetrics-Gynecology, UCLA School of Medicine, Los Angeles, Calif.

We have previously postulated that the umbilicoplacental circulation and the vascular shunts act as 'buffering' structures which dampen fetal cardiovascular response to stressful stimuli. To test further this hypothesis, near-term fetal lambs were studied acutely under maternal phenobarbital and spinal anesthesia and chronically without anesthesia. In addition, acutely prepared fetuses were studied in the immediate neonatal period following cord clamping and lung ventilation. Blood volume (BV) was measured or estimated in all animals in addition to heart rate (HR) and arterial pressure (AP). Ascending aortic flow (QAA) was also measured in all acute preparations. Each lamb was studied during control, hemorrhagic hypovolemia, blood reinfusion and recovery periods. Results show: (1) in the acute fetal group, BV reduction of $28 \%$ to lower AP $50 \%$ in pentobarbital group, whereas in spinal group the BV reduction was $40 \%$; (2) in the chronic unanesthetized fetal group a BV reduction of $44 \%$ resulted in a $31 \%$ AP reduction; (3) in neonate $\mathrm{BV}$ reduction of $18 \%$ reduced AP $50 \%$; (4) the pattern of change in pressure and flow was 
similar in all groups; (5) bradycardia occurred in all groups but was more profound under pentobarbital. Conclusions: (1) chronic unanesthetized fetal preparations have a greater tolerance to hypovolemia;

presence and type of anesthesia effect the fetal cardiovascular response to hypovolemia; fetus tolerates a greater loss of BV than neonate; (4) fetal tolerance to blood loss is related to umbilico-placental circulation and vascular shunts.

105 Effects of One-Kidney Renal Hypertension on Uterine Hemodynamics in Pregnant Sheep C.R. Brinkman, III, J.R. Woods, jr., A. Dandavino and N.S. Assali Department of ObstetricsGynecology, UCLA School of Medicine, Los Angeles, Calif.

We have previously reported the uterine hemodynamic effects of a two-kidney model of renal hypertension in pregnant sheep, which are: (1)a prompt increase in the mean arterial pressure (MAP); (2) a transient decrease in uteroplacental blood flow (QUP) lasting 7-10 days, and (3) a significant increase in uteroplacental vascular resistance (UVR) which returns toward control levels, but remains slightly elevated for the duration of the pregnancy. This report deals with a group of pregnant sheep which were chronically instrumented for measurement of MAP and QUP at 85 gestational days. At 100 days a right renal artery flow transducer and externally adjustable constrictor implanted and a contralateral nephrec-tomy performed. Approximately 9 days later the right renal blood flow was reduced by an average of $26 \%$. Results show: (1) a prompt and significant increase in MAP of $18 \%$ which remained elevated for the next 3 weeks; (2) a steady decrease in QUP during the 3 weeks following renal artery constriction; (3) a 50\% increase in UVR by the 3rd week when compared to the week of renal surgery. Conclusions: (1) the effects of one- and two-kidney renal hypertension on MAP are similar; (2) one-kidney renal hypertension has a progressive and prolonged effect on QUP and UVR; (3) behavior of uteroplacental circulation differs in various forms of renal hypertension. Data on plasma renin activity and pregnancy outcome will also be presented.

Scientific Abstracts

75

106 Lamb Ductus Arteriosus: 02 and PGE, Ronald I. Clyman, Michael A. Heymann and Abraham M. Rudolph

CVRI and Departments of Pediatrics and Obstetrics-Gynecology, University of California, San Francisco, Calif.

It previously has been suggested that (a) delayed closure of the ductus arteriosus in premature infants is related to an ineffective constriction in response to increases of p02 and that (b) prostaglandin E, (PGE,) which relaxes the vessel in low p02 in fetal life has little effect in the raised p02 of postnatal life. However, in the experiments reported here there was no significant difference between the tension developed in oxygen of rings of lamb ductus arteriosus in vitro from immature ( $70 \pm 4$ days gestation, $n=9)$ and mature $(137 \pm 3$ days gestation, $n=11)$ fetuses incubated in a dark enclosed box. It is suggested that earlier reports of ineffective oxygen induced tension in vessels from immature animals may be related to the effects of light on this tissue. Overhead room light inhibited the tension developed in oxygen of immature vessels by 63 $\pm 10 \%(\mathrm{n}=9)$ but had no effect on that of mature vessels. In another series of experiments PGEi relaxed rings of ductus arteriosus at both low (14-20 torr) and high (680-720 torr) p02 and the ED50s of PGE, relaxation were $5.5 \pm 0.7 \times 10$ " ${ }^{\circ} \Lambda$ Í and $8.5 \pm 3.4 \times 10-10 \mathrm{M}$, respectively $(\mathrm{n}=$ 6 ). The magnitude of relaxation was greater for the oxygen contracted ductus arteriosus than for that exposed to low p02. It is suggested that earlier reports of the lack of response to PGE, in high p02 following relaxation in low p02 may be related to the loss of response of the ductus 
arteriosus to repeated doses of PGE, rather than to differences in p02. The roles of $\rho 02$ and PGE, need to be reevaluated in persistent patency of the ductus arteriosus of premature infants.

107 Vascular Compliance in the Maternal Rabbit Placenta

Raymond D. Gilbert, Gwendolyn L. Brownfield and Gordon G. Power Loma Linda University School of Medicine, Loma Linda, Calif.

We studied compliance on the maternal side of the placenta in 20 New Zealand white rabbits, using slCr and 125I labels to determine erythrocyte, plasma and whole blood volumes per $\mathrm{g}$ placental tissue under varying maternal pressure conditions. At normal maternal arterial $(\mathrm{Pa})$ and venous $(\mathrm{Pv})$ pressures of 71.8 and $5.5 \mathrm{~mm} \mathrm{Hg}$, placental blood volume was $0.453( \pm 0.051$ $\mathrm{SEM}) \mathrm{ml} / \mathrm{g}$ placental tissue. When venous pressure was raised $(\mathrm{Pa}=45.5, \mathrm{Pv}=12.2)$ by clamping the IVC, blood volume increased to $0.706( \pm 0.066) \mathrm{ml} / \mathrm{g}$, a significant $56 \%$ rise. However, when pressure was lowered by clamping the aorta in two steps, dropping to $\mathrm{Pa}=33.8$, $\mathrm{Pv}=7.0$ and $\mathrm{Pa}=13.5, \mathrm{Pv}=5.4$, volume did not decrease significantly. We calculated intervillous space pressure from arterial and venous pressures assuming a ratio of arterial to venous resistance of 9:1. Over the intervillous space pressure range from normal to high, placental compliance was $0.068 \mathrm{ml} / \mathrm{mm} \mathrm{Hg} / \mathrm{g}$. Maternal placental hematocrit averaged $30 \%$, appreciably less than the circulating hematocrit of $41 \%$, indicating that erythrocytes transit the placenta faster than plasma. Overall, the results suggest that maternal volume and its placental oxygen reserve would be maintained during hypotension and would increase when venous pressure is elevated.

(Supported by HL 15655 and HD 10029.)

Society for Gynecologic Investigation

76

108 Magnesium Sulfate Metabolic Effects in Mother and Infant

DwightP. Cruikshank, Roy M. Pitkin, W. Ann Reynolds, Gerald A. Williams and Gary K. Hargis Department of Obstetrics-Gynecology, University of Iowa College of Medicine, Iowa City, Iowa, and Departments of Anatomy and Medicine, University of Illinois College of Medicine, Chicago, 111.

Magnesium $(\mathrm{Mg})$, total calcium $(\mathrm{Ca})$, ionized calcium $(\mathrm{Ca}++)$, phosphorus $(\mathrm{P})$, parathyroid hormone (PTH), and calcitonin (CT) were measured in (1) serial maternal blood samples, (2) umbilical arterial (UA) and umbilical venous (UV) blood at delivery, and (3) capillary blood from the newborn. Subjects included pre-eclamptic gravidas treated with intravenous MgS04 infusions, and controls (both normotensive and hypertensive) infused with dextrose-water solutions. Maternal: MgS04 infusion raised maternal Mg levels by $82-135 \%$ and lowered maternal $\mathrm{Ca}$ and $\mathrm{Ca}++$ by $9-25 \%$. That more marked hypocalcemia did not occur probably reflected increasing maternal PTH secretion which averaged $62 \%$ above baseline. CT did not change significantly in either treated or control subjects. Delivery: Mean $\mathrm{Mg}$ levels at delivery in treated (and control) subjects were $3.05(1.27) \mathrm{mEq} /$ liter in maternal serum, 2.64 (1.43) in UA, and 2.71 (1.45) in UV; thus, MgS04 treatment did not raise fetal Mg levels to the same degree as maternal, resulting in a reversal of the placental gradient (maternal-fetal ratio 0.88 in controls and 1.12-1.22 in treated subjects), and indicating a partial 'protective' action of the placenta against fetal hyper-magnesemia. UA and UV Ca++ levels were 7 and $10 \%$, respectively, lower in treated than in control subjects. Newborn: Elevated $\mathrm{Mg}$ and lowered Ca persisted for at least $48 \mathrm{~h}$ (e.g., at $24 \mathrm{~h} \mathrm{Mg}$ was 58\% higher and $\mathrm{Ca} 5 \%$ lower in treated than in controls). Conclusion: MgS04 treatment influences calcium metabolism in mother, fetus, and newborn, but adverse effects are minimized by adjustments involving principally PTH. 
109 Incomplete Surfactant Phospholipid Complex Formation: Absence of Phosphatidylglycerol M. Douglas Cunningham, John W. Greene, jr. and John L. Duhring Department of Pediatrics and Obstetrics-Gynecology, University of Kentucky, College of Medicine, Lexington, Ky.

Fetal formation of surface-active pulmonary phospholipids (PPL) was studied in amniotic fluid of 73 high-risk pregnancies: 49 diabetic, 18 normal-repeat cesarean section, $8 \mathrm{Rh}$ sensitized, and 8 hypertensive. Individual PPL were separated and identified by TLC and reflectance densitometry. Mean L/S ratios for all groups exceeded 2 between 35 and 36 weeks of gestation. One or more PPL were absent in 35 of 100 specimens: phosphatidyl-dimethylethanolamine, 4/35; phosphatidylinositol, 2/35; phosphatidylserine, 1/35, and phosphatidylglycerol (PG), 32/35. PG concentration in remaining specimens was $10.4 \%$ of total amniotic fluid PPL from 33 to 38 weeks, increasing to $14.5 \%$ through 40 weeks. PG was absent from $48 \%$ of specimens assayed during the L/S ratio transitional period of 34 to 37 weeks. Diabetic pregnancies comprised $67 \%$ of the study and $78 \%(25 / 32)$ of PG deficiencies in the transitional period. Rh-sensitized pregnancies accounted for $8 \%$ of the study, and 19\% of PG deficiencies. Six of 10 Rh-sensitized specimens assayed in the transitional period were without PG. Nine instances of transient neonatal respiratory distress occurred in the study: no PG was detected in 6/9. All cases were diabetic and delivered in the transitional period with $\mathrm{L} / \mathrm{S}$ ratios of 2 or greater. $\mathrm{PG}$ may be an adjunctive index to fetal lung maturation in diabetic and Rh-sensitized pregnancies.

Scientific Abstracts

77

110 Perinatal Effect of Fetoscopy and Fetoplacental Blood Sampling in the Rhesus Monkey Ezra C. Davidson, jr., John Anderson, Andrew G. Hendrickx and John A. Morris Department of Obstetrics-Gynecology, Charles R. Drew Postgraduate Medical School, Los Angeles, Calif., and California Primate Research Center, University of California at Davis, Davis, Calif.

This is the first phase evaluation of the long-term perinatal effect of fetoscopy/ fetoplacental blood sampling in the subhuman primate. Two prior study groups of pregnant ovines used to select endoscopy devices, refine surgical approach and collect blood samples formed the basis for this current protocol. Despite technical advances in the ovine, there was a disturbing $36 \%$ and $39 \%$ uncorrected fetal loss, respectively. Present studies subject 15 pregnant rhesus monkeys to a scheduled dual endoscopy approach - laparoscopy and fetoscopy - with sampling. Laparoscopy affords preselection of the uterine puncture site under direct vision to minimize injury and hemorrhage in the monkey with its characteristic bidiscoid placenta which in part occupies the anterior uterus. The 'free space' between the placental discs arching over the uterine fundus between the utero-tubal junctures provide the puncture site. A $2.7 \mathrm{~mm}$ O.D. Stortz Hopkins rodlens fibre-optic endoscope contained in a $3.1 \mathrm{~mm}$ O.D. rigid cannula with a $25 \mathrm{~g}$ sampling needle was introduced. Dissociative Ketamine and light endotracheal halothane anesthesia with aseptic surgical preparation, precede conventional development of pneumoperitoneum and laparoscopy. The discussion will include photo documentation of the procedure with description of its advantages. Preliminary conclusions: (a) fetoscopy/sampling is feasible in anterior placentation with current devices when the puncture site can be preselected; (b) fetal loss is an unlikely event; (c) no adverse effects on neonate, and (d) the prospects for human application are favorable.

111 Effect of Placental Lactogen (PL) on Maternal and Fetal Carbohydrate Availability Peggy J. Rapoport, Yoshio Miyazaki, David L. Bolam, Hobart E. Wiltse and Charles L. Paxson, jr.

Department of Pediatrics and Physiology, University of Nebraska Medical Center, Omaha, Nebr. 
The current concept of the role of PL during human gestation is that it inhibits peripheral maternal carbohydrate utilization and thereby ensures adequate carbohydrate for use as a fetal fuel. To test this concept we have chronically prepared 5 pregnant ewes of 90-120 days gestation and following baseline studies infused PL into the maternal circulation. Surgical preparation consisted of implantation of bilateral uterine and femoral artery electromagnetic flow transducers, bilateral uterine, femoral, jugular vein catheters, and femoral and cystic artery catheters. Following a minimum 4-day recovery period and during optimum maternal nutrition, PL was infused at a constant rate and whole blood samples for glucose analysis were drawn at 14-hour intervals. Peripheral maternal glucose uptake as measured via hind limb uptake, and uterine glucose uptake were calculated by the Fick equation. A total of 34 infusion studies was completed.

The infusions produced no consistent alterations in maternal glucose levels, uterine blood flow or peripheral blood flow. Samples obtained at the hourly intervals revealed a $40 \%$ increase in uterine glucose uptake (p \&lt; 0.005), and peripheral glucose uptake decreased

Society for Gynecologic Investigation

78

by approximately $35 \%$ (p \&lt; 0.01 ). We conclude that PL inhibits peripheral maternal glucose uptake and concomitantly increases uterine glucose uptake. The conclusions support the current concept of the role of PL, however the exact mechanisms involved remain to be elucidated. 112 Cervical Dilatation Patterns in Spontaneous and Induced Labor Henk C.S. Wallenburg, Frans Th. Kok and Juriy W. Wladimiroff Department of Obstetrics-Gynecology, Erasmus Universiteit, AZR-Dijkzigt, Rotterdam

The development of an ultrasonic cervimeter has created the possibility to continuously monitor cervical dilatation during the first stage of labor (Am. J. Obstet. Gynec. 726.' 288, 1976). By means of this method cervical dilatation patterns were recorded in 37 primigravidas (group I) in clinically normal spontaneous (12) or oxytocin-induced (25) labor, and in 28 multigravidas (group II) in spontaneous (12) or induced (16) labor. In-trauterine pressure was simultaneously measured. Signals were stored on magnetic tape, sampled by an LPS/AD 12 analog/digital converter at $1-\mathrm{sec}$ intervals, and the resulting tape was read into a PDP 11/10 computer, programmed to supply all previously defined parameters of both signals. It was found that (1) no differences could be demonstrated between cervical dilatation patterns in spontaneous and induced labor; (2) significant acceleration of cervical dilatation occurred at a mean dilatation of 5.0 (range 4.2-6.1) $\mathrm{cm}$ in group I and at 3.3 (range 2.2-4.6) $\mathrm{cm}$ in group II; (3) mean speed of cervical dilatation $(\mathrm{cm} / \mathrm{h})$ before acceleration was 0.5 in group I and 0.4 in group II, whereas after acceleration it was 2.7 (group I) and 3.7 (group II); (4) in group I the mean active pressure area $\times 10 \sim 3 / \mathrm{cm}$ of dilatation was 77.5 before the acceleration point was reached and 26.0 thereafter; values in group II were 48.6 and 23.0, respectively; (5) the observed increase in magnitude of cervical excursions in response to uterine contractions (effectivity) was less pronounced in group I than in group II. The data indicate that cervical dilatation depends less on uterine activity than on intrinsic qualities of the cervix itself.

113 Amniotic Fluid Fatty Acid Side Chain Analysis for Assessment of Fetal Lung Maturation George O’Neil, I. John Davies, Julie Siu and Kenneth J. Ryan Harvard Medical School, Boston Hospital for Women, Laboratory of Human Reproduction and Reproductive Biology, Department of Obstetrics-Gynecology, Boston, Mass.

Amniotic fluid (AF) lecithin fatty acid side chain analysis has been performed on AF samples from 150 pregnant patients. The lipid extract of AF was subjected to thin layer chromatography 
and the lecithin fraction was analyzed by gas liquid chromatography. The palmitic/stearic ratio $(\mathrm{P} / \mathrm{S})$ was utilized as an indirect measurement of the amount of dipalmitoyl lecithin present relative to other lecithins in the AF. Of the 150 patients studied, there were 33 cases in which samples were obtained within $72 \mathrm{~h}$ of delivery of the infant which will be considered here. Sixteen of these patients were insulin-dependent diabetics and 17 were nondiabetic.

Of the 17 infants of nondiabetic mothers, 6 developed the respiratory distress syndrome (RDS). The mean $\mathrm{P} / \mathrm{S}$ ratio in the RDS AF was $3.75 \pm 1.2$ (SD) while the mean value of the non-RDS $\mathrm{AF}$ was $11.4 \pm 4.7$ (SD), (p \&lt; 0.001). Of the 11 patients with $\mathrm{P} / \mathrm{S}$ ratios of Scientific Abstracts

79

5 or greater, only one developed RDS (P/S 5.2). Of the 6 patients with values less than 5 , all except one developed RDS (P/S 4.3).

Of the 16 infants of diabetic mothers, 6 developed RDS. The mean P/S ratio of the diabetic RDS AF was $5.5 \pm 1.7$ (SD) while the mean P/S ratio of the diabetic non-RDS AF was $12.7 \pm 5.2$ (SD), (p \&lt; 0.003). Of the 9 patients with values of 9 or greater, none of the infants developed RDS. Of the 7 patients with values less than 9, all except one developed RDS (P/S 4.3).

These initial results suggest that AF lecithin fatty acid side chain analysis may be a useful method for assessment of fetal lung maturation.

114 Effect of the Combination of Vascular Restriction and Maternal Hypoxia on Fetal Brain Development in the Rabbit

Edward J. Quilligan and Mary J. Donahue

Department of Obstetrics-Gynecology, University of Southern California School of

Medicine, Los Angeles, Calif.

The model utilized is a pregnant rabbit. At 26-27 days a laparotomy is performed. The fetuses are identified and 1 of the 3-4 vessels of every other fetus in both horns omiting the fetus closest to the ovary is ligated. The nonligated fetuses have 1 drop of Evans blue injected subcutaneously. The laparotomy incision is closed and the mother allowed to recover. She is placed in a 10\% oxygen environment for $3 \mathrm{~h}$ on days 27, 28 and 29. At birth fetuses are weighed and half the litter sacrificed. The cerebrum and cerebellum are quick frozen and later analyzed for protein, DNA and RNA by a modified Lowrey method for protein, Burton's assay for DNA and Orcinol assay for RNA. The other half of the litter is allowed to live for 2 months and then sacrificed for similar cerebellar and cerebral studies. Suitable nonoperated and nonexposed to low oxygen controls have been studied. In a few animals exposed to low oxygen a catheter was placed in the uterine vein to demonstrate a decreased 02 environment for the fetus. Results of protein, DNA and RNA contents will be presented.

115 Calcitonin Secretion in Response to Hypercalcemia in the Fetal Monkey

W. Ann Reynolds, R.M. Pitkin, A.F. Bauman, G.A. Williams and G.K. Hargis Departments of Anatomy and Medicine, University of Illinois College of Medicine and West Side VA Hospital, Chicago, 111., and Department of Obstetrics-Gynecology, University of Iowa College of Medicine, Iowa City, Iowa

The capacity of the fetus to cope with excess calcium loads by releasing calcitonin (CT) was studied in the last trimester of pregnancy in the macaque. Calcium gluconate $(12-30 \mathrm{mg} / \mathrm{kg})$ was infused into a maternal vein or directly into a fetal interplacental vein over a 2 -hour interval. Total calcium was measured by autoanalyzer and CT by radioim-munoassay in both fetal and maternal plasmae over the ensuing $4 \mathrm{~h}$. 
Within 15 min after direct infusion of calcium into the fetus or mother, CT began to rise and reached levels of $46-78 \%$ above baseline by the end of the infusion. Maternal infusion of calcium resulted in but modest increases in fetal serum calcium levels (11-22\%) and in appropriately lesser elevations in fetal CT levels (15-46\%). Baseline values of CT were similar in mother $(0.28 \pm 0.04 \mathrm{ng} / \mathrm{ml})$ and fetus $(0.33 \pm 0.04 \mathrm{ng} / \mathrm{ml})$ as were the extents and patterns of release of CT in response to hypercalcemia.

Society for Gynecologic Investigation

80

Fetal CT response was also examined by infusion of glucagon $(1 \mathrm{OO} \mu \mathrm{g} / \mathrm{kg})$, a CT secretagogue, directly into the fetal circulation for $1 \mathrm{~h}$. An attenuated response was noted reaching levels $43-$ $47 \%$ above baseline values some $2 \mathrm{~h}$ after the end of the infusion. Thus, the primate fetus is capable of responding to either hypercalcemia or glucagon by the release of immunoreactive calcitonin.

(Supported by NIH grant HD-09373-01.)

116 Concentrations of Metanephrine in Amniotic Fluid

Raul Artal, Calvin J. Hobel, Robert W. Lam and Delbert A. Fisher UCLA School of Medicine, Harbor General Hospital, Department of Obstetrics-Gynecology and Pediatrics, Torrance, Calif. Catecholamine secretion is known to increase with stress and aging. Thus a practical method to determine catecholamines in amniotic fluid might prove useful in assessing the fetoplacental unit and/or the relative maturity of the fetus. Concentrations of metanephrine in amniotic fluids from pregnancies differing in gestation age and associated conditions have been measured using a newly developed specific radioimmunoassay.

Metanephrine, a major metabolite of epinephrine, was found in the free and conjugated form. Results available to date in 37 pregnancies (mean values $\mathrm{pg} / \mathrm{ml}$, and the free/total metanephrine ratios) were as follows:

The results indicate: (a) a positive correlation of amniotic fluid metanephrine concentrations with gestational age, and (b) an increase in amniotic fluid metanephrine concentration during labor at term.

117 Steroid Changes during the Menstrual Cycle of the Baboon and Human: a Model for Corpus luteum Function OR. KlingandP.K. Westfahl

Department of Obstetrics-Gynecology, University of Oklahoma College of Medicine, Oklahoma City, Okla.

Estrone (E), estradiol (E2), testosterone (T), dihydrotestosterone (DHT), andros-tenedione (A) and progesterone $(\mathrm{P})$ were simultaneously measured by radioimmunoassay following celite chromatography during a complete menstrual cycle in the peripheral serum of 5 baboons (Papio cynocephalusj and 5 humans. A similarity in hormonal patterns during the cycle was observed between the two species. An analysis of variance using the log normal distribution of all steroid measurements verifies significant variation between individual cycle days for all steroids measured in each species except for DHT. No significant difference between human and baboon at $\mathrm{p} \& \mathrm{gt} ; 0.05$ were noted during the midfol-

Scientific Abstracts

81

licular, periovulatory or midluteal phases of the cycle for E, E2, T and P. The level of A in the baboon rose during the periovulatory phase but remained significantly lower than the human at midcycle while no significant difference was observed during the foUicular or luteal phase. A 
noncyclic secretory pattern for DHT was observed in both the human and baboon, with the mean serum level significantly higher in the baboon $74.3 \pm 19.2 \mathrm{ng} \%$ than in the human $48.7 \pm 14.9$ $\mathrm{ng} \%$ (p \&lt; 0.001, mean $\pm \mathrm{SD}$ ). Contrary to a previous report (Goncharov et al.: Acta endocr. 82: 396, 1976) we observed a midcycle rise in T, a secondary rise in Et and E2 during the luteal phase and did not find a significant rise in A during the luteal phase of either the human or baboon. We propose the baboon is an appropriate model for studying corpus luteum regulation of implantation and gestation.

118 Serum Calcitonin Levels before and after Pentagastrin Stimulation in Rhesus Monkeysduring Pregnancy, Lactation, Infancy, Early Childhood, and Adulthood N.A. Samaan and G.L. Raulston

Departments of Medicine and Experimental Animals, The University of Texas System Cancer Center, M.D. Anderson Hospital and Tumor Institute, Houston, Tex.

We have previously reported that the immunoreactive serum calcitonin (iCT) in man is elevated in the neonate and pregnant mother at basal level compared to that found in normal nonpregnant subjects. We have also shown that the serum iCT concentration is high in early life but diminished with age (Am. J. Obstet. Gynec. 121: 622-625, 1975).

Because of the ethical considerations of intravenous (i.v.) pentagastrin administration in pregnant mothers, infants, and children, we measured the iCT concentration in the serum of Rhesus monkeys at basal and after pentagastrin stimulation. We studied 5 pregnant, 6 nursing mothers, 6 nursing infants, and 6 juveniles, and the results were compared to that found in 6 adult unbred females and 4 adult males.

Intravenous pentagastrin administration produced a significant rise of the serum iCT in all groups of monkeys studied. The serum iCT concentration was significantly high at basal and after pentagastrin stimulation in pregnant mothers, infants, and juveniles compared with adult nonpregnant monkeys ( $\mathrm{p} \& 1 \mathrm{l} ; 0.05$ or less). The lactating mothers had a higher mean level of serum iCT but this was not significantly different from nonpregnant adults ( \&lt; $p$ \&lt; 0.1). These results extend our observation in man and suggest that calcitonin may play an important role in the calcium metabolism during pregnancy, infancy, and childhood.

119 Correlation between Ovulation as Determined by Corpus luteum (CL) Biopsy andSerum Levels of Gonadotrophins and Steroids in Women

Stephen P. Boyers, John R. Marshall, Manuel Maqueo, Guy E. Abraham and Salim Abu-Fadil

Department of Obstetrics-Gynecology, Harbor General Hospital, UCLA School of Medicine, Torrance, Calif,

Periovulatory serum levels of LH, FSH, estradiol-17(3 (E2), estrone (Ei), progesterone (P), 17 $\alpha$ hydroxyprogesterone (17P), and androstenedione (A) were measured by radioim-munoassay in sera collected serially every $8 \mathrm{~h}$ for 6 days from 6 normally ovulating women. On the estimated day of ovulation the ovaries were examined and photographed at laparoto-my. Fresh CL or preovulatory follicles were excised. CL dating established ovulation time $\pm 12-24 \mathrm{~h}$. All subjects had discrete, coincident LH and FSH peaks. Data from one subject are inconsistent with present concepts of normal ovulation. Three subjects were postovula-tory at surgeries 38,52 , and $84 \mathrm{~h}$ after their respective LH peaks. In two with very early

Society for Gynecologic Investigation

82

(12-24 h) CL for which histologic dating is most precise, LH peaked 14-26 and 29-41 h and E2 peaked 22-34 and 58-70 h prior to ovulation. E2 peaked 8 and $29 \mathrm{~h}$ before LH. 17P peaked 8 
and $16 \mathrm{~h}$ after $\mathrm{LH}$ and $6-18$ and $13-25 \mathrm{~h}$ before ovulation. In the third the CL was $24-48 \mathrm{~h}$ old and LH and E2 peaked 37-61 and 99-123 h, respectively before ovulation. 17P peaked $13 \mathrm{~h}$ before LH and 50-74 h before ovulation. Two subjects, operated 12 and $5 \mathrm{~h}$ before their LH peaks, had not ovulated. In both, E2 peaked $11 \mathrm{~h}$ before surgery. In all subjects, E, essentially mirrored E2 and A did not vary relative to ovulation. Five additional subjects are presently under study. Regression analysis is in progress and will additionally correlate time of first significant rise and ovulation.

(Supported by WHO grant H9/181/81 (Q) and an ACOG-ORTHO Academic Training Fellowship.)

120 Inhibition of Rat Pituitary Prolactin Release during Perfusion of Pituitary GlandExplants Howard A. Zacur, Giraud V. Foster, John E. Tyson and William E. Mitch Departments of Obstetrics-Gynecology, Medicine, and Physiology, The Johns Hopkins University School of Medicine, Baltimore, Md.

A new system using in vitro perfusion of explanted rat pituitary glands has been developed in order to study factors regulating the secretion of rat pituitary prolactin (rPRL). The technique employs the transplantation of two female rat pituitary glands beneath the kidney capsule of a third female. 3 weeks following pituitary transplantation, the kidney containing the explant is removed and perfused in a closed system with an oxygenated solution of Krebs bicarbonate buffer containing albumin. Aliquots from the solution are obtained at frequent intervals during the 2-hour perfusion and frozen until assayed for rPRL by radioimmunoassay. Utilizing this system, rPRL concentrations in the perfusate progressively increased from 0 to $70.4 \pm 8.0 \mathrm{ng} / \mathrm{ml}$ by $120 \mathrm{~min}(\mathrm{n}=11)$. Various substances were then added to the perfusate to test their ability to affect prolactin secretion. Addition of haloperidol $(100 \mathrm{ng} / \mathrm{ml})$, a specific dopamine receptor blocker, did not significantly change either the rate of rPRL release or amount of rPRL released by $120 \mathrm{~min}$. Addition of Bromocryptine (BR-C), $20 \mathrm{ng} / \mathrm{ml}$, after $15 \mathrm{~min}$ of perfusion prevented any subsequent increase in rPRL concentration so that at 120 min the mean rPRL concentration was $17.0 \pm 2.5 \mathrm{ng} / \mathrm{ml}$ (p \&lt; 0.001). When added to the perfusate prior to BR-C, haloperidol successfully blocked the ability of BR-C to inhibit further rPRL release. These results are consistent with the hypothesis that inhibition of prolactin secretion by BR-C is at the site of dopamine receptors in the pituitary gland.

121 The Effect of Total Hypophysectomy on Peripheral Luteinizing HormoneReleasingHormone Levels (LHRH) in Human Subjects

Bernard Cantor, Satya P. Kalra, Pushpa S. Kalra and Jack Maniscalco Departments of Obstetrics-Gynecology and Neurosurgery, University of Florida College of Medicine, Gainesville, Fla.

Three females and two males underwent transphenoidal total hypophysectomy for treatment of metastatic cancer. Circulating levels of LH, FSH, E2, testosterone and LHRH were determined by radioimmunoassay prior to surgery, every $6 \mathrm{~h}$ for $24 \mathrm{~h}$ and every $12 \mathrm{~h}$ for $96 \mathrm{~h}$ after surgery. All had extremely low or nondetectable levels of circulating testosterone and/or estradiol, although one female and two males received hormonal therapy up to 3 days prior to surgery. Preoperative plasma LH $($ mean $=82.8 \mathrm{mlU} / \mathrm{ml})$ and $\mathrm{FSH}($ mean $=$ Scientific Abstracts

83

$83.7 \mathrm{mlU} / \mathrm{ml}$ ) declined precipitously following hypophysectomy in the females to a mean LH of $23.2 \mathrm{mlU} / \mathrm{ml}$ at $6 \mathrm{~h}$ and a mean $\mathrm{FSH}$ of $27.9 \mathrm{mlU} / \mathrm{ml}$ at $24 \mathrm{~h}$. At $120 \mathrm{~h}$ post hypophysectomy, mean LH and FSH were 9.5 and $12.5 \mathrm{mlU} / \mathrm{ml}$, respectively. In comparison, male preoperative 
levels were low (mean $\mathrm{LH}=5.6 \mathrm{mlU} / \mathrm{ml}$; mean $\mathrm{FSH}=1.8 \mathrm{mlU} / \mathrm{ml}$ ) and fluctuated at barely detectable levels throughout the postoperative period. Mean preoperative plasma LHRH (methanol extracted) was $5.78 \mathrm{pg} / \mathrm{ml}$. At $36 \mathrm{~h}$, plasma LHRH was significantly $(\mathrm{p}=\& 1 \mathrm{t} ; 0.05)$ elevated $($ mean $=8.67 \mathrm{pg} / \mathrm{ml}$ ) and at $96 \mathrm{~h}$ was $11.12 \mathrm{pg} / \mathrm{ml}$ when the entire group was examined. The rise in plasma LHRH activity appeared temporally related to marked declines in the level of plasma LH. The data indicate persistence of LH and FSH activity at low levels 5 days after 'total' hypophysectomy and provides evidence for the existence of a regulatory influence of pituitary LH on LHRH secretion.

122 Ethinyl Estradiol (EE) Administration and Plasma Steroid Concentrations inOvariectomized Women

Damodar K. Mahajan, Reinhart B. Billiar, Majida Jassani and A. Brian Little Department of Reproductive Biology, Case Western Reserve University, Cleveland, Ohio

The administration of estrogens to women might result in an altered adrenal steroid hormone pattern by a direct affect on the adrenal, by increasing the plasma concentration of transcortin or by affecting tissue metabolism of the steroids. Changes in liver metabolism (a major site of steroid metabolism) might be especially important since the administration of estrogens may result in the development of hepatomas. Ovariectomized women were studied before (I), during -3 days (II) and 3 weeks (III) - and 3 weeks after (IV) the oral administration of $0.2 \mathrm{mg} \mathrm{EE} /$ day. Plasma concentrations of F, corticosterone (B), 11-deoxy-corticosterone (DOC), testosterone (T), dehydroepiandrosterone plus its sulfate (DHEA) and $\mathrm{P}$ were measured by the double antibody RIA method (androstenedione and estrone, in progress). Plasma F increased from $3.3 \pm 0.7$ (I) to $8.2 \pm 1.5 \mu \mathrm{g} / 100 \mathrm{ml}$ at II, $17 \pm 1.2$ at III and remained elevated $5.2 \pm 0.6 \mu \mathrm{g} / 100 \mathrm{ml}$ at IV. Plasma $B$ also increased with EE administration: $135 \pm 47 \mathrm{ng} / 100$ (I), $208 \pm 72$ (II), $243 \pm 19$ (III) and back to $138 \pm 47$ (IV). Although the plasma DHA values changed from $224 \pm 28 \mu \mathrm{g} / 100 \mathrm{ml}$ (I) to $272 \pm 39$ (II) to $191 \pm 23$ (III) and back to $213 \pm 25$ (IV), the differences were not statistically significant. Plasma DOC, P and T did not change. The production rate (MCR X concentration) of $\mathrm{F}$ was significantly higher during estrogen administration and remained significantly higher 3 weeks after discontinuing EE. The results indicate that whereas the major effect of EE treatment is to increase plasma binding of $\mathrm{F}$ and $\mathrm{B}$, it may also increase the adrenal secretion of cortisol and alter the metabolism of cortisol.

123 ACTH Is Trophic to the Fetal Zone of the Fetal Adrenal (Macaca mulattojI. John Davies, Koji Yoshinaga, Kurt Benirschke and Kenneth J. RyanHarvard Medical School, Boston Hospital for Women, Laboratory of HumanReproduction and Reproductive Biology, Department of Obstetrics-Gynecology, Boston, Mass., and University of California at San Diego, Medical School, Departmentof Pathology, San Diego, Calif.

The authors previously reported that the administration of dexamethasone (Dex-Rxd) to pregnant monkeys resulted in atrophy of the fetal zone of the fetal adrenal. While this was interpreted as evidence for trophic support of the fetal zone by ACTH, a mechanism other than suppression of ACTH secretion could not be excluded. In the present experiments, pregnant monkeys were Dex-Rxd according to the previous regimen $(8 \mathrm{mg} /$ day i.m.

Society for Gynecologic Investigation

84

from day 150 until parturition), and, in addition, ACTH was injected transabdominally into a fetal limb (20 IU 3 times each week). The fetuses were delivered near term by cesarean section. The mean weight of the fetuses did not differ from that of Dex-Rxd or untreated controls. The combined weight of the adrenals in untreated controls $(n=5)$ was $798 \pm 221(\mathrm{SD}) \mathrm{mg}$, and in 
Dex-Rxd animals $(\mathrm{n}=5)$ it was reduced by $60 \%, 310 \pm 195(\mathrm{SD}) \mathrm{mg}$ (p \&lt; 0.02). The fetuses which were Rxd with ACTH in addition to maternal Dex $(n=3)$ had adrenal weights of 774 , 1,133 , and 1,148 , mean $1,018 \pm 212(\mathrm{SD})$. This is greater than that of the Dex-Rxd animals (p \&lt; 0.007), and also greater than that of untreated controls ( $p$ \&lt; 0.01) Histology confirmed that ACTH prevented regression of the fetal zone in the Dex-Rxd monkeys. We conclude that ACTH is trophic to the fetal zone of the fetal adrenal in the rhesus monkey.

124 Comparison of Unconjugated and Total Plasma with 24-Hour Urinary Estriols in theManagement of the Pregnant Diabetic

Steven G. Gabbe, Wolfgang Distler, Roger K. Freeman, Jorge H. Mestman and Uwe Goebelsmann

Department of Obstetrics-Gynecology, University of Southern California School of Medicine and Los Angeles County-University of Southern California Medical Center, Los Angeles, Calif. 62 consecutive diabetic women (class A:7, B:41, C:6, D:5, F:3), hospitalized from 1 to 8 weeks prior to delivery who volunteered for daily plasma estriol (E3) assays were included in this prospective and blinded evaluation of unconjugated (UPE3) and total plasma E3 (TPE3) assays in the management of diabetic pregnancies. Some 1,100 simultaneous UPE3, TPE3, 24-hour urinary E3 (UE3) and creatinine (C) assays were performed on an almost daily schedule. Clinical management was based upon a weekly oxytocin challenge test and daily 24-hour UE3 and C determinations. 20 patients had spontaneous onset of labor and 34 were delivered electively at 38 weeks, while 3 were delivered for maternal and 5 for fetal indications. Gestational age at delivery averaged 38 and ranged from 35 to 42 weeks. A total of 840 day-to-day variations of UPE3, TPE3, UE3 and the UE3/C ratio were computed as percent rise or fall from the highest mean of 3 consecutive preceding values. Observed were 370, 419 and 428 decreases in UPE3, TPE3 and UE3/C, respectively, averaging $12.8 \pm 9.6(\mathrm{SD}), 13.4 \pm 10.1$ and $14.4 \pm 10.6 \%$. One perinatal death occurred, a stillbirth, which was preceded by a $42 \%$ decrease in UPE3, but unheralded by either a drop in TPE3, UE3, or UE3/C. There were fewer significant ( \&gt; 40\%) falls unassociated with perinatal morbidity and mortality with UPE3 $(n=3)$ than with TPE3 $(n=$ $8)$ and UE3/C $(n=8)$. These data indicate that UPE3 is the most predictive test among presently available E3 assays for managing the pregnant diabetic.

(Supported by NICHD grant 05932.)

125 Secretion of HCG-/3 in Seminal Plasma of Normal MalesHans D. Taubert and Jeanne S.E. Dericks-Tan

Department of Obstetrics-Gynecology, J.W. Goethe University School of Medicine, Frankfurt am Main

Recent evidence supports the view that HCG-like material is produced in the nonneoplastic human testis (Braunstein et at: New Engl. J. Med. 293: 1339, 1975). As considerably higher levels of LH as compared to FSH have been found to occur in human Scientific Abstracts

85

seminal plasma \{Sheth et al: Fertil. Steril. 27: 933, 1976), we investigated whether or not this discrepancy might be due to a cross-reaction between LH and HCG. The concentrations of LH, $\mathrm{FSH}$, and prolactin were determined by RIA in the seminal plasma and serum of 53 normal males. No significant difference between prolactin levels in serum and seminal plasma were found, but FSH was invariably lower $(0.87 \pm 0.40$ vs. $2.14 \pm 1.4 \mathrm{ng} / \mathrm{ml})$ and LH higher $(4.0 \pm$ 0.93 vs. $1.95 \pm 0.83 \mathrm{ng} / \mathrm{ml}$ ) in semen as compared to serum. Consequently, we measured HCG-0 by a homogenous RIA supplied by NIA-MDD. The standard curve for HCG-0 was found to be 
parallel to that obtained by diluting a pool of seminal plasma. Accordingly, the concentration of HCG-0 in seminal plasma of 14 fertile male volunteers was significantly higher in serum $(3.2 \pm$ 1.1 vs. $1.6 \pm 0.5 \mathrm{ng} / \mathrm{ml}$ ). It is concluded that the actual LH level in seminal plasma is lower than in serum, and that the HCG-like material identified in testis homogenate is also secreted in semen.

126 Organ Culture of a Gonadoblastoma from a Patient with Secondary Amenorrhea Isadore G. Ances, Chik-Kwun Tang, Alen H. Reese and Abram B. Fajer Departments of Obstetrics-Gynecology, Pathology and Physiology, School of Medicine, University of Maryland, Baltimore, Md.

A 16-year-old patient was evaluated for secondary amenorrhea and found to have full Mullerian structures and to be 46XY karyogram. Exploratory laparotomy revealed bilateral

gonadoblastoma containing ovarian stroma, Leydig cells, sustentacular granulosa and germ cells similar to those found in disgerminoma.

Samples weighing $200 \mathrm{mg}$ divided in small pieces were cultured in plastic organ culture dishes in Medium 199 plus 20\% fetal calf serum under air and 5\% C02. The medium was changed on day 2, 6 and 9 and frozen until radioimmunoassay determinations of progesterone, estrogens and androgens were performed.

The tissue from both sides produced steroids. Progesterone was secreted in similar amounts bilaterally until day 6 when the left side exceeded the right side $(114.4 \pm 2.8$ to $32.4 \pm 1.7 \mathrm{ng} / 200$ $\mathrm{mg}$ tissue). This difference was markedly accentuated by the addition of luteinizing hormone. A similar pattern was observed with estrogens. Estradiol-17-/3 secretion from the left side rose earlier than that of progesterone - day 2, left side $21.7 \pm 0.8$ to right side $4.5 \pm 0.6 \mathrm{ng} / 200 \mathrm{mg}$ tissue - but was not affected by luteinizing hormone.

127 The Pharmacokinetics of Diethylstilbestrol in the Pregnant Rat

Richard K. Miller, Mary E. Heckmann and Kathleen A. Reich

Departments of Obstetrics-Gynecology and Pharmacology-Toxicology, The Perinatal

Center, University of Rochester, Rochester, N.Y.

Can the prenatal environment, especially placental transport function, contribute to the increased susceptibility of the progeny to tumor induction following the maternal administration of diethylstilbestrol (DES)? Placental transfer studies in the 20-day pregnant Wistar rat were performed using femoral vein infusions or fetal injections of 14C- or 3H-DES. After $3 \mathrm{~h}$ of infusion, the maternal plasma levels of radioactivity $(\mathrm{C}-\mathrm{H})$ were constant, and the fetal to maternal plasma ratio for the $\mathrm{C}-\mathrm{H}$ was $2.69 \pm 0.30$. Both the chorioallantoic placenta (CAP) and the visceral yolk sac (VYS) concentrated the C-H to tissue/maternal plasma ratios of $4.26 \pm 0.85$ and $5.10 \pm 1.21$, respectively. In addition, fetal tissues concentrated the $\mathrm{C}-\mathrm{H}$ to even higher levels, especially the ovary, testis, uterus, adrenal. When Society for Gynecologic Investigation

\section{6}

the fetuses were injected with '4C- or $3 \mathrm{H}-\mathrm{DES}$, the $\mathrm{C}-\mathrm{H}$ rapidly appeared in the maternal circulation; however, the tissue/fetal plasma ratios \&lt; 1 for both the CAP and VYS. Using thin layer chromatography, DES, dienestrol and glucuronides were separated. The C-H was associated with the DES in the maternal plasma (75\%), fetal plasma (85\%), CAP (85\%), VYS (92\%). The remaining C-H was associated with the glucuronides, except for the maternal plasma where $10 \%$ remained unidentified. 
Thus, in addition to the elevated $\mathrm{C}-\mathrm{H}$ within the fetal reproductive tissues, the con-centrative placental transport of DES and not dienestrol may contribute to the increased prenatal susceptibility to DES carcinogenicity.

(Supported by GRSG RR-05403.)

128 Hypothalamic-Pituitary Function in Patients with Primary Amenorrhea

Oscar A. Kletzky, Val Davajan, John T. Nicoloff and Daniel R. Mishell,jr. Department of

Obstetrics-Gynecology and Medicine, University of Southern California School of Medicine and the Los Angeles County Medical Center, Los Angeles, Calif.

It is not known whether primary amenorrhea with normal or low LH, FSH and E2 is an hypothalamic or pituitary disorder. 8 women with this syndrome were studied by a sequential pituitary stimulation test (SST) of i.v. insulin followed by Gn-RH-TRH and $2 \mathrm{~h}$ later by a second dose of Gn-RH. 2 patients had normal responses while the other 6 patients had abnormal PRL responses to insulin, but normal responses to TRH, suggesting hypothalamic disorders. 6 patients had LH and FSH responses to Gn-RH-TRH which were significantly lower than the controls while only 2 patients had abnormally low FSH. Following the second dose of Gn-RH, 6 patients had significantly lower LH and FSH responses. 6 of the 8 patients had TSH responses to TRH which were significantly lower than $95 \%$ confidence limits of the control group. In order to determine whether the abnormal gonadotropin response was of pituitary origin three of these patients were then given $10 \mu \mathrm{g}$ Gn-RH for 4 days and on the fifth day the SST was repeated. At this time the LH response was significantly greater and in the normal range while the FSH response was similar to the pretreat-ment results. In conclusion, patients with primary amenorrhea with normal or low LH, FSH and E2 have a pituitary dysfunction secondary to derangement of the hypothalamus or higher CNS center(s). Furthermore, gonadotropin responses to $\mathrm{Gn}-\mathrm{RH}$ in some patients with primary amenorrhea resemble those of prepubertal girls. The etiology of primary amenorrhea in this group of patients may be due to failure of maturation of the hypothalamus.

129 Hormonal Effects on Calcium Uptake by Uterine Microsomes

M.L.J. Lockey, J.M. Roberts and A. Goldfien

Department of Obstetrics-Gyecology and Reproductive Sciences, Cardiovascular Research Institute, and Department of Medicine, University of California, San Francisco, Calif.

Progesterone inhibits myometrial contraction. This effect could be due, in part, to sequestration of free calcium within the cell since this ion is required for smooth muscle contraction. We examined the uptake of $45 \mathrm{Ca}$ by microsomes prepared from myometrium of immature rabbits treated with estrogen $(\mathrm{E})$ or progesterone $(\mathrm{P})$. The uterine microsomes were incubated with $4 \mathrm{SCa}$ and ATP and the incubation was stopped by rapid filtration. 45Ca uptake was maximal in 8 min; was saturable and reversible, and was consistently greater in the groups treated with $P$. Thermodynamic analysis of binding indicates that the concentra-

Scientific Abstracts

87

tion of binding sites was $0.94 \mathrm{~nm} / \mathrm{mg}$ protein and $\mathrm{K} \gamma \mathrm{j}=3.10 \mathrm{X} 10-6 \mathrm{M}$ after P treatment and after E was $0.72 \mathrm{~nm}$ of sites $/ \mathrm{mg}$ protein and $\mathrm{Krj}=8.27 \times 10$ " $6 \mathrm{M}$. We conclude that myometrial microsomes from $\mathrm{P}$ treated rabbits bind $4 \mathrm{SCa}$ at more sites and with greater avidity than after $\mathrm{E}$ and propose that these alterations account, in part, for observed differences in contractility. 130 Relationship between Metabolic Clearance Rate (MCR) and Sex Steroid Binding Protein (SBP) in Adult Rhesus Monkeys 
Kenneth Burry, Toru Tabeí, Pearl Namkung, John Resko, Philip Petra, Harvey Schiller and W. LeRoy Heinrichs

Departments of Obstetrics-Gynecology and Biochemistry Laboratory, Medical University of Washington, Seattle, Wash., and Oregon Regional Primate Research Center, Beaverton, Oreg. A proposed physiological role of SBP is in regulating the metabolic clearance of androgens from the circulation. We have measured the MCR of dehydroepiandrosterone (DHA) and testosterone (T), the plasma binding capacities of dihydrotestosterone (SBP) and corti-costerone (CBG), and the metabolism in vitro of $\mathrm{T}$ by skin. Chronically castrated adult rhesus males $(\mathrm{M})$, females $(\mathrm{F})$ and prenatally androgenized females (AF) were treated for 8 weeks wth silastic implants of estradiol (E2) that increased plasma concentrations 3-4 fold (83, 97 and $77 \mathrm{pg} / \mathrm{ml}$, respectively). The initial sex difference in SBP was eliminated by the treatment as the mean values ( $\mu \mathrm{g}$ bound $/ \mathrm{ml}$ ) for $\mathrm{M}$ increased (3.95 \pm 0.42 to $4.46 \pm 0.53)$ and those for $\mathrm{F}$ and $\mathrm{AF}$ decreased (5.85 \pm 0.40 to $4.54 \pm 0.27$, and $4.88 \pm 0.46$ to $4.65 \pm 0.27$ ). SBP values increased in every $\mathrm{M}$ and decreased in all but one $\mathrm{F}$; the response by AF varied. CBG decreased in all groups. The MCRj of M was significantly reduced by E2 $(7.1 \pm 0.8$ to $4.9 \pm 0.6)$ and was also decreased in 5 of $6 \mathrm{~F}$ and in most AF; MCR $\gamma$ jha was unchanged in $\mathrm{F}$ but was reduced in most M and AF.

These data indicate an inverse relationship between the MCRt ar, d SBP binding capacity only in adult male rhesus monkeys, and physiological concentrations of E2 suppress SBP values in females of this species.

(Supported by PHS grants No. HD08736, and HDO0272.)

131 Comparison of Peripheral Metabolism Estimated in vitro and Metabolic Clearance Rate (MCR) in vivo of Dehydroepiandrosterone (DHA) and Testosterone (T) in Normal and Perinatally Androgenized Rats

Yoshinori Kuwabara, Pearl Namkung, Toru Tabei and W. LeRoy Heinrichs Department of Obstetrics-Gynecology, University of Washington, School of Medicine, Seattle, Wash.

Enzymatic transformations and inactivation by binding are the major mechanisms for the metabolic clearance of free hormonal steroids from the circulation. To relate transformations and clearance, we have compared the specific activities of several steroid reduc-tases, dehydrogenases, or hydroxylases found in liver or skin from 105-day-old Sprague-Dawley rats with the MCR of DHA and T.

The MCRrjHA o'" normal males $(\mathrm{M}), 97 \pm 17$ liter/day/kg (mean $\pm \mathrm{SD}$ ) was similar to that of females (F), $125 \pm 38$, but hepatic hydroxylation of DHA by M, $3.38 \pm 0.89$ was significantly greater than that of F, $1.36 \pm 0.19 \mu \mathrm{mol} \mathrm{mg}-1 \mathrm{~min}-1$. The MCRj of M, $66 \pm$ Society for Gynecologic Investigation

88

17 was the same as that of F, $75 \pm 16$, but hepatic production of DHT was significantly greater in F: $26.1 \pm 4.8$ vs. $5.5 \pm 1.0$ for $\mathrm{M}$. In contrast, abdominal skin from $\mathrm{M}$ metabolized $\mathrm{T}$ to $\Delta 4-\mathrm{A}$ and $5 \alpha-\mathrm{A}$ at greater rates than $\mathrm{F}$. T metabolism was greatest in genital skin of F.

These data indicate that enzyme activities of skin or liver do not accurately reflect the MCR but different organs are likely to have quantitatively different enzyme specific activities, the presumed sum of which produces equal clearances between sexes of this species. This preliminary conclusion was confirmed by study of perinatally androgenized (A) rats; AF had 2fold greater clearance rates of both DHA and T than AM, but the skin and liver metabolic activities measured did not necessarily reflect either the magnitude or direction of the change in MCR.

(Supported by PHS grant No. HD08736.) 
132 Microsomal-Estradiol Receptor of Rabbit Uteri

L. Devoto, G.L. Flickinger and G. Mikhail

Department of Obstetrics-Gynecology, University of Pennsylvania School of Medicine, Philadelphia, Pa.

Properties and levels of estradiol (E2) binding in microsomal preparations were studied in estrous and pseudopregnant (day 7) rabbit uteri. When suspensions of microsomes in buffer containing $0.25 \mathrm{M}$ sucrose were incubated in the presence of 10 "10 to 10-9 M 3H-E2 evidence for high affinity as well as low affinity binding of the steroid was observed. The high affinity binding of 3H-E2 to the microsomes was not displaced by progesterone or testosterone. Following extraction of microsomes with hypotonic buffer only low affinity-binding remained in the particulate fraction while \&gt; $90 \%$ of the high affinity binding was accounted for in the extract. The binding protein of the extracts had properties similar to those of the cytosol E2 receptor; namely, sedimentation as $4 \mathrm{~S}$ (high salt) or $8 \mathrm{~S}$ (low salt) on sucrose gradients, a $\mathrm{K}_{i}$ of 0.9 X 10 " $10 \mathrm{M}$, and specificity for estrogen binding. In estrous rabbit uteri $(\mathrm{n}=6)$ the level of receptor in microsomes and cytosol was $0.24 \pm 0.05 \mathrm{pmol}$ and $11.5 \pm 1.9 \mathrm{pmol} / \mathrm{g}$ tissue, respectively, while in the pseudopregnant animal $(n=4)$ receptor was not detected in the microsomal extracts and the level in cytosol was $4.1 \pm 0.3 \mathrm{pmol} / \mathrm{g}$ tissue. No significant estradiol binding was detected in the mitochondrial or lysosomal fractions. The endogenous concentration of E2 in cytosol and microsomal fractions was $63 \pm 10$ and $38 \pm 1 \mathrm{Opg} / \mathrm{g}$ during estrus and $20+8$ and \&lt; 1Opg/g during pseudopregnancy. Our data confirm the presence of an additional intracellular site of estradiol binding and retention where progesterone may regulate the mode of action of estrogen.

133 Progesterone Metabolism by the Placenta and Uterine Decidua at Various Stages of Human Gestation

Leon Milewich, Norman F. Gant, Barry E. Schwarz, Grace T. Chen and

Paul C. MacDonald

Department of Obstetrics and Gynecology, University of Texas Southwestern Medical School, Dallas, Tex.

Progesterone is metabolized by human fetal membranes at declining rates after 33 weeks' gestation. To ascertain if this declining rate of progesterone metabolism is unique to fetal membranes or rather a generalized phenomenon in target tissues with advancing human Scientific Abstracts

89

gestation, progesterone metabolism was studied in human placenta and uterine decidua from various stages of pregnancy.

Isolated uterine decidua and placental tissue were incubated with $(3 \mathrm{H})$ progesterone and added NADPH. The results of these studies are summarized in the table below.

From this data it is apparent that as pregnancy advances, there is no decrease in the rate of progesterone metabolism in the placenta or uterine decidua. Thus the declining rate of progesterone metabolism in human fetal memanes may represent a specific phenomenon that is related to cellular or subcellular progesterone deprivation in these tissues.

134 Prostaglandin E Levels in Nonpregnant and Pregnant Sheep

Kenneth E. Clark, David Meldrum, Charles R. Brinkman, HI and Nicholas S. Assali Department of Obstetrics-Gynecology, UCLA School of Medicine, Los Angeles, Calif. 
Numerous reports have indicated that uterine venous prostaglandin E (PGE) levels are elevated during pregnancy in several species. In addition, earlier reports from our laboratories have shown that estrogen increases uterine PGE production. Since systemic estrogen levels are known to increase during pregnancy, the possibility that PGE levels were also elevated in pregnant sheep was investigated. Nonpregnant and 80-day pregnant sheep were chronically instrumented for arterial pressure measurements, uterine blood flow determinations and arterial (carotid artery, $\mathrm{CA}$ ) and venous (jugular vein, JV; uterine vein, UV) blood samples. Blood samples were taken weekly and levels of PGE determined by radioim-munoassay. Results: CA blood samples of nonpregnant sheep contained $226 \mathrm{pg} / \mathrm{ml}$ of PGE while JV levels of PGE were slightly higher $(233 \mathrm{pg} / \mathrm{ml})$. These values were not significantly different in the pregnant sheep. In contrast, uterine venous effluent of pregnant sheep in the latter half of gestation contained PGE levels which were approximately $30 \mathrm{pg} / \mathrm{ml}$ higher than systemic arterial plasma. This elevation in uterine venous PGE levels was not observed in the nonpregnant sheep. Conclusion: (1) systemic levels (CA and JV) of immunoreactive PGE were not altered during pregnancy; (2) uterine venous levels of immunoreactive PGE appear to be elevated in the unanesthetized chronically instrumented pregnant sheep; (3) when arterial-uterine venous differences are multiplied by uterine blood flow, uterine production rates are elevated during pregnancy and tend to increase during gestation.

Society for Gynecologic Investigation

90

135 Relationship of Placental Blood Flow to the Placental Clearance of Maternal Plasma Dehydroisoandrosterone Sulfate (DS) through Estradiol (PC-DSE2)

Paul C. MacDonald, Norman F. Gant and John C. Porter

Department of Obstetrics-Gynecology, University of Texas Southwestern Medical

School at Dallas, Dallas, Tex.

We have proposed that PC-DSE2 is proportional to maternal placental blood flow (F). In an elegant mathematical analysis, Clewell and Meschia showed that PC-DSE2 was related to F as follows: Cobs $=\mathrm{F}(1-\mathrm{e}-\mathrm{c} / \mathrm{F})$, where Cobs $=\mathrm{PC}-\mathrm{DSE} 2$ and $\mathrm{C}=$ placental clearance of DS. They assumed that $\mathrm{C}$ was constant. Using $19.7 \mathrm{ml} / \mathrm{min}$ for $\mathrm{C}$, they allowed PC-DSE2 to vary widely and computed F. In some cases, F was unrealistically low; and they concluded that PC-DSE2 was not related to $F$. They erred in assuming that PC-DSE2 and C did not vary directly with one another. Indeed, negative values for F obtain for low values of PC-DSE2 when C $=19.7 \mathrm{ml} / \mathrm{min}$, an impossible result. It is apparent that PC-DSE2 and $\mathrm{C}$ have closely related values since $\mathrm{C}$ varies little when $\mathrm{PC}-\mathrm{DSE} 2=19.3 \mathrm{ml} / \mathrm{min}$ despite wide variation in $\mathrm{F}$. $\mathrm{C}$ is the sum of all routes of irreversible clearance of DS by the placenta, i.e., $\mathrm{C}=\mathrm{PC}-\mathrm{DSE} 2+\mathrm{C},+\mathrm{Cj}+\mathrm{Cj}+. \mathrm{Cj}$, where $\mathrm{C}^{\wedge} \mathrm{Cj}$, etc. are routes of placental removal of maternal DS other than through maternal E2. Suppose that $\mathrm{Cl}$ is irreversible loss of DS to the fetus, $\mathrm{C} 2$ is conversion of DS to androstenedione that escapes aromatization, etc. If $\mathrm{C}$ remains constant when PC-DSE2 decreases, then $\mathrm{C} 1+\mathrm{C} 2+\mathrm{C} 3+. . \mathrm{Cn}$ must increase. It is more likely that $\mathrm{C}$ bears a constant relationship to PC-DSE2 such that Cobs $=\mathrm{kC}$, where $\mathrm{k} \& \mathrm{lt}$; 1 . If so and if $\mathrm{k}$ were known, $\mathrm{C}$ can be computed; and the formula of Clewell and Meschia can be utilized to compute F from PC-DSE2. An analysis of MCR-DS shows that 0.92 \&lt; k \&lt; 0.99; k is likely 0.97 .

136 Free and Protein Bound Hormones in Amniotic Fluid

Chung H. Wu, Michael Mennuti and G. Mikhail

Department of Obstetrics-Gynecology, University of Pennsylvania School of Medicine, Philadelphia, $\mathrm{Pa}$. 
Human mid-pregnancy amniotic fluid ( $\mathrm{n}=97,14-18$ weeks' gestation) was analyzed for its hormonal contents. The biologic activity of steroids based on their protein binding properties was determined.

Hormone Concentration \pm SE Free, $\%$ Specific binding, \%

$\begin{array}{llll}\text { Androstenedione }(\mathrm{A}) \text {, male } & 658 \pm 33^{*} & 32.3 \pm 2.7 & 1.1 \pm 0.3 \\ \mathrm{pg} / \mathrm{ml} \text { female } 360 \pm 28 & 27.1 \pm 2.7 & 3.6 \pm 0.7 & \\ \text { Testosterone }(\mathrm{T}) \text {, male } & 277+16^{*} & 13.6+0.6 & 28.5 \pm 1.0 \\ \mathrm{pg} / \mathrm{ml} \text { female } 41 \pm 3.711 .7 \pm 0.7 & 31.7 \pm 1.3 & \end{array}$

$\mathrm{pg} / \mathrm{ml}$ female $41 \pm 3.711 .7 \pm 0.7 \quad 31.7 \pm 1.3$

$\mathrm{FSH}, \mathrm{mlU} / \mathrm{ml}$ male $1.36 \pm 0.14 *$

female $10.1 \pm 1.6$

* p \&lt; 0.001 .

The concentration of estrone (Et) was $280 \mathrm{pg} / \mathrm{ml}$ with $27 \%$ nonprotein bound and only $2 \%$ bound tightly to protein. The corresponding values for estradiol (E2) were $94 \mathrm{pg} / \mathrm{ml}, 15 \%$ free and 13\% specifically bound; for progesterone (P) $55 \mathrm{ng} / \mathrm{ml}$ with $20 \%$

Scientific Abstracts

91

free, $4 \%$ bound with high affinity. In the amniotic fluid T and E2 have the lowest $\%$ free fraction and highest specifically bound fraction; however, the \% free is more than 10 times that found in maternal plasma. There was no sex difference in the total concentration of E, E2 and P, or in the binding properties of all the steroids studied. Sex differences are reflected in hormones that play a role in sex differentiation and are primary products of the fetus. Accuracy in sex prediction based on A concentration is $80 \%$, T concentration is $97 \%, \mathrm{FSH}$ is $94 \%$ and for combined $\mathrm{T}$ and FSH is $100 \%$. The determination of amniotic fluid T and FSH provide a useful supplement to cell karyotype studies in prenatal genetic diagnosis.

137 The Development of Rhythmic Patterns of Gonadotropin and Estrogen Excretion before, during and after Puberty J.D. Hoff, S. Kundell, B. Hopper and S.S.C. Yen Department of Reproductive Medicine, UCSD School of Medicine, La Jolla, Calif.

To define the pattern of gonadotropin (GTP) and estrogen (E) secretion during the period of sexual maturation, daily morning urinary GTP and E levels, corrected for creati-nine, were measured in a cross sectional study of 15 healthy schoolchildren over a period of 57 days. In boys, urinary excretion of GTP was low and flat with FSH exceeding LH during stage I puberty. As pubertal development progressed, from stages 2 to 5 , mean LH and, to a lesser extent, FSH levels increased. In girls, urinary excretion of GTP in stage I of puberty is similar to that of stage I boys. In stages 2 and 3, prior to menarche, there is a rise in mean GTP levels and both LH and FSH assume a clear pattern of day-to-day fluctuations of greater than $100 \%$. Spectral analysis confirmed a 2-day rhythm as dominant and, in contrast to a similar study by Hansen et al. (Science, N.Y. 190: 161, 1975), longer rhythms of cyclic pattern were not found. The LH and FSG excretion in post-menarchial girls, assumed the monthly rhyhm of adult pattern and became more pronounced as pubertal stages advanced from 3 to 5. Although in girls, mean urinary E excretion increased progressively through the pubertal stages, in all premenarchial girls from stages 1 to 3, the pattern of E excretion was flat, even in those subjects showing marked day-today fluctuation in GTP. After menarche, the daily E excretion showed a cyclic pattern similar to that of adult women. These data suggest that (1) hypothalamic-GTP maturation during pubertal development is associated with a gradual onset of rhythmic release of GTP from a short (2 days) to a long and cyclic pattern, and (2) ovarian E plays little or no role in the maturation of hypothalamic-GTP system prior to menarche. 
138 Further Delineation of the Role of Dopamine (DA) in the Regulation of LH and Prolactin (PRL) Secretion in Humans S.J. Judd, J.S. Rakoff, L.A. Riggand S.S.C. Yen Department of Reproductive Medicine, UCSD School of Medicine, La Jolla, Calif.

We have reported that DA and DA receptor agonists cause a decrease in circulating LH and PRL in eugonadal subjects. In the present study, the effect of DA infusion $(4 \mu \mathrm{g} / \mathrm{kg} / \mathrm{min})$ in subjects with elevated LH and normal PRL levels were investigated. In addition, the site of the inhibitory action of DA was studied. During DA infusion, the mean maximum decline of LH is significantly greater in 5 patients with polycystic ovary disease (PCO) than in 5 agonadal women (45.6\% vs. $36.6 \%$; p \& 1 t; 0.005$)$ and the maximum decline in both groups was significantly greater than the normal subjects (p \&1t; 0.01). The decrease in PRL levels was also significantly greater in PCO than in agonadal women (p \&lt; 0.05). Upon

Society for Gynecologic Investigation

92

cessation of DA infusion, the significant rebound of LH release observed in normal subjects did not occur in either group. In contrast, the PRL rebound in both PCO and agonadal women was present but the latter was significantly smaller than the former (p \& 1t; 0.05). The LH response to $10 \mu \mathrm{g}$ of LRF was significantly less ( $\mathrm{p} \& \mathrm{lt} ; 0.05$ ) during DA infusion as compared to preinfusion control which is independent of gonadal function ( 9 normal women, 4 normal men and 5 agonadal women). These findings suggest that (1) the inhibitory effect of DA on LH-release is, in part, acting at. the pituitary level; (2) the increased sensitivity to DA in conditions with accelerated LH secretion may reflect either an increased number of pituitary DA-receptors or the presence of a facilitating factor for DA action, and (3) the dissociation of rebound between LH and PRL upon cessation of DA inhibition in both PCO and agonadal women implicates a difference in the DA-receptor activity of the lactotrophs and gonadotroph.

139 Hypothalamic-Gonadotropin (H-GTP) Maturation in the Absence of Gonadal Feedback: Chronologic Studies in Gonadal Dysgenesis R. Rebar, A. Lucky, J. Rakoff, R. Johnsonbaugh, J. Vaitukaitis and S. Yen La Jolla, Calif., Bethesda, Md., Boston, Mass.

The syndrome of gonadal dysgenesis with its absence of functioning gonads provides a unique model for the delineation of the maturational events of the H-GTP system during human puberty. Chronological changes in basal LH and FSH secretion and responses to an i.v. pulse of $10 \mu \mathrm{g}$ LRF were analyzed in 12 patients with Turner's syndrome ranging in age from 9.5 to 56 years not previously treated with estrogen. Basal levels of LH and FSH were elevated above those found in normal women in all patients, supporting an inhibitory role for normal prepubertal gonads on the releasing mechanism of the H-GTP system. In response to LRF, the preteenage subjects had greater release of FSH than LH. Through the teenage years, the magnitude of peak release increased concurrently with rising basal LH and FSH levels, and the greater FSH response was progressively shifted in favor of LH response. This differential response between FSH and LH and the reversal with chronological age are clearly independent of gonadal feedback and qualitatively similar to pubertal changes noted in normal girls. Sequential studies in an elderly patient from age 56 to 60 revealed lower basal GTP levels and diminished release in response to LRF, implying possible GTP exhaustion. These data indicate that the increasing functional activity of the H-GTP system during pubertal development represents either an inherent maturational event of the CNS independent of target organ control and/or its development is temporally coupled with the progressive increase in the hypothalamic-ACTH axis and the associated androgen secretion at adrenarche. 
140 Intravaginal and Intranasal Absorption of Micronized 170-Estradiol (E2) L.A. Rigg, B. Villanueva, B. Milanes and S.S.C. Yen Department of Reproductive Medicine, UCSD School of Medicine, La Jolla, Calif.

We have reported that a rapid conversion of E2 to E! occurs following oral ingestion of E2. Thus, alternate routes of administration of E2 to circumvent this conversion were explored. E2 suspended in saline was placed in the vaginal vault of 8 castrate women or intranasally in 8 eugonadal and 3 castrate women. Blood samples were obtained at frequent intervals before and after E2 administration for $24 \mathrm{~h}$. Changes in serum levels of E2, E, LH and FSH were analyzed. At 1 - or 0.5 -mg doses, the absorption of E2 is extremely rapid

Scientific Abstracts

93

(within $5 \mathrm{~min}$ ) and reaches comparable maximum serum levels in $2 \mathrm{~h}$ for both doses $(900-1,000$ $\mathrm{pg} / \mathrm{ml}$ or $120 \mathrm{X}$ basal level). Thereafter, a more sustained level of E2 is maintained for at least 8 $\mathrm{h}$ for $1 \mathrm{mg}$ dose, but a progressive decline to basal level is seen at $24 \mathrm{~h}$ for the $0.5-\mathrm{mg}$ dose. The increments of serum E, are much slower and of much smaller magnitude (mean $240 \pm 40 \mathrm{pg} / \mathrm{ml}$ or $8 \mathrm{X}$ basal level). The ratio and the time course of increments of E2/E! can account for the endogenous conversion of E2 to E,. At both doses, comparable maximal suppression of FSH $(17 \%)$, and $\mathrm{LH}(48 \%)$ levels occur at 7-8 $\mathrm{h}$ and return to basal levels at $24 \mathrm{~h}$. Absorption of E2 via intranasal route $(1 \mathrm{mg})$ is also rapid but short lasting. Peak E2 levels (11- to 15-fold) are reached in $15 \mathrm{~min}$ and followed by a sharp decline to basal level at $7 \mathrm{~h}$. The increments of serum Et follow an identical time course of that of E2 initially, but exhibit a relatively large and sustained rise (3.5- to 5-fold) lasting for at least $24 \mathrm{~h}$. The most plausible explanation for this finding is the local enzymatic or microorganis-mal conversion of E2 to Ei in the nasal mucosa. Thus, vaginal administration constitutes an effective mode for the delivery of E2 in the circulation.

141 Baroreceptor Activity in Pregnancy-Induced Hypertension (PIH)

Kenneth Leveno, Stanley Shoemaker, Gary Cunningham, Richard Worley, Jack Pritchard and Norman Gant

Department of Obstetrics-Gynecology, University of Texas Southwestern Medical School, Dallas, Tex.

The purpose of this study was to characterize baroreceptor activity in patients with PIH. Acute decreases in systolic pressure, concomitant with increased heart rate brought on by lateral to supine position changes of the mother were used to identify baroreceptor activity in four patients. Baroreceptor function was analyzed by measuring continuously radial artery systolic pressure simultaneous with R-R intervals and expressed as the slope of $\Delta \mathrm{msec}$ of heart rate and $\Delta \mathrm{mm} \mathrm{Hg}$ calculated by the least squares' method.

Baroreceptor activity in PIH was depressed to values between 3.6 and $4.7 \mathrm{msec} / \mathrm{mm} \mathrm{Hg}$. These values in PIH are less than the $10.3-19.9 \mathrm{msec} / \mathrm{mm} \mathrm{Hg}$ range seen in normal pregnancy, but are similar to the $2.9-5.7 \mathrm{msec} / \mathrm{mm} \mathrm{Hg}$ range seen in pregnancies complicated by chronic hypertension (CHBP) reported by Seligman.

Baroreceptor function is decreased in PIH such that there is less change in heart rate per $\mathrm{mm} \mathrm{Hg}$ change in systolic pressure. The decreased baroreceptor sensitivity observed in patients with PIH is similar to the depressed baroreceptor activity reported in gravidas with CHBP. Furthermore, animal studies by Guyton have shown decreasing baroreceptor activity associated with increasing arterial pressure, a situation that appears analogous to the findings of this study. These 
observations and the similarly depressed baroreceptor activity seen in patients with PIH suggest that depressed baroreceptor activity in PIH is the result of HBP and not its cause.

142 Long-Term Effects of Dexamethasone (Dex) on 24-Hour Patterns of LH, FSH

andAndrogens in Polycystic Ovarian Syndrome (PCO)

H. Judd, S. Swanson, M. Hauck, G. Lachelin, D. Parker and S. Yen

Department of Reproductive Medicine, UCSD School of Medicine, La Jolla, Calif.

To examine the long-term effects of Dex on 24-hour hormonal patterns 4 patients with PCO and 4 normal women on the 1 st day of menses were studied. Blood samples were drawn every 20 min for $24 \mathrm{~h}$ beginning at $8 \mathrm{a} . \mathrm{m}$. Following this $1 \mathrm{mg}$ Dex was given nightly at $11 \mathrm{p} . \mathrm{m}$. and daily 8 a.m. samples were obtained for 30 days (PCO) or until next menses

Society for Gynecologic Investigation

94

(normals). On the last day of Dex hourly samples were drawn for $24 \mathrm{~h}$ beginning at 8 a.m. Serum $\mathrm{LH}, \mathrm{FSH}$, Testosterone (T), androstenedione $(\Delta)$, dehydroepiandrosterone (DHEA), $\Delta 5$ androstenediol (A) and cortisol were measured on each sample.

During the baseline day the mean LH but not FSH, T and $\Delta$, but not DHEA, A or cortisol were significantly elevated in the PCO patients. In both groups episodic fluctuations of all 5 steroids were observed and the pulsatile pattern of cortisol, DHEA and $\Delta$ were parallel and most prominent. No correlation was apparent between the pulsatile release of any of the steroids and the periodic fluctuations of either LH or FSH. Significant diurnal fluctuations of all steroids were seen with the most prominent being cortisol and DHEA. During Dex, ovulation occurred in the normal but not PCO patients. There were large and prompt decreases of DHEA, A and cortisol with an obliteration of both the pulsatile and diurnal release of these steroids. Dex had no significant effect on $\mathrm{T}, \Delta$, LH or FSH.

These data indicate that long-term administration of nightly Dex suppressed the mean level, and obliterated the pulsatile and diurnal release of DHEA, A and cortisol. It had no significant effect on elevated $\mathrm{T}$ and $\Delta$ levels.

143 Origin of Ring B Unsaturated Estrogens in the Pregnant MareB.R. Bhavnani and C.A. Woolever

Departments of Obstetrics-Gynecology and Clinical Biochemistry, University of Toronto, St. Michael's Hospital, Toronto, Ont.

In vivo studies in the pregnant mare have shown that the ring B unsaturated estrogens equilin and equilenin are formed from acetate, mevalonic acid and isopentenylpyrophos-phate, but not from squalene or cholesterol. In order to define more clearly the point at which the classical pathway of steroid biosynthesis bifurcates give rise to the ring B unsaturated estrogens, the precursor role of farnesylpyrophosphate (FPP) was investigated. A mixture of $1.25 \mathrm{mCi} 4,8,12-14 \mathrm{C}-\mathrm{FPP}$ and $19 \mu \mathrm{Ci} 7-3 \mathrm{H}$-dehydroisoandrosterone (3H-D) was injected into a 10-month horse fetus in utero. Maternal urine was collected for 4 days. Steroid conjugates were extracted by absorption onto a $2 \mathrm{~kg}$ Amberlite XAD-2 column, eluted, hydrolysed and separated into neutral and phenolic fractions. Estrone and equilin were isolated from the phenolic fraction and their radiochemical purity established. Estrone contained both $3 \mathrm{H}$ and $14 \mathrm{C}$ while equilin contained only $14 \mathrm{C}$ indicating that it is formed from 14C-FPP but not from $3 \mathrm{H}-\mathrm{D}$. Therefore, the bifurcation in the classical biosynthetic pathway of estrogens occurs just before the formation of squalene. This is the first in vivo demonstration that FPP can be transformed to steroids.

(Supported by Medical Research Council, M.R.C. grant No. MT-3724.)

144 Adrenal Steroid Synthesis and Hyperprolactinemia due to Pituitary Microadenoma 
James D. Madden, Leon Milewich, John C. Porter, Robert M. Boyar and

Paul C. MacDonald

Department of Obstetrics-Gynecology, University of Texas Southwestern Medical

School at Dallas, Dallas, Tex.

Prolactin receptor sites have been identified in the adrenal cortex, and prolactin has been

implicated in the development of adrenal hyperplasia, in cholesterol storage in steroid-producing cells and as a second trophic stimulus to fetal adrenal C-19 hormone production. These

considerations prompted us to examine the relationship between hyperprolactinemia and adrenal function in adult women.

The mean concentration of serum dehydroisoandrosterone sulfate (DS) in 8 normal

Scientific Abstracts

95

ovulatory women studied daily throughout the menstrual cycle (samples obtained between 08.00 and $10.00 \mathrm{~h}$ ) was $2,062 \pm 137$ (mean $\pm \mathrm{SEM}$ ) ng/ml. In 2 women of similar body weight and height with hyperprolactinemia, hypogonadotropic hypogonadism, and poly-tomographic evidence of an intrasellar microadenoma, the concentrations of DS between 08.00 and $10.00 \mathrm{~h} \mathrm{(7}$ determinations for each patient) were 3,379 $\pm 109 \mathrm{ng} / \mathrm{ml}$ and 3,943 $\pm 433 \mathrm{ng} / \mathrm{ml}$. The respective 24-hour mean concentrations of prolactin (hPr) when sampled at 20-min intervals were $858 \pm 8.6$ $\mathrm{ng} / \mathrm{ml}$ and $96 \pm 2.7 \mathrm{ng} / \mathrm{ml}$ in these 2 patients. There was no sleep-associated rise in hPr. The 24hour secretory pattern and mean concentrations of cortisol (F) when sampled at 20-min intervals were normal. The 24-hour secretory patterns of DS and F when sampled at frequent intervals in the hyperprolactinemic individuals are remarkably similar and resemble the normal endogenous rhythm. These findings are consistent with the view that high concentrations of hPr may act in concert with ACTH to promote increased secretion of $\Delta 5-31$ ?-hydroxy-C-19 steroids by the adrenal.

145 The Effect of Intraamniotic Thyroxine on Thyroid Function in the Human Fetus andNewborn

Calvin J. Hobel, Joseph Sack, Larry M. Cousins and Delbert A. Fisher UCLA School of Medicine, Harbor General Hospital, Departments of Obstetrics-Gynecology and Pediatrics, Torrance, Calif.

Thyroxine (T4) can be administered to the human fetus by intraamniotic injection. Moreover, in the sheep we have shown that T4 injected into amniotic fluid is quantitatively absorbed by the fetus within $24 \mathrm{~h}$. This route of administration was used to assess the effect of exogenous T4 on fetal serum TSH and on the TSH and thyroid hormone responses to birth.

200-700 $\mu \mathrm{g}$ T4 was injected intraamniotically (IA) to 10 term pregnancies $24 \mathrm{~h}$ before elective cesarean section. Serum T4, triiodothyronine (T3) and thyrotropin (TSH) were measured in cord blood and serially during the first $4 \mathrm{~h}$ of life. Increasing IA-T4 progressively increased mean cord serum T4 $(15.3 \mu \mathrm{g} / \mathrm{dl}$ in control to $26.6 \mu \mathrm{g} / \mathrm{dl}$ at 300-700 $\mu \mathrm{g}$ IA-T4 doses) and suppressed mean cord blood TSH concentrations $12 \mu \mathrm{U} / \mathrm{ml}$ in control to $5.5 \mu \mathrm{U} / \mathrm{ml}$ at $300-700 \mu \mathrm{g}$ IA-T4 doses). Mean serum T3 levels remained low (37 ng/dl at 300-700 $\mu \mathrm{g}$ IA-T4 vs. $47 \mathrm{ng} / \mathrm{dl}$ in controls). The 30-min mean peak of the postnatal TSH surge decreased progressively with increasing IA-T4 (from $67 \mu \mathrm{U} / \mathrm{ml}$ in control to $11 \mu \mathrm{U} / \mathrm{ml}$ at 300-700 $\mu \mathrm{g}$ IA-T4 doses) but the 4hour mean peak of the postnatal T3 surge remained unchanged $(173 \mathrm{ng} / \mathrm{dl}$ at 300-700 $\mu \mathrm{g}$ IA-T4 vs. $173 \mathrm{ng} / \mathrm{dl}$ in controls).

We conclude: (a) that fetal serum TSH is suppressible by T4 at term; (b) T4 is effective in suppression in the absence of conversion to T3; (c) the TSH surge can be (at least partially) 
suppressed by T4; (d) the newborn T3 surge can be dissociated from the TSH surge suggesting that the T3 surge is due (at least in part) to increased T4 to T3 conversion.

146 Interrelationships of Maternal 17 $\alpha$-OH-Progesterone (17P), 16 $\alpha$-OH-Progesterone(16P), Progesterone (P), Estradiol (E2), Estriol (E3), and Dehydroepiandrosteronesulfate (D-S) Levels in Normal Third Trimester Pregnancies

J.E. Buster, R.J. Chang, L.M. Cousins, G.E. Abraham, C.J. Hobel and J.R. Marshall Department of Obstetrics-Gynecology, Harbor General Hospital, UCLA School of Medicine, Torrance, Calif. Serial serums from 19 normal pregnant women between 26 and 40 weeks of gestation were assayed for 17P, 16P, P, E2, E3 and D-S. After plotting concentrations semiloga-rithmically against gestational age, individual curves were analyzed for slope segmentation Society for Gynecologic Investigation

96

by sequential regression lines utilizing $95 \%$ confidence interval future $\mathrm{Y}$ value predictions as initial markers of slope change and were compared by $\log \mathrm{X}$ on $\log \mathrm{Y}$ regressions utilizing the $\log \log$ slope (LLS) line of unity 1.0 to indicate identity. 17P and 16P have near identical LLS (0.993; r 0.986; p \&lt; 0.01), positive, 3 segment curves beginning at 26-27 to 32-33 weeks as shallow slopes (17P $0.015 ; 16 \mathrm{P} 0.016)$, transforming at 32-33 to 37 weeks to steeper slopes (17P $0.069 ; 16 \mathrm{P} 0.062)$, and terminating at $37-40$ weeks as shallow slopes (17P $0.014 ; 16 \mathrm{P} 0.00006)$.

$\mathrm{P}$ and E2 have mutually similar LLS $(0.900 ; \mathrm{r} 0.974$; $\mathrm{p}$ \&lt; 0.01$)$, shallow, positive (P 0.025; E2 0.022 ) single segment curves. E3 and 16P are similar (LLS 0.852; r 0.985; p \&lt; 0.01). D-S has a shallow, negative (-0.015), single segment curve which is similar to 1/E2 (LLS -0.894; r 0.697; p \&lt; 0.05) and 1/P(LLS -0.855; r -0.794;p \&lt; 0.01) curves and much less similar to E3 (LLS - 0.694; r -0.786; p \&lt; 0.01) and 16P (LLS 0.620; r -0.764; p \&lt; 0.01). Conclusions: (1) nearly identical 17P, 16P, and E3 curves suggest common feto-placental regulatory mechanisms; (2) same applies for E2 and P; (3) nearly identical 1/E2 and D-S curves probably reflect placental conversion of D-S to E2.

147 Effects of Oral Contraceptive Steroids on Pituitary Function

Josef Z. Scott, Paul F. Brenner, Oscar A. Kletzky and Daniel R. Mishell,jr. Department of Obstetrics-Gynecology, University of Southern California School of Medicine, Los Angeles County Medical Center, Los Angeles, Calif.

51 subjects who had used various formulations of oral contraceptives (OC) for periods of time ranging from 1-9 years were stimulated with $50 \mu \mathrm{g}$ of $\mathrm{Gn}-\mathrm{RH}$ during the last week of OC ingestion. 44 (86\%) had LH and FSH responses which were lower than the 95\% confidence limits of a control group indicating pituitary suppression. The remaining $7(14 \%)$ subjects had normal responses indicating that inhibition of ovulation occurred due to hypothalamic suppression. No correlation was found between these 2 responses and age, type of OC used, or length of use. In order to determine whether these responses vary in individual women over time, 30 of the original subjects were again stimulated, 3-6 months later. The responses to the second Gn-RH stimulation were similar to the first in all women tested, indicating that the pituitary suppressive effect of OC on LH and FSH release is related more to the individual woman than the type of formulation or length of use. Stimulation with $250 \mu \mathrm{g}$ of TRH was also performed in these subjects. 27 of the 30 had a PRL response greater than controls. This study indicates that OCs have a direct effect on the pituitary as well as the hypothalamus in the majority of women. This suppressive effect of LH and FSH and stimulating effect on PRL may persist in some women after stopping OCs accounting for the syndrome of post-OC amenorrhea-galactorrhea. 
148 Galactorrhea and Infertility Associated with Elevated Serum TSH and PRL:Restoration of Fertility with Bromocryptine

Theresa M. Siler-Khodr, Adnan M. Mroueh, Gabriel S. Khodr, Zuheir Hemadeh and

Samir Najjar

Departments of Obstetrics-Gynecology and Pediatrics, American University of Beirut, Beirut

In 12 patients with infertility and galactorrhea basal TSH and PRL were increased. In another 2 patients elevated TSH and PRL was associated with galactorrhea and precocious puberty. Thyroid deficiency was found in 8 patients. However, in 3 cases circulating thyroid hormones were normal and in the other 3 they were not determined.

Scientific Abstracts

97

Seven of the 12 infertile patients were amenorrheic and the other 5 had regular menses. In the amenorrheic women LH was greater than FSH and in 3 cases LH was above $20 \mathrm{mlU} / \mathrm{ml}$. FSH was suppressed or in the low normal range in 5 patients. Serum testosterone was normal in all the infertile women. However, androstenedione was decreased in the amenorrheic patients. In addition, the plasma estrogens in the amenorrheic women were sizable, estrone $(171 \pm 30$, mean $\pm \mathrm{SE})$ greater than estradiol $(88.1 \pm 8.3$, mean $\pm \mathrm{SE})$.

Treatment with bromocryptine in 6 amenorrheic patients resulted in suppression of PRL, cessation of lactation, return of normal ovarian function and conception in 3 cases. Correction of hypothyroidism with exogenous thyroid hormone in 3 cases produced similar results as well as suppressing TSH. It is proposed that the abnormal gonadal function often associated with primary hypothyroidism is a result of hyperprolactinemia, and not an alteration in estrogen metabolism induced by the hypothyroid state, since normal ovarian function can be restored by bromocryptine while hypothyroidism persists.

149 Postpartum Serum Prolactin and Cortisol and Their Relationship with Maternal andAffective Behaviors in the Macaca nemestrina.

Robert J. Gross, Harvey S. Schiller and Douglas M. Bowden

Departments of Psychiatry and Behavioral Sciences, and Obstetrics-Gynecology, University of Washington School of Medicine, Seattle, Wash.

The purpose of this investigation is to measure postpartum prolactin and cortisol as well as to seek a correlation with maternal and affective behaviors for the first 4 weeks. At term delivery 12 Macaca nemestrina monkeys were immediately separated from their infants and housed in individual cages. Venous blood $(3 \mathrm{~cm} 3$, without anesthesia, within $5 \mathrm{~min}$ of capture) was drawn at 8 a.m. on alternate days, 3 times a week. Serum was analyzed by radioimmunoassay for prolactin and by competitive protein binding for cortisol. A testing chamber with several choice compartments was used to measure maternal preference for her infant. The subjects were observed by time-lapse video recording 3 days per week for $10 \mathrm{~h}$ a day on nonblood drawing days. Statistically significant findings were as follows. Prolactin showed an elevated level during days 1 and 2, rapidly dropping till day 4, then peaking at days 10-12 followed by a gradual decline through day 28. Cortisols showed a drop after the first day and remained decreased until day 9 when they rose to a peak occurring on day 12 and remained elevated through day 28 . Maternal behavioral data revealed decreased preference for her infant during days $1-8$, a sudden rise of infant preference which reached a peak on days 9 and 10, and which remained elevated through day 22. Affective behaviors revealed exploring and locomotion to be essentially constant and huddling to be elevated days $1-6$. The most striking finding was the consistent relationship 
between the increase in maternal infant preference and the rise in serum prolactin and cortisol levels on day $10 \pm 1$ day.

150 The Pulsatile Pattern of Gonadotropin Release in Normal Men, Normal Women, andAmenorrheic Women

R.C. Strickler, R. Borth and C.A. Woolever

Department of Obstetrics-Gynecology, St. Michael's Hospital, University of Toronto, Toronto, Ont.

Serum FSH and LH levels were measured in blood samples drawn every 10 min during 3 or $6 \mathrm{~h}$ from 6 healthy men, 6 women during an ovulatory cycle, and 8 acyclic women. The pulsatile patterns of relative (rather than absolute) variation were studied by examining Society for Gynecologic Investigation

98

means, standard deviations, variances, and peak frequencies after a logarithmic transformation of the data. Similarly, relative day-to-day variation in gonadotropin levels was studied throughout the ovulatory menstrual cycle of 5 women. In men, cycling women, and amenorrheic subjects, LH and FSH levels, their magnitudes of variation, and their time pattern of release vary independently. Differences in variation pattern were random and unrelated to mean levels, to the phase of the normal cycle, or to the clinical pathological diagnosis - i.e. to the sex steroid hormone environment. We conclude that (1) the amplitude of absolute variation in gonadotropin pulses is merely in proportion to the mean level, while the relative variation and the pulsation frequency are fairly constant under a variety of normal and abnormal conditions; (2) the analysis of pulsatile pattern of gonadotropin release suggests no diagnostic value.

151 Progesterone Deprivation in the Chorioamnion from Laboring Women

Barry E. Schwarz, Charles L. Heaton, Leon Milewich, Robert A they and

Paul C. MacDonald

Department of Obstetrics-Gynecology, University of Texas Southwestern Medical

School at Dallas, Dallas, Tex.

We have presented evidence supporting a central role for the fetal membranes (chorion laeve and amnion) in the initiation of human parturition, and have suggested that this role may be subserved by the action or metabolism of progesterone in these tissues. While it is clear that there is a dramatic decline in maternal plasma progesterone concentration prior to the onset of labor in many mammals, such a decrease does not obtain in most normal gravidas. For these reasons, we measured the progesterone concentrations in whole homoge-nates and subcellular fractions of human chorioamnions obtained prior to the onset of labor or after vaginal delivery. Samples were prepared for radioimmunoassay employing a technique which eliminated the

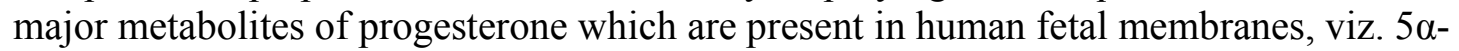
dihydroprogesterone and 20 chorioamnion before and after labor were $26.4 \pm 3.5$ (SEM) $\mathrm{ng} / \mathrm{ml}$ protein and $13.1 \pm 1.6$ (SEM) $\mathrm{ng} / \mathrm{mg}$ protein, respectively. These concentrations are significantly different (p \&lt; 0.01 ) as were the mean progesterone concentrations of each subcellular fraction investigated except that fraction containing predominantly mitochondria. Considered in context with the dramatic increase in the amount of human fetal progesterone binding protein associated with the chorioamnion after the 37 th week of gestation, this progesterone deprivation, at a local tissue site and in most but not all subcellular fractions of this tissue, argues in favor of a hypothesis in which a decline in available progesterone within the human fetal membranes precedes the onset 
of labor in women in a manner analogous to the decline in maternal plasma progesterone concentration in other species.

152 Isolation of Mycoplasma from the Endocervix in Patient Population of the

EndocrineInfertility Clinic of the B.M.H., N.Y.

Zeev W. Koren, Michael Lev Gur and Eli Spigland

Department of Obstetrics-Gynecology, Albert Einstein College of Medicine, Bronx, N.Y.

Investigation was performed to examine the relationship between the presence of: mycoplasma in endocervix; habitual abortion; infertility of unknown origin. Endocervical culture for mycoplasma was taken from 262 patients. The patients were divided into four Scientific Abstracts

99

groups: (a) 32 women with history of 2 or more consecutive spontaneous abortions; (b) 112 women with primary or secondary infertility; (c) 72 women during their first or second trimester of pregnancy, and (d) 46 women from the family planning to serve as controls.

Only 30 of total 262 patients revealed mycoplasma in their endocervix. No significant

differences were found among the four groups. Our results indicate that the presence of mycoplasma in endocervix is of no clinical importance.

153 Progesterone-Altered Protein Synthesis in Human Endometrium

Sander S. Shapiro

University of Wisconsin Center for Health Science, Department of

Obstetrics-Gynecology, Madison, Wise.

Human endometrium contains more protein per unit wet weight or DNA during secretory than during the proliferative phase. Prolíferative endometrium in organ culture can be stimulated to synthesize increased amounts of protein by the addition of progesterone $(\mathrm{P})$. The present protocol was designed to establish whether $\mathrm{P}$ is also a stimulus to the production of specific endometrial proteins. Human endometria obtained at various times in the menstrual cycle were evaluated for cytoplasmic protein profiles, new protein synthesis and $\mathrm{P}$ altered protein synthesis using polyacrylamide gel electrophoresis. Freshly extirpated endometrium was incubated for $2 \mathrm{~h}$ in MEM containing either $14 \mathrm{C}$ - or $1 / 8$ labeled leucine. The $100,000 \mathrm{Xg}$ supernatants from tissue homogenates were electrophoresed either singly or after combining samples (opposite labels) from two different patients. Gels were then either stained and scanned or sliced and counted. Proliferative endometrium was maintained in organ culture for up to 4 days with and without the addition of $\mathrm{P}(0.1 \mu \mathrm{g} / \mathrm{ml}$ of medium $)$. Cultured endometria were isotopically labeled after various periods of culture. Supernatants from a single culture experiment, having opposite labels, were combined, electrophoresed and counted. Analysis of gel scans from various cycle days showed significant profile differences. Isotope ratios in gels combining pre- and post-ovulatory samples showed ratio changes in the same area as did the scans. Isotope ratios in gels from culture experiments showed a single peak ratio change. This peak was at the same $\mathrm{Rf}$ as one of the scan and ratio changes found in the experiments involving comparison of tissues from different cycle days. The mol wt of proteins at this $\mathrm{Rf}$ is estimated to be 22,500. These changes are consistent with P-induced specific protein synthesis.

154 The Effects of Halothane and Enflurane on Calcium Accumulation by Sarcoplasmic Reticulum from Bovine Smooth Muscle

Jordan D. Miller and Mary E. Carsten

Departments of Anesthesiology and Obstetrics-Gynecology, University of California 
School of Medicine, Los Angeles, Calif.

The uterine relaxant effects of anesthetics such as halothane have been well documented though the cellular site of action is not presently known. This laboratory has previously shown that sarcoplasmic reticulum (SR) which controls the maintenance of free calcium in the cell is modified in its ability to take up calcium by contractile and relaxing hormones. The direct effect of anesthetics on SR derived from pregnant bovine uterus were studied. Halothane up to $4 \%$ or enflurane $10 \%$ in equilibration with the incubation medium

Society for Gynecologic Investigation

100

produced no effects on ATP-dependent calcium binding. 10\% halothane caused a decrease in ATP-dependent calcium binding. There was no change in SR calcium in the absence of ATP. Since an agent which causes relaxation should increase the calcium binding in the presence of ATP, the anesthetics do not seem to work through this mechanism. The effects of very high levels of halothane which produce a decreased accumulation of calcium by SR may represent a toxic effect of halothane but this is not the mechanism by which it produces relaxation under clinical conditions.

155 Heart Rate Variability in Brain-Damaged Adults

Richard I. Lowensohn, Martin H. Weiss and Edward H. Hon

Department of Obstetrics-Gynecology, University of Southern California School of Medicine, Los Angeles County-University of Southern California Medical Center, Los Angeles, Calif. Short- and long-term heart rate (HR) variability as seen on the cardiotachometer records in the fetus and neonate appear to reflect the integrity of the central nervous system. For this reason, a study was done of HR variability and patterns in a group of normal and a group of neurologically damaged adults. These results were then compared to normal fetal and newborn values. To limit the known effect of subject age on variability, the normal group was composed of 8 individuals at rest, aged 28-34. The normals were homogenous, with mean HR of 82 b.p.m. and range of 70-90. Short-term variability (STV) was greater than 3 b.p.m./beat, and long-term variability (LTV) was 6-10 b.p.m./min in two cases, $11-25$ b.p.m./min in six. There was uniform variability throughout the monitoring period of $30 \mathrm{~min}$ in all cases. Normal STV is $2-5$ b.p.m./beat in the fetus and 2-12 b.p.m./ beat in the neonate; normal LTV is $6-25$ b.p.m./min in the fetus and in the neonate.

The neurologically damaged group consisted of patients in coma from trauma or intra-cerebral hemorrhage; with no medication given. Their patterns during coma were characterized by wide cyclic swings in variability. Almost all cases had periods of STV and LTV of 0-2 b.p.m. which were associated with quiet periods clinically, and periods of marked LTV of 30-60 b.p.m./min associated with STV of less than 10 b.p.m. - in most instances less than 5 b.p.m./beat. These active periods were associated with decerebrate posturing and heart rate accelerations in all cases. This STV/LTV dissociation is not seen in the normal fetus or neonate, nor in our group of normal adults.

156 Interaction of Adrenergic Agents, Oxytocin (OT) and Prostaglandins (PG) on the Rat Uterus in vivo

Mutsuo Ishikawa and Anna-Riitta Fuchs

The Population Council, Center for Biomedical Research, Rockefeller University, New York, N.Y.

The effect of adrenergic receptor activation and inhibition on oxytocin and prostaglan-din stimulation on the rat myometrium has mainly been studied in vitro, and the results do not 
necessarily apply in vivo. The interaction of sympathomimetics and oxytocic substances was therefore studied in conscious, unrestrained rats by means of intrauterine balloons for pressure recording (IUP) and extracellular electrodes for recording of electrical activity. Ovariectomized rats were treated with vehicle oil $(\mathrm{O}), 1 \mu \mathrm{g}$ estradiol-17íi (E) or $5 \mathrm{mg}$ proges-

Scientific Abstracts

101

terone (P) for 3 days. In E animals, OT and PG caused an immediate increase in electrical activity, consisting of bursts of action potentials synchronously along the uterine horn. Norepinephrine (NE) also initiated synchronous bursts of action potentials, while epineph-rine (EP) caused relaxation and cessation of all electrical activity. Phenoxybenzamine, $5 \mu \mathrm{g}$, i.v., and $\alpha$-receptor blocker, inhibited the response to NE, PGFtq, $(5 \mu \mathrm{g}$ i.v. $)$ and to $1 \mathrm{mU}$ OT; the effect of $5 \mathrm{mU}$ OT was not inhibited but the conduction of the electrical activity was impaired. In the P-rats, both NE and EP caused relaxation and abolished electrical activity, but Ø-receptor blockers prevented this effect. The stimulatory effect of OT and PGF2 $\alpha$ was enhanced by (3blockers. In $\mathrm{O}$ rats, the results were ambiguous.

The results suggest that the balance of a- and /3-receptors in the rat uterus is controlled by steroids and that adrenergic mechanisms modulate the uterine response to oxytocic agents. 157 Dissociation of Mechanical and Electrical Activities of Rat Myometrium in vivo by Progesterone

Anna $\cdot$ Riitta Fuchs and Mutsuo Ishikawa

The Population Council, Center for Biomedical Research, Rockefeller University, New York, N.Y.

Previous studies (Fuchs: 1974, 1975) have shown that the classical concept of stimulation of uterine activity by estrogen-17(3 (E2) and inhibition by progesterone (P) does not hold for the rat, where the opposite effects are found. To elucidate this paradox, intra-uterine pressure (IUP) was recorded in conscious, unrestrained rats simultaneously with electrical activity, recorded by thin insulated wires (OD $90 \mu$ ) inserted at several sites along the uterus. 3 days after ovariectomy, daily injections of vehicle oil $(\mathrm{O}), 1 \mu \mathrm{g}$ E2, or $5 \mathrm{mg} P$ were given i.m. Electrical activity of the longitudinal muscle layer consisted of bursts of action potentials (AP); the duration, amplitude and frequency of bursts were hormone-dependent. Ovariectomy was followed by an increase of burst frequency and duration and a decrease of amplitude and conduction velocity along the uterine horn. The frequency of IUP changes increased with the increase of burst frequency. E2 treatment resulted in infrequent bursts of short duration, high amplitude and rapid conduction, associated with IUP changes. Treatment with P resulted within $24 \mathrm{~h}$ in marked depression of AP and complete disappearance of burst activity, but marked contractile activity persisted. The IUP changes recorded at different sites were asynchronous. After withdrawal of $\mathrm{P}$ and treatment with $\mathrm{E} 2$ the electrical activity reappeared.

$158 \mathrm{~T}$ and B Lymphocytes in Normal and Abnormal Pregnancies

James R. Scott and Thomas L. Feldbush

Departments of Obstetrics-Gynecology and Microbiology, University of Iowa College of Medicine, Iowa City, Iowa

The percentage of Thymus derived (T) (sheep RBC rosette forming) lymphocytes responsible for cellular immune responses and Bone marrow derived (B) (immunofluores-cence of membrane bound immunoglobulins) antibody producing cells in maternal blood has been established for normal gestation as follows:

Society for Gynecologic Investigation 
102

Group Lymphocytes/ T cells B cells

$\mathrm{mm} 3 \pm \mathrm{SEM} \quad \% \pm \mathrm{SEM} \quad \% \pm$ SEM

Nonpregnant $(\mathrm{n}=10) 1,278.7 \pm 131.9 \quad 64.5 \pm 1.9 \quad 16.8 \pm 1.0$

Pregnant: first trimester $(\mathrm{n}=10) \quad 1,000.5 \pm 111.1 \quad 58.2 \pm 2.2 \quad 18.9 \pm 1.3$

second trimester $(\mathrm{n}=16 \quad 1,167.4 \pm 106.7 \quad 58.7 \pm 1.9 \quad 18.6 \pm 1.3$

third trimester $(\mathrm{n}=14) \quad 1,167.4 \pm 111.5 \quad 59.2 \pm 2.3 \quad 18.5 \pm 1.1$

$\operatorname{Postpartum}(\mathrm{n}=5) \quad 1,346.2 \pm 241.7 \quad 67.5 \pm 5.0 \quad 20.2 \pm 1.9$

These data are in conflict with a recent proposal that reversal of the T/B cell ratio associated with the serum HCG peak of early pregnancy assists in fetoplacental allograft acceptance but support our contention that it would be unlikely that a single clone of blocking antibody producing B cells could appreciably alter the proportion of circulating T or B lymphocytes. Moreover, variability in lymphocyte dynamics in 4 women followed serially throughout pregnancy as well as similar $\mathrm{T}$ and $\mathrm{B}$ cell values in 17 patients whose pregnancy complications are potentially related to maternal-fetal immunologic aberrations (abortion, hydatidiform mole, preeclampsia, $\mathrm{Rh}$ immunization, twins) suggest that this type of immunologic monitoring of the host immune response will not be as clinically useful in obstetrics as it has been in renal transplantation.

159 A New Mechanism for Late Deceleration of the Fetal Heart Rate

Ming-Neng Yeh, Hisayo O. Morishimo, Raymond I. Stark, Leonard Indyk and L. Stanley James Division of Perinatal Medicine, College of Physicians and Surgeons, Columbia University, New York, N.Y.

Late deceleration of the fetal heart rate (FHR) is a sign of severe fetal asphyxia, but is also seen occasionally when the fetus is neither acidotic nor hypoxic. In a search for other possible causes we postulated that with partial occlusion of the umbilical cord during uterine contractions, the low pressure venous flow would be reduced before changes in arterial flow. This would result in the accumulation of fetal blood in the placenta. Release of the partial occlusion after the contraction would be followed by an increase in venous return and bradycardia from parasympathetic stimulation.

Catheters and electrodes were inserted into 12 fetal baboons, mean gestational age 153 days and an occluding device was placed round the intraabdominal portion of the UV. After $2 \mathrm{~h}$ recovery (fetal pHa $7.36 \pm 0.004$ and Sa02 62 $+2.3 \%$ ) water was gradually injected into the cuff in a volume previously shown to partially occlude the UV. With partial occlusion, FHR rose from 189 to 203 beats/min. These changes in heart rate were significantly different from control (p \&lt; 0.001). The bradycardia was accompanied by a significant elevation of BP.

These observations provide an alternative explanation for the pattern of late deceleration of the FHR and stress the importance of monitoring the fetal acid-base state for correct interpretation of fetal heart rate patterns.

Scientific Abstracts

103

160 Response of the Fetal Lamb Kidney to Vasopressin and Norepinephrine

Jacques M. Milliez, Salha S. Daniel, Raymond I. Stark, Míng-Neng Yeh and L, Stanley James Division of Perinatal Medicine, College of Physicians and Surgeons, Columbia University, New York, N.Y.

Following asphyxia from occlusion of the umbilical cord there is a loss of electrolytes in the urine of the fetal lamb. Since both vasopressin (VP) and catecholamine levels are elevated in fetal blood during asphyxia, experiments have been conducted on 12 fetal lambs, chronically 
instrumented to determine whether there is a relationship between these hormones and the changes in the renal function. Administration of VP (5.0-10 $\mathrm{mU} / \mathrm{kg}$ over $1 \mathrm{~min})$ increased urinary output from 0.17 to a maximum of $0.58 \mathrm{ml} / \mathrm{kg} / \mathrm{min}$, and urine osmolality from 149 to 310 $\mathrm{mOsm} / \mathrm{kg}$ at the end of $1 \mathrm{~h}$. Urine sodium and chloride concentrations increased and free water clearance decreased from 0.08 to $0.02 \mathrm{ml} / \mathrm{kg} / \mathrm{min}$. These changes persisted over $2 \mathrm{~h}$ after the administration of VP. Fetal BP increased only transiently by a maximum of $15 \mathrm{~mm} \mathrm{Hg}$ following VP. Administration of norepinephrine at a rate of $0.05 \mu \mathrm{g} / \mathrm{kg} / \mathrm{min}$ over $30 \mathrm{~min}$ resulted in an increase in urine output from 0.31 to $0.53 \mathrm{ml} / \mathrm{kg} / \mathrm{min}$. Urine osmolality decreased from 170 to $130 \mathrm{mOsm} / \mathrm{kg}$. Free water clearance increased from 0.13 to $0.28 \mathrm{ml} / \mathrm{kg} / \mathrm{min}$, while urine sodium and chloride concentrations remained the same. Control values were achieved $1 \mathrm{~h}$ after the end of the infusion. At this rate of administration norepinephrine had minimal and only transient effect on fetal BP and HR. Thus, in the doses given vasopressin elicited a sodium diuresis and norepinephrine a water diuresis. The combined effect of these two hormones could thus lead to a loss of water and electrolytes.

161 The Effects of Local Anesthetics on Blood Flow and 02 Consumption of the Uterus ofNonpregnant Sheep

Egon Lanz, Donald Caton and Helene Schlereth

Department of Anesthesia and Obstetrics-Gynecology, University of Florida, Gainesville, Fla.

This study was undertaken to define effects of commonly used local anesthetics (LA) on the blood flow (UBF) and 02 consumption (Q02) of the uterus.

Ten nonpregnant sheep were prepared with an electromagnetic flow probe around one uterine artery and catheters in the femoral artery (A) and both uterine veins (UV). UBF and arterial blood pressure (AP) were recorded continuously, A- and UV-02 contents (Van Slyke) and partial pressures before and at the end of a 30-min infusion of the $4 \mathrm{LA}$, administered at rates resulting in clinically observed blood concentrations.

In the absence of marked changes of AP the $\%$ changes between pre- and postinfusion values were:

LA UBF A-UVD02 Q02

Bupivacaine $\quad(0.06 \mathrm{mg} / \mathrm{kg} / \mathrm{min}) \quad-38.5 \quad+35.2 \quad-12.4$

Lidocaine $\quad(0.2 \mathrm{mg} / \mathrm{kg} / \mathrm{min}) \quad-14.7+23.0 \quad-10.9$

Etidocaine $\quad(0.06 \mathrm{mg} / \mathrm{kg} / \mathrm{min}) \quad-7.0 \quad+23.8 \quad-5.9$

2-Chloro-procaine $\quad(0.5 \mathrm{mg} / \mathrm{kg} / \mathrm{min}) \quad-24.0 \quad-13.1 \quad-25.8$

The data suggest that these LA decrease 02 consumption of uterine tissue with concomitant vasoconstriction in the resistance vessels.

Society for Gynecologic Investigation

104

162 Dihydrotestosterone-Binding by Human Endometrium

Eberhard K. Muechler and Donna Kohler

Department of Obstetrics-Gynecology, University of Rochester, School of Medicine and Dentistry, Rochester, N.Y.

The properties of dihydrotestosterone-binding proteins in the human uterus were investigated. Human endometrial tissue was obtained from hysterectomy specimens. The tissue was homogenized in $0.05 \mathrm{M}$ Tris-0.002M EDTA buffer $\left(\mathrm{pH} 7.4\right.$ at $4{ }^{\circ} \mathrm{C}$ ) with or without $10 \%$ glycerol. The $160,000 \times \mathrm{g}$ supernatant was used for dextran-coated charcoal separation of bound hormone after overnight incubation with $(1,2-3 \mathrm{H})$ dihydrotestosterone (DHT) at $4{ }^{\circ} \mathrm{C}$ and 
sucrose density ultracentrifugation. The Krj and binding capacity for DHT were calculated by Scatchard analysis (results represent mean $\pm \mathrm{SE}$ ). The $\mathrm{I} 1 / 8$ for all endometrial samples $(n=7)$ was $5.3 \pm 0.2 \times 10$ " $10 \mathrm{M}$ and the binding capacity was $186.8 \pm 28.5 \mathrm{fmol} / \mathrm{mg}$ protein. The results for proliferative and secretory endometrium were not significantly different. The Krj and binding capacity in the proliferative phase $(\mathrm{n}=3)$ were $5.2 \pm 0.5 \times 10$ "“o $\mathrm{M}$ and $206.6 \pm 55.7 \mathrm{fmol} / \mathrm{mg}$ protein. The respective values for the secretory phase $(\mathrm{n}=4)$ were $5.3 \pm 0.1 \times 10^{\text {” }} \Lambda \mathrm{f}$ and 172 $\pm 33.3 \mathrm{fmol} / \mathrm{mg}$ protein. Heating of cytosol at $56^{\circ} \mathrm{C}$ for $1 \mathrm{~h}$ destroyed DHT-binding. Nonlabeled steroids competed with DHT-binding in the following order: DHT \&gt; testosterone \&gt; estradiol \&gt; norethindrone \&gt; dimethisterone. Sucrose-density and glycerol gradients in TrisEDTA buffer of low ionic strength result in DHT-binding with a 4S. The addition of Trasylol $(1,000 \mathrm{U} / \mathrm{ml})$ and $10 \%$ glycerol to the buffer and a high protein concentration ( \&gt; $10 \mathrm{mg}$ protein $/ \mathrm{ml}$ cytosol) result in $8 \mathrm{~S}$ and $4 \mathrm{~S}$ sedimentation coefficients. These experiments suggest that androgens may influence the development of the endometrium by binding with high affinity to a specific androgen receptor.

163 Influence of Fetal and Newborn Ovaries and Testis on the Onset of Meiosis in vitro Abram B. Fajer, Isadore G. Ances, S. Efhimios Polakis and Alden H. Reese Departments of Physiology, Biochemistry and Obstetrics-Gynecology, School of Medicine, University of Maryland,

Baltimore, Md.

The factors regulating the onset of meiosis in female germ cells in fetal or newborn animals and male germ cells at puberty are poorly understood. It is well established that meanwhile meiosis can proceed in organs maintained in vitro, its onset under the same conditions has not been established.

We have studied in vitro the reciprocal influence of tissues in which meiosis is occurring on premeiotic tissues, male and female. Hamster ovaries and testis of fetuses and newborn animals of known age were maintained in a medium in which $15 \%$ fetal calf serum was the only element of undefined composition. Ovaries showing various stages of the meiotic prophase - days 15-16 postcoitum (p.c.) and days 1-10 postpartum (p.p.) - were incubated with premeiotic ovaries (days $12-14$ p.c.) and testis.

After various periods of coculture (4-10 days) the following results were observed: (1) meiotic ovaries may induce meiosis'in premeiotic ovaries and fetal testis, and (2) fetal testis may inhibit the initial stages of the ovarian meiotic prophase, up to zygotene in very young ovaries, but have no influence on more advanced stages and the consequent follicular organization in the more developed ovaries.

Scientific Abstracts

105

164 Liver and Ductus Venosus Flow in Fetal Lambs

Daniel I. Edelstone, Michael A. Heymann and Abraham M. Rudolph

CVRI, Pediatrics and Obstetrics-Gynecology, University of California, San Francisco,

Calif.

The circulation of the fetal liver was studied 7 times in 5 chronically prepared fetal lambs (123136 days' gestation). Radioactive microspheres were injected simultaneously into inferior vena cava, portal vein (PV), and umbilical vein (UV). Hepatic arterial (HA), PV and UV blood flows $(\mathrm{ml} / \mathrm{min} / 100 \mathrm{~g}$ liver$)$ to the left and right lobes were determined. Mean total liver flow was $472 \pm$ 85 ( \pm SD) consisting of HA $76 \pm 69$, PV $76 \pm 27$ and UV $320 \pm 60$. Total liver flow and the proportion supplied by UV were relatively constant between fetuses, yet the flow to each lobe fluctuated widely. The relative and absolute HA, PV and UV flows within each lobe also varied 
considerably. The left lobe was perfused primarily by UV without significant PV flow (see table). The right lobe was supplied by all 3 circulations, but predominantly by UV. Of UV flow to the liver, $39 \%$ was directed to the right lobe. Ductus venosus (DV) flow ranged between 59 and $154 \mathrm{ml} / \mathrm{min} / \mathrm{kg}$ fetal weight and was unrelated to fetal or liver weight.

The results suggest that the fetal liver is able to maintain its flow within a relatively constant range by altering lobar and DV flows. Since umbilical vessels do not extend to the right lobe, its large UV blood flow is probably related to mixing in the portal sinus with flow through portal vessels; distribution may be determined by the relative vascular resistances in each lobe and DV. 165 The Effects of Maternal Hyperventilation Associated with Exercise on Fetal Oxygenation James F. Clapp, HI

Department of Obstetrics-Gynecology, University of Vermont College of Medicine, Burlington, Vt.

The chronically instrumented ewes and their fetuses were studied before and during graded maternal exercise which produced varying degrees of maternal respiratory alkalosis. In six ewes where maternal pC02 fell to less than $25 \mathrm{~mm} \mathrm{Hg}$ umbilical arterial p02 fell from $17 \pm 0.7 \mathrm{~mm} \mathrm{Hg}$ to $10 \pm 1.5 \mathrm{~mm} \mathrm{Hg}$ and umbilical arterial oxygen content fell from $6.4 \pm 0.3 \mathrm{vol} \%$ to $4.1 \pm 0.8$ vol\%. Despite these observations there was no fall in fetal oxygen consumption, mean values being $9.7 \pm 0.5 \mathrm{~cm} 3 / \mathrm{kg} / \mathrm{min}$ and $10.1 \pm 0.5 \mathrm{~cm} 3 / \mathrm{kg} / \mathrm{min}$. When maternal exercise produced a $\rho \mathrm{C} 02$ of less than $25 \mathrm{~mm} \mathrm{Hg}$ there was a concomitant decrease in both uterine (235 \pm 15 $\mathrm{ml} / \mathrm{kg} / \mathrm{min}$ to $184 \pm 16 \mathrm{ml} / \mathrm{kg} / \mathrm{min})$ and umbilical blood flow $(287 \pm 18 \mathrm{ml} / \mathrm{kg} / \mathrm{min}$ to $263 \pm 17$ $\mathrm{ml} / \mathrm{kg} / \mathrm{min}$ ) resulting in increased exposure time of maternal and fetal bloods at the placental site. With increased exposure time the oxygen difference

Society for Gynecologic Investigation 106 across both placental circulations increased, thereby maintaining oxygen uptake. In these six animals the uterine arteriovenous oxygen difference increased from $4.1 \pm 0.3 \mathrm{vol} \%$ to $5.9 \pm 0.6$ vol $\%$ and the umbilical venoarterial oxygen difference from $3.4 \pm 0.3 \mathrm{vol} \%$ to $3.9 \pm 0.2 \mathrm{vol} \%$. (Supported by National Foundation March of Dimes No. 1-402.)

166 Light Microscopic, Transmission and Scanning Electron Microscopic Studies of Vaginal Colonization

Bryan Larsen, Allen J. Markovetz and Rudolph P. Galask

Departments of Obstetrics-Gynecology and Microbiology, University of Iowa College of Medicine, Iowa City, Iowa

To understand the relationship between the vaginal microflora and the underlying epithelium the bacterial content of the genital tract was compared to the cytological and ultrastructural characteristics of the vaginal epithelium. During the estrous cycle bacterial counts varied cyclically and were highest during estrus. Cytologic examination showed large numbers of bacteria associated with exfoliated cornified epithelial cells. These results were corroborated by scanning electron microscopy of vaginal epithelium of ovariectomized rats with or without estrogen replacement. Scanning electron microscopy showed that prior to estrogen treatment the vaginal epithelium was composed of an intact layer of epithelial cells with microvillous-like projections but lacked any associated bacterial forms. Following estrogen treatment bacterial colonization increased as vaginal cornification increased. Bacterial forms associated with the vaginal epithelium as microcolonies predominantly segregated along intercellular borders.

Bacterial colonization of exfoliated cornified vaginal cells appeared to be greater than colonization of the underlying epithelium. Transmission electron microscopy of the estrogen 
stimulated vaginal epithelium also suggested that the exfoliated vaginal epithelial cells were more heavily colonized than the underlying epithelium. Transmission electron microscopy also indicate; that enhanced colonization of the cornified epithelium may have been related to degradation of keratoprotein.

167 Isolation, Characterization and Spectrum of Activity of an Antibacterial System in Amniotic Fluid (AF)

Rudolph P. Galask, Patrick M. Schlievert and William Johnson

Departments of Obstetrics-Gynecology and Microbiology, University of Iowa College of Medicine, Iowa City, Iowa

The low molecular weight polypeptide component of the inhibitory system was isolated by ultrafiltration, gel filtration, and ion exchange chromatography. Purity was determined by polyacrylamide gel electrophoresis and amino acid composition by an amino acid analyzer. The necessity for zinc as part of the peptide inhibitor complex was demonstrated by dithiazone chelation. The necessity for the peptide as part of the inhibitor complex was shown by loss of activity following carboxypeptidase digestion.

The antibacterial activity of the inhibitory complex against a variety of bacterial species was determined. Using the bacterial plate count technique and an inoculum size of between 103-104 organisms the effect of the inhibitor on bacterial growth was compared to that in a noninhibitory control. Organisms tested include gram positive and gram negative

Scientific Abstracts

107

aerobic and anaerobic bacteria. With the P04-Zn ratio between 100 and 200 the inhibitory effect on the organisms tested varied from bacteriostatic, e.g., Escherichia coli /3-hemolytic

Streptococcus group B to bactericidal, e.g., Klebsiella pneumoniae, Proteus vulgaris, Staphylococcus aureus. Exceptions were Pseudomonas aeruginosa and Streptococcus faecalis which were not inhibited by the peptide-zinc complex using this method. This variability emphasizes the need for a better understanding of the inhibitory nature of the peptide-zinc complex in AF.

168 The Preejection Period of Cardiac Cycles in Fetal Lambs Yuji Murata, Kaoru Miyake, Edward J. Quilligan and Chester B. Martin, jr. Department of Obstetrics-Gynecology, Los Angeles County-University of Southern California Medical Center, Los Angeles, Calif.

Preejection period (PEP) of the cardiac cycle in fetal lambs was estimated by measuring an interval between the onset of Q-wave on fetal ECG and the onset of upstroke of arterial blood pressure tracing. 22 pregnant ewes (gestational age 110-148 days) were used for this study. Fetal ECG electrodes, femoral artery and venous catheters were implanted surgically for continuous biophysical monitoring of the fetus as well as periodic sampling for biochemistry. Electromagnetic flow probe was placed around a fetal carotid artery and an external maxillary branch of jugular vein was catheterized for subsequent injection of radioactive microspheres $(51 \mathrm{Cr}$ and $141 \mathrm{Ce})$. The animals were permitted to recover and experiments performed to study the cardiovascular effect of vagotomy, atropine, hypoxemia and hypercarbia on fetuses. All information was recorded on magnetic tapes which subsequently were played back for PEP analysis.

Due to the difference in location of a tip of catheter, PEP values were varied between different fetuses. PEP, however, exhibited significant increase as the fetal gestational age advanced ( $p$ \&lt; 
0.01). An inverse relationship was found between PEP and arterial blood $\mathrm{pH}$ (p \&lt; 0.01). The was a tendency for a decrease in PEP when coronary blood flow $(\mathrm{ml} / \mathrm{g} / \mathrm{beat})$ increased.

169 Systolic Time Intervals of Cardiac Cycle in Fetal Rhesus Monkeys - Ventricular Ejection Time

Yuji Murata, Chester B. Martin, jr., Kaoru Miyake and Tsuyomu Ikenoue Department of Obstetrics-Gynecology, Los Angeles County-University of Southern California Medical Center, Los Angeles, Calif.

Ventricular ejection time (VET) of the fetal cardiac cycle was studied in chronic rhesus monkey preparations. VET was measured as the interval from the opening to closing signals of semilunar valves on ultrasound Dopplercardiogram. Determinations of VET were carried out on fetuses under physiologic conditions as well as during various experimental and spontaneous stresses. Fetal ECG and BP were recorded continuously, and fetal blood pH and respiratory gas tensions were sampled intermittently.

In normal fetuses, VET exhibited a linear increase as the R-R interval increased. The increment of VET was larger at R-R intervals between 240 to $320 \mathrm{msec}$ than those between 320 to 400 msec. There was no further increase in VET at R-R intervals of more than

Society for Gynecologic Investigation

108

400 msec. Accordingly, all values of VET were corrected for R-R interval for all subsequent analysis. VET showed an inverse linear correlation with diastolic blood pressure (p \&lt; 0.05) and a positive correlation with pulse pressure ( $\mathrm{p} \& \mathrm{lt}$; 0.05). VET was shortened in fetuses with combined acidosis and hypoxemia, but either one alone did not change the VET. Epineph-rine tended to shorten the VET while atropine produced no consistent change. These findings suggest that VET reflects myocardial contractility and is potentially a useful indicator for evaluation of fetal well-being.

170 The Preejection Phase of the Fetal Cardiac Cycle in Diabetic Patients: Antepartum Evaluation

Yuji Murata, Patricia Schmidt, Kaoru Miyake, Peter S. Lu and Chester B. Martin, jr. Department of Obstetrics-Gynecology, Los Angeles County-University of Southern California Medical Center, Los Angeles, Calif.

Several studies have evaluated fetal cardiac performance using noninvasive techniques to determine the preejection period (PEP). Antepartum fetal PEP examinations in diabetic patients were carried out to assess the applicability of this test in a population at risk for sudden fetal distress.

A method obtaining fetal PEP using maternal abdominal wall fetal ECG (AFECG) and Dopplercardiogram (DCG) has been previously described. A total of 82 fetal PEP determinations from 41 hospitalized patients with diabetes mellitus, classes A through D, were studied. The gestational ages (GA) ranged from 33 to 40 weeks. Ten determinations were discarded because of poor DCG record (4) or poor AFECG record (6). All fetuses had normal outcomes with no fetal or neonatal distress. Comparison of fetal PEP with GA showed a positive correlation with $r$ $=0.60, \mathrm{n}=71, \mathrm{p} \& 1 \mathrm{t} ; 0.01$. When fetal PEP, obtained within 7 days of delivery, was compared to neonatal body weight, which ranged from 2,200 to $5,440 \mathrm{~g}$, there was a direct correlation with $\mathrm{r}$ $=0.63, \mathrm{n}=21$ and $\mathrm{p} \& 1 \mathrm{t} ; 0.01$.

Previous studies have determined normal ranges for antepartum and intrapartum fetal PEP values. Present data suggest that in addition to the variable of gestational age, fetal body weight 
must be taken into consideration as a possible etiology in prolongation of PEP, especially when fetal macrosmia is suspected.

171 A Fever Index Evaluation of Chloramphenicol and Clindamycin

William J. Ledger, Carol L. Gee and William P. Lewis

Departments of Obstetrics-Gynecology and Pathology, Los Angeles County-University

of Southern California Medical Center, Los Angeles, Calif.

This random study measured the effectiveness of either chloramphenicol or clindamycin in seriously ill patients by use of the fever index. Other antibiotics were always employed, usually penicillin and an aminoglycoside. During a 24-month interval, 102 patients were studied, 53 received chloramphenicol and 49 clindamycin. The calculation of the fever index in degree hours was performed with the F program of the USC-PACK program, available nationwide on the GE terminal system. All calculations will be expressed in degree hours. Of the 53 women receiving chloramphenicol, the median was 75.1 the mean was 160.2 , SD was $\pm 296.7, \mathrm{SE} \pm 40.8$. For the 49 women receiving clindamycin, the median was 93.8, the mean was 126.9, the SD was \pm 128.2 , and the SE was \pm 18.3 . The difference between these two populations is not statistically significant. This fever index evaluation indicates there is no therapeutic advantage of either of these antibiotics over the other in

Scientific Abstracts

109

women with serious pelvic infections. The decision on which antibiotic is to be selected, should be made on the basis of the physicians concern about the relative toxicity of these two agents.

172 Microbiologic Etiology of Acute Salpingitis

Richard L. Sweet

Department of Obstetrics-Gynecology, University of California at San Francisco School of Medicine, San Francisco, Calif.

In an attempt to establish the microbiologic etiology of acute salpingitis, specimens for culture were obtained by culdocentesis and laparoscopy from peritoneal fluid and tubal exudate in patients with acute salpingitis. The diagnosis of acute salpingitis was visually confirmed laparoscopically. Cultures were obtained from the endocervix for N. gonor-rhoeae, Chlamydia trachomitis, Herpes virus and genital tract mycoplasma. Peritoneal fluid and tubal exudate were cultured for aerobic and anaerobic bacteria, N. gonorrhoeae, C. trachomitis, Herpes and mycoplasma.

Despite the isolation of TV. gonorrhoeae from the endocervix in $46 \%$ of salpingitis cases, this organism was recovered from peritoneal fluid and tubal exudate in only $18 \%$ of these patients. Bacterial isolates from the peritoneal fluid have revealed mixed aerobicanaerobic bacteria in $25 \%$, aerobic bacteria only $17 \%$ and anaerobic only $58 \%$. Although mycoplasma has been isolated from the endocervix in $40 \%$ of salpingitis patients, no isolates of mycoplasma have been recovered from peritoneal fluid.

173 Dopamine Agonists and Serotonin Antagonists in the Management of Hyperprolactinemic States

P. G. Crosignani, E. Reschini, A. Mattei, G. Cammareri and M. Peracchi

Section of Endocrinology, Department of Obstetrics-Gynecology and Department of

Internal Medicine, University of Milan School of Medicine, Milan

Dopamine agonists and serotonin antagonists have been used for the inhibition of puerperal lactation and the treatment of hyperprolactinemic amenorrhea. 34 puerperal women received the dopamine agonist bromocriptine $(2.5 \mathrm{mg}$ b.i.d., p.o. for 14 days $)$ while 20 were treated with 
serotonin antagonist, metergoline ( $4 \mathrm{mg}$ b.i.d., p.o. for 5 days). Puerperal lactation was effectively suppressed by both regimens. The subjects treated with bromocriptine showed a rapid lowering of plasma prolactin $(12 \mathrm{ng} / \mathrm{ml} \pm 4 \mathrm{SD}$ on the 4 th day of treatment $)$ while in those who received metergoline the decrease was less pronounced $(35 \mathrm{ng} / \mathrm{ml} \pm 18 \mathrm{SD})$ but still significant (lactating women $97 \mathrm{ng} / \mathrm{ml} \pm 21 \mathrm{SD}$ ) p \&lt; 0.025. In 4 patients with amenorrhea-galactorrhea (A-G) the intravenous infusion of dopamine $(5 \mu \mathrm{g} / \mathrm{kg} / \mathrm{min}$ for $2 \mathrm{~h}$ was followed by a clear decrease of plasma prolactin levels. In 16 patients with A-G (5 with adenoma), chronic bromocriptine administration (2.5 $\mathrm{mg}$ b.i.d., p.o.) markedly lowered plasma prolactin levels; galactorrhea was stopped in all patients and menses reappeared in all patients but 2, who had evidence of pituitary tumor. 4 patients became pregnant. The long-term treatment with metergoline ( $4 \mathrm{mg}$ b.i.d., p.o.) induced menses in 7 of 12 patients and pregnancy occurred in 1 of them after 2 months of treatment. Plasma prolactin was constantly depressed by metergoline in patients without signs of pituitary tumors (5) while in the adenoma group (7) the trend was quite variable. As in puerperal women, also in A-G patients the effect of metergoline on prolactin levels was less pronounced and more gradual than that exerted by bromocriptine.

Society for Gynecologic Investigation

110

174 Human Fetal Breathing Movements at 34-35 Weeks' Gestation

John Patrick, William Fetherston, Harold Vick and Richard Voegelin

Departments of Obstetrics-Gynecology and Physiology, University of Western Ontario

Medical School, London, Ont.

Human fetal chest wall movements have been suggested as an indicator of fetal health but ultrasonic A-scan methods used to record fetal chest wall movements are technically difficult and include many artifacts. This study was designed to define human fetal breathing movements in utero using a real time ultrasonic scanner.

Continuous recordings were made on 10 fetuses of 34-35 weeks' gestational age between 09.00$17.00 \mathrm{~h}$. Longitudinal scanning of each fetus permitted continuous observation of fetal chest and abdominal wall echoes. During each fetal breathing movement the anterior and posterior fetal chest walls each moved inwards $2-5 \mathrm{~mm}$ and the anterior abdominal wall moved outwards $3-8$ $\mathrm{mm}$. Breathing movements were irregular in amplitude and rate and occurred episodically. Movements described as hiccoughs were observed from time to time in all fetuses. The mean percent time spent breathing from $12.00-17.00 \mathrm{~h}$ was $35.0 \pm 2.5 \%$ (SEM) and was higher than the mean of $26.4 \pm 3.3 \%$ measured from $09.00-12.00 \mathrm{~h}$ ( $\mathrm{p} 0.05)$. During the hour preceding lunch the mean percentage time spent breathing was $18.2 \pm 4.6 \%$ and was significantly less than during the hour following lunch when the fetus breathed $43.6 \pm 5.8 \%$ of the time (p \&lt; 0.02). The mean rate of breathing movements was $49 \pm 0.7 / \mathrm{min}$ and did not change significantly with the time of day.

Real time ultrasonic scanning permits identification of fetal breathing movements. At 34- 35 weeks' gestation human fetal breathing activity is related to the time of day and to ingestion of food by its mother.

175 Inhibition of Leukocyte Migration by Progesterone (P) in vivo and in vitro A.N.

Contopoulos, L.E. Clemens, S. Ortiz, D.P. Stites and P.K. Siiteri Departments of ObstetricsGynecology, Anatomy, Medicine and Laboratory Medicine, University of California at San Francisco School of Medicine, San Francisco, Calif.

Inflammatory and cellular immune responses are mediated by leukocytes that migrate to the site of antigenic stimulation. In the present studies we have observed the migration of cells into the 
placentas of pregnant rats ovariectomized for $0,4,8,12$ or $24 \mathrm{~h}$ on the 11 th day of pregnancy. Placental P concentrations, measured by radioimmunoassay, decreased from 266 to $78 \mathrm{ng} / \mathrm{g}$ tissue between 4 and $12 \mathrm{~h}$ after ovariectomy. A marked infiltration of macrophages and neutrophilic leukocytes into material vessels was apparent $4 \mathrm{~h}$ after ovariectomy. $8 \mathrm{~h}$ after ovariectomy the cell populations were reversed so that the predominant cells were lymphocytes and very few polymorphs were observed. At 8 and $12 \mathrm{~h}$ histological examination demonstrated maternal lymphocytes in the processes of diapedesis and blasto-genesis. The integrity of fetal trophoblast began to degenerate at $12 \mathrm{~h}$ and by $24 \mathrm{~h}$ it was marked with large hemorrhagic areas and almost complete disruption. The direct effect of $\mathrm{P}$ on neutrophil migration was also measured in vitro. Replicate samples (5-7) of human neutrophils were placed in wells in $1 \%$ agar gels containing either P, estradiol (E), testosterone (T) or cortisol (C) each at $20 \mu \mathrm{g} / \mathrm{ml}$. The opaque areas of cell migration were measured after $20 \mathrm{~h}$. In three experiments, $\mathrm{P}$ and $\mathrm{E}$ were inhibitory, $\mathrm{T}$ had no effect and $\mathrm{C}$ stimulated cell migration $(\mathrm{P},-32 \%, \mathrm{E},-19 \%, \mathrm{C},+29 \%)$. These data suggest that placental and/or decidual $\mathrm{P}$ may restrict the movement of leukocytes into the normal placenta prior to parturition.

(Supported by NIH grants HD 8692 and HD 3939.)

Scientific Abstracts

111

176 Ovum Transport in the Ampulla of the Rabbit Oviduct: the Role of Muscle

Sheridan A. Halbert and Richard J. Blandau

Center of Bioengineering and Department of Biological Structure, University of

Washington, Seattle, Wash.

The transport of the egg in cumulus may be effected by either cilia or muscle or both. The purpose of this study was to differentiate between the effectiveness of these two mechanisms. To assess separately the role of muscle, surrogates for cumulus masses were used which were not transported by tue cilia. Boluses of petroleum jelly stained with Sudan black were used as surrogates, and their transport was studied in ovulatory rabbits by using the in vivo abdominal dish preparation of Blandau. The surrogates were introduced into the ampulla with a small pipette. Those deposited within $1 \mathrm{~cm}$ of the ostium were all regurgitated. When placed more than $1 \mathrm{~cm}$ past the ostium, the stained boluses were usually retained. Their motion consisted of discrete, high velocity (up to $2 \mathrm{~mm} / \mathrm{sec}$ ), forward and backward movements. About one third of the surrogates made no net progress in the direction of the ampu Пo-isthmic junction (AIJ). An equal number moved forward to the AIJ at net velocities from 0.02 to $0.2 \mathrm{~mm} / \mathrm{sec}$ but did not reach it. The remainder were transported to the AIJ at net velocities ranging up to $0.1 \mathrm{~mm} / \mathrm{sec}$. All normal cumulus masses were transported to the AIJ at about $0.1 \mathrm{~mm} / \mathrm{sec}$ net velocity. Our observations show that muscle activity is capable of effecting ampullary cumulus mass transport but that the muscle mechanism is much less efficient and effective than the cilia. The relative behavior of surrogates and cumulus masses observed in the first centimeter of the ampulla indicates that cumulus mass transport is not possible without the cilia mechanism.

(Supported by NIH Contract N01-3-2788.)

177 A Stochastic Model of Oviductal Egg Transport

P. Verdugo, W.I. Lee, S.A. Halbert and R.J. Blandau

Center for Bioengineering and Department of Biological Structure, University of

Washington, Seattle, Wash.

A mathematical description of the relationship between apparent movements of the ovum in the Fallopian tube and the various forces generated by the mechanical effectors of this organ will be 
presented. Within the framwork of a stochastic approach, we have used Langevin's equation to formulate a description of tubal transport which is deduced from qualitative features of this phenomenon rather than induced from numerical fitting of experimental data. We show that egg transport in the tube can be represented as a one-dimensional random walk in a field of external force. The motion of the egg can be described by:

$\mathrm{m}^{\wedge}=-\mathrm{fv}+\mathrm{A}(\mathrm{t})+\mathrm{F}$

at

where $\mathrm{v}$ is the velocity of the egg. The influence of the intraluminal forces on the motion of the egg are represented by: a frictional force $-\mathrm{fv}$; a randomly fluctuating force $\mathrm{A}(\mathrm{t})$, generated by the muscle component of the oviductal wall; and the driving force F generated by cilia. Accordingly the description of egg transport in terms of the probability distribution of ovum positions along the tube has the general form of the Fokker-Plank equation. The specific constraints of the model provide the identification and characterization of the mechanisms involved and predict the various potential alternatives for physiologic regulation of the egg transport processes.

(Supported by USPHS grant GM-1643 and contract HD3-2788.)

Society for Gynecologic Investigation

112

178 In vitro Reduction of the Stretch Modulus of Human Cervical Tissue by the Prostaglandins, PGE2 and PGF2û,

John T. Conrad and Kent Ueland

Department of Obstetrics-Gynecology, School of Medicine, University of Washington, Seattle, Wash.

Samples of human cervical tissue were obtained from women immediately following term delivery from spontaneous labor or oral PGE2-induced labor. An informed consent was obtained in each case. The tissue was cut into strips, measured and placed in a well-oxygenated Ringer's solution bath at $37^{\circ} \mathrm{C}$. The tissue samples were stretched at a constant rate while continuously recording length and tension. The resulting data were converted to stress-strain diagrams from which a stretch modulus was computed for each sample. A total of 44 strips from 21 patients was used. During the course of the stretch, one of the prostaglandins, PGE2 or PGF2 $\alpha(10-6 \mathrm{~g} / \mathrm{ml})$, was added to the test strip of the pair of matched strips. The resulting changes in the stretch modulus were noted and compared to the untreated matched strip.

The PGE2 reduced the stretch modulus an average of $36.2 \%$, as compared to the control; PGF2 $\alpha$ reduced the stretch modulus by an average of $51.2 \%$. The reduction of the yield value was $48.4 \%$ for PGE2 and 50.4\% for PGF2 $\alpha$. Both PGF2 $\alpha$ and PGE2 reduce the stretch modulus of pregnant human cervical tissue in vitro, and it appears that PGF2 $\alpha$ does so to a greater degree.

(Supported by a grant from the Upjohn Company.)

179 Spectral Analysis of Individual Pressure Wave Forms in Spontaneous Active Labor

Marvin L. Chatkoff and Joseph Seitchik

Department of Obstetrics-Gynecology, University of Texas Health Science Center at

San Antonio, San Antonio, Tex.

Previous statistical analyses of selected pressure wave-form parameters discriminated between normal spontaneous, hypocontractile and hypercontractile labor. Spectral analyses of individual wave forms were investigated to define more discriminating wave parameters. 182 contractions obtained from 10 women selected according to a definition of normal spontaneous labor were analyzed. The data was prefiltered at $0.045 \mathrm{~Hz}$. Of the first six harmonics investigated, the first 
harmonic contained on average $91 \%$ of the amplitude and $96 \%$ of the total power in the wave. The fundamental cosine term which is of significance in spreading contractile wave models contained on average $86 \%$ of the amplitude and $92 \%$ of the total spectral power. The fundamental sine term contained on average $4 \%$ of the total power and accounted for a major portion of the wave asymmetry. The phase angle of the first harmonic ranged between $+140^{\circ}$ and $+220^{\circ}$ corresponding to longer or shorter wave tails. Although the 2 nd through 6 th harmonics contain little spectral power, on average less than $4 \%$, they contributed significantly to the first derivative of the pressure and hence to the rates of rise and decay of the wave form. The experimentally determined linear relationship between maximum uterine pressure and maximum rate of pressure rise when analyzed in terms of spectral coefficients indicates that deviations from linearity are related to the magnitudes of the higher order frequency terms. Repetitive patterns in normalized spectral coefficients obtained from series of contractions suggest individual fingerprint characteristics.

Scientific Abstracts

113

180 An Alternative to Prophylactic Antibiotics in the Prevention of Serious Infection following Cesarean Section

Gere DiZerega, Carol L. Gee and William J. Ledger

Department of Obstetrics-Gynecology, Los Angeles County-University of Southern California Medical Center, Los Angeles, Calif.

This random study evaluated the effectiveness of two antibiotic regimens in the post-cesarean section patient at the first clinical sign of infection. This strategy avoided both the use of antibiotics in all high risk patients undergoing cesarean section and the transplacental passage of antibiotics to the fetus. The initiation of therapy parallels the animal model of Gorbach et al. with early onset infection prior to abscess formation. To evaluate the significance of Bacteroides fragilis, the regimens included either penicillin or clindamycin used with gentamicin. To date, 36 patients have received penicillin-gentamicin and 31 clinda-mycin-gentamicin. The differences in treatment outcome have been striking. For those patients receiving penicillin, the median fever index was 91.3 degree hours, the mean 119.2, $\mathrm{SD} \pm 103.7$, and $\mathrm{SE} 17.3 .13$ women $(36 \%)$ required a third antibiotic for cure. For the clindamycin group, the median fever index was 85.5 degree hours, the mean $81.2, \mathrm{SD} \pm 38.4, \mathrm{SE} \pm 6.9$. Three patients $(9.7 \%)$ required a third antibiotic for cure. Seven patients receiving penicillin had a fever index that exceeded the highest in the clindamycin group. If this therapeutic response trend continues an alternative to prophylaxis may be the use of systemic antibiotics limited to patients with clinical evidence of infection.

The Society for Gynecologic Investigation Membership Roster, December 1976 Active Members

Raja Abdul-Karim, MD, Professor of Obstetrics-Gynecology, State University of New York, Upstate Medical Center, 766 Irvin Avenue, Syracuse, NY 13210.

Guy, E. Abraham, MD, Associate Professor of Obstetrics-Gynecology, University of California at Los Angeles, Harbor General Hospital, Torrance, CA 90509.

Robert M. Abrams, DDS, PhD, Associate Professor of Obstetrics-Gynecology, University of Florida College of Medicine, Box 738-MSB, Gainesville, FL 32610.

John Q. Adams, MD, Clinical Professor of Obstetrics-Gynecology, University of Tennessee, 920 Madison Avenue, Suite 926, Memphis, TN 38103. 
Reuben H. Adams, MD, Professor and Chairman of Obstetrics-Gynecology, Baylor University Medical Center, 3500 Gaston Avenue, Dallas, TX 75246.

Karlis Adamsons, MD, PhD, Professor and Chairman of Obstetrics-Gynecology, Brown University, c/o Women and Infants Hospital, 50 Maude Street, Providence, RI 02908.

Silvio Aladjem, MD, Professor of Obstetrics-Gynecology, Head, Perinatal Medicine, Department of Obstetrics-Gynecology, Abraham Lincoln School of Medicine, University of Illinois, 840 South Wood Street, Chicago, IL 60612.

Anthony P. Amarose, PhD, Associate Professor of Obstetrics-Gynecology, University of Chicago, Chicago Lying-In Hospital, Chicago, IL 60637.

Marvin S. Amstey, MD, Associate Professor of Obstetrics-Gynecology, University of Rochester, School of Medicine and Dentistry, 260 Crittenden Boulevard, Rochester, NY 14642.

I.G. Ances, MD, Professor of Obstetrics-Gynecology, University of Maryland, Baltimore, MD 21201.

Gerald G. Anderson, MD, Associate Professor of Obstetrics-Gynecology, Yale University

School of Medicine, 333 Cedar Street, New Haven, CT 06510.

Kenneth L. Barker, PhD, Professor of Obstetrics-Gynecology and Biochemistry, University of Nebraska, 42nd and Dewey, Omaha, NB 68105.

Frederick C. Battaglia, MD, Professor of Obstetrics-Gynecology and Pediatrics, University of Colorado Medical Center, 4200 East Ninth Avenue, Denver, CO 80220.

Alan E. Beer, MD, Associate Professor of Cell Biology and Obstetrics-Gynecology, University of Texas Health Science Center, Southwestern Medical School, 5323 Harry Hines Boulevard, Dallas, TX 75235.

Richard E. Behrman, MD, Carpentier Professor and Chairman, Department of Pediatrics, Scientific Abstracts

115

Columbia University, and College of Physicians and Surgeons, 630 West 168th Street,

New York, NY 10032. Fritz K. Beller, MD, Department of Obstetrics-Gynecology, Westfälische Wilhelms Universi-

tat, Münster, Westfalen, Westring 11, FRG. George Betz, MD, PhD, Associate Professor of

Obstetrics-Gynecology, Research Associate in

Biochemistry, University of Colorado Medical Center, 4200 East Ninth Avenue,

Denver, CO 80220. Reinhart B. Billiar, PhD, Associate Professor, Reproductive Biology and Biochemistry, Case

Western Reserve University, Cleveland, OH 44106. Jack N. Blechner, MD, Professor and Head of Obstetrics-Gynecology, University of Connecticut Health Center, Farmington, CT 06032. Eric Bloch, PhD, Professor of Obstetrics-Gynecology and Biochemistry, Albert Einstein

College of Medicine, 1300 Morris Park Road, Bronx, NY 10461. Robert G. Brame, MD,

Professor of Obstetrics-Gynecology, Duke University Medical Center,

Durham, NC 27710. Paul F. Brenner, MD, Department of Obstetrics-Gynecology, LAC/USC

Medical Center,

1240 North Mission Road, Los Angeles, CA 90033. William E. Brenner, MD, Associate

Professor of Obstetrics-Gynecology, University of North

Carolina, School of Medicine, Chapel Hill, NC 27515. Charles R. Brinkman, III, MD, Professor of Obstetrics-Gynecology, Center for the Health

Sciences, University of California, Los Angeles School of Medicine, Los Angeles, 
CA 90024. John C. Buckingham, MD, Clinical Associate Professor of Obstetrics-Gynecology, The University of New Mexico School of Medicine, 1133 Santa Ana S.E., Albuquerque, NM 87123. Roy L. Butcher, PhD, Department of Obstetrics-Gynecology, West Virginia University

Medical Center, Morgantown, WV 26506. Donald Caton, MD, Associate Professor of Obstetrics-Gynecology, University of Florida,

Box J-254, College of Medicine, Gainesville, FL 32610. David Charles, MD, Professor and Chairman, Division of Obstetrics-Gynecology, Faculty of

Medicine, Memorial University of Newfoundland, St. Johns, Newfoundland, A1C 5S7, Canada. Robert T. Chatterton, jr., MD, Associate Professor of Obstetrics-Gynecology, Department of

Physiology, University of Illinois, Abraham Lincoln School of Medicine, Chicago,

IL 60612. Ronald A. Chez, MD, Pregnancy Research Branch, NICHD, NIH Clinical Center, Room

13N234, Building 10, Bethesda, MD 20014. CD. Christian, MD, Professor and Head of Obstetrics-Gynecology, University of Arizona

Medical Center, 1501 North Campbell Avenue, Tucson, AZ 84724. Luis A. Cibils, MD, Mary

Campau Ryerson Professor of Obstetrics-Gynecology, University

of Chicago, Chicago Lying-In Hospital, 5841 South Maryland Avenue, Chicago,

IL 60637. Robert E. Geary, MD, Associate Professor of Obstetrics-Gynecology, Indiana University

Medical Center, 1100 West Michigan Street, Indianapolis, IN 46202. Thomas H. Clewe, MD, Associate Medical Director, Institute of Clinical Medicine, Syntex

Research, 3401 Hillview Avenue, Palo Alto, CA 94304. Antonio E. Colas, MD, PhD, Professor of Obstetrics-Gynecology and Physiological Chemistry, University of Wisconsin, 1300 University Avenue, Madison, WI 53706. Robert K. Creasy, MD, Associate Professor of Obstetrics-Gynecology, University of California at San Francisco, San Francisco, CA 94143.

Society for Gynecologic Investigation

116

M. Carlyle Crenshaw, jr., MD, E.C. Hamblin Professor of Reproductive Biology and Family Planning, Co-Director, Division of Perinatal Medicine, Department of Obstetrics-Gynecology, Duke University Medical Center, Durham, NC 27706.

Warren Crosby, MD, Professor and Vice Chairman, Department of Obstetrics-Gynecology, University of Oklahoma Medical Center, 800 N.E. 13th Street, Oklahoma City, OK 73104.

Luis B. Curet, MD, Professor of Obstetrics-Gynecology, University of Wisconsin, 1300 University Avenue, Madison, WI 53606.

Maria Delivoria-Papadopoulos, MD, Associate Professor of Physiology, Pediatrics, and Obstetrics-Gynecology, Hospital of the University of Pennsylvania, 3400 Spruce Street, Philadelphia, PA 19104.

Preston V. Dilts, jr., MD, Professor and Chairman of Obstetrics-Gynecology, University of Tennessee College of Medicine, 800 Madison Avenue, Memphis, TN 38163.

Ben Harold Douglas, PhD, Department of Medicine, University Medical Center, Jackson, MS 39216.

William E. Easterling, jr., MD, Professor of Obstetrics-Gynecology, Associate Dean, University of North Carolina, School of Medicine, Old Clinic Building, N.C. Memorial Hospital, Chapel Hül, NC 27514. 
Edward N. Ehrlich, MD, Madison General Hospital, 202 South Park Street, Madison, WI 53715. Theodore Fainstat, MD, PhD, Professor of Obstetrics-Gynecology, University of Kansas Medical Center, Kansas City, KS 66103.

Michel J. Ferin, MD, Assistant Professor of Obstetrics-Gynecology, Columbia University College of Physicians and Surgeons, 630 West 168th Street, New York, NY 10032.

George L. Flickinger, jr., VMD, PhD, Endocrine Section, Department of Obstetrics-Gynecology, University of Pennsylvania Hospital, 3400 Spruce Street, Philadelphia, PA 19104.

Roger K. Freeman, MD, Associate Clinical Professor of Obstetrics-Gynecology, University of Southern California, School of Medicine, Medical Director, Women's Hospital Medical Center, 3801 Atlantic Avenue, Box 1428, Long Beach, CA 90801.

Uwe Ernst Freese, MD, Professor and Chairman of Obstetrics-Gynecology, University of Health Sciences, The Chicago Medical School, 2020 West Ogden Avenue, Chicago, IL 60612.

Emanuel A. Friedman, MD, ScD, Professor of Obstetrics-Gynecology, Harvard Medical School, Beth Israel Hospital, 330 Brookline Avenue, Boston, MA 02215.

Dr. S. Anna-Riitta Fuchs, Staff Scientist, Population Council, Rockefeller University, York Avenue and 66th Street, New York, NY 10021.

Rudolph P. Galask, MD, Associate Professor of Obstetrics-Gynecology and Microbiology, University of Iowa Hospitals, Iowa City, IA 52242.

Norman F. Gant, jr., MD, Associate Professor of Obstetrics-Gynecology, University of Texas, Southwestern Medical School, 5323 Harry Hines Boulevard, Dallas, TX 75235.

James R. Givens, MD, University of Tennessee, Department of Obstetrics-Gynecology, 800 Madison, Memphis, TN 38163.

Robert H. Glass, MD, Associate Professor in Residence, Department of Obstetrics-Gynecology, University of California at San Francisco, San Francisco, CA 94143.

Uwe T. Goebelsmann, MD, Associate Professor of Obstetrics-Gynecology, University of Southern California, 1240 North Mission Road, Room 1M2, Los Angeles, CA 90033.

Mitchell S. Golbus, MD, Associate Professor of Obstetrics-Gynecology, University of California at San Francisco, M1484, 3rd Avenue and Parnassus Street, San Francisco, CA 94143.

Scientific Abstracts

117

Alan Goldfien, MD, Professor of Medicine, Cardiovascular Research Institute and Departments of Medicine and Obstetrics-Gynecology, University of California at San Francisco, Department of Obstetrics-Gynecology, San Francisco, CA 94143. Donald P. Goldstein, MD, Assistant Professor of Obstetrics-Gynecology, Harvard Medical

School, Peter Bent Brigham Hospital, Boston, MA 02115. Robert C. Goodlin, MD, Professor of Obstetrics-Gynecology, University of California, Davis

Sacramento Medical Center, 2315 Stockton Boulevard, Sacramento, CA 95817. Mary Jane Gray, MD, Professor of Obstetrics-Gynecology, University of Vermont, College

of Medicine, Burlington, VT 05401. John W. Greene, jr., MD, Professor and Chairman of Obstetrics-Gynecology, University of

Kentucky, University Hospital, Lexington, KY 40506. Frank C. Greiss, jr., MD, Professor and Chairman of Obstetrics-Gynecology, Wake Forest

University, Bowman Gray School of Medicine, Winston-Salem, NC 27103. Stanley J. Gross, MD, Professor of Anatomy, The University of California at Los Angeles, Center for the Health Sciences, Los Angeles, CA 90024. Erlio Gurpide, PhD, Professor of Obstetrics-Gynecology, Mt. Sinai School of Medicine, City 
University of New York, Mt. Sinai Hospital, New York, NY 10029. John P. Gusdon, jr., MD, Professor of Obstetrics-Gynecology, Wake Forest University,

Bowman Gray School of Medicine, Winston-Salem, NC 27103. Dwain D. Hagerman, MD, Professor of Biochemistry and Obstetrics-Gynecology, University

of Colorado Medical Center, Endocrinology Laboratory, Cont. B197, 4200 East Ninth

Avenue, Denver, CO 80220. Charles B. Hammond, MD, P.O. Box 3143, Duke University

Medical Center, Durham,

NC 27710. Charles E. Hamner, jr., DVM, PhD, Associate Professor of Obstetrics-Gynecology, University

of Virginia, School of Medicine, Charlottesville, VA 22901. Guy M. Harbert, jr., MD, Professor of Obstetrics-Gynecology, University of Virginia,

Box 179, Charlottesville, VA 22901. Paul G.R. Harding, MD, Associate Professor of ObstetricsGynecology, University of Western Ontario, St. Joseph's Hospital, Suite 357, Grosvenor Street, London, Ontario,

Canada W. LeRoy Heinrichs, MD, PhD, Professor and Chairman of Obstetrics-Gynecology,

Stanford

University, Stanford, CA 94305. Andre E. Hellegers, MD, Professor of Obstetrics-Gynecology, Physiology, and Biophysics,

Georgetown University Hospital, Washington, DC 20007. Walter L. Herrmann, MD, Professor of Obstetrics-Gynecology, University of Washington,

School of Medicine, Seattle, WA 98105. Michael A. Heymann, MD, Associate Professor of

Pediatrics and Obstetrics-Gynecology,

1403 HSE, University of California at San Francisco, San Francisco, CA 94143. Richard J.

Hildebrandt, MD, Department of Obstetrics-Gynecology, Harrisburg Polyclinic

Hospital, Harrisburg, PA 17105. John C. Hobbins, MD, Department of Obstetrics-Gynecology,

Yale University School of

Medicine, 333 Cedar Street, New Haven, CT 06510. Calvin J. Hobel, MD, Associate Professor,

Chief of Obstetrics, Obstetrics-Gynecology and

Pediatrics, University of California at Los Angeles, Harbor General Hospital, 1000 West

Carson, Torrance, CA 90509. Barrie John Hodgson, PhD, Assistant Professor of Obstetrics-

Gynecology and Pharmacology,

University of Texas, Health Science Center, 7703 Floyd Curl Drive, San Antonio,

TX 78284. Jaroslav F. Hulka, MD, Associate Professor of Obstetrics-Gynecology and Maternal and

Society for Gynecologic Investigation

118

Child Care, University of North Carolina, School of Medicine and Public Health,

Chapel Hill, NC 27514. Charles A. Hunter, jr., MD, Professor and Chairman of Obstetrics-

Gynecology, Indiana

University Medical Center, 1100 West Michigan Street, Indianapolis, IN 46202. Benjamin T.

Jackson, MD, Associate Professor, Department of Surgery, Boston University

School of Medicine, 80 East Concord Street, Boston, MA 02118. Robert B. Jaffe, MD, Professor

and Chairman of Obstetrics-Gynecology, University of

California at San Francisco, 3rd Avenue and Parnassus Street, San Francisco, 
CA 94143. Raphael Jewelewicz, MD, Associate Professor of Obstetrics-Gynecology, Columbia University, College of Physicians and Surgeons, 630 West 168th Street, New York, NY 10032. Donald C. Johnson, PhD, Professor of Obstetrics-Gynecology and Physiology, University of Kansas Medical Center, Rainbow Boulevard at 39th Street, Kansas City, KS 66103. John W.C. Johnson, MD, Associate Professor of Obstetrics-Gynecology and Environmental

Medicine, Johns Hopkins University Hospital, Baltimore, MD 21205. Wayne L. Johnson, MD, Professor and Chairman of Obstetrics-Gynecology, State University

of New York at Buffalo, 1402 Hodge Avenue, Buffalo, NY 14222. John B. Josimovich, MD, Professor of Obstetrics-Gynecology, University of Pittsburgh,

Magee-Womens Hospital, Forbes and Halket Streets, Pittsburgh, PA 15213. Howard L. Judd, MD, Associate Professor, Department of Reproductive Medicine, University of California, San Diego, School of Medicine, La Jolla, CA 92037. Nathan G. Kase, MD, Professor and Chairman of Obstetrics-Gynecology, Yale University

School of Medicine, 333 Cedar Street, New Haven, CT 06510. John V. Kelly, MD, Professor of Obstetrics-Gynecology, University of Arizona Medical

School, Chairman, Department of Obstetrics-Gynecology, Maricopa County Hospital, 2601 East Roosevelt, Phoenix, AZ 85008. William G. Kelly, PhD, Professor of ObstetricsGynecology, University of Minnesota,

Box 295 Mayo Memorial Building, Minneapolis, MN 55455. William Kiekhofer, MD, Professor of Obstetrics-Gynecology, Clinical Sciences Building,

Michigan State University, East Lansing, MI 48824. Moon Hyun Kim, MD, Associate Professor of Obstetrics-Gynecology, Ohio State University

Hospital, 410 West 10th Street, Room N-611, Columbus, OH 43210. Theodore M. King, MD, $\mathrm{PhD}$, Professor and Chairman of Obstetrics-Gynecology, Johns

Hopkins University, University Hospital, Baltimore, MD 21205. Thomas H. Kirschbaum, MD, Professor and Chairman of Obstetrics-Gynecology, Michigan

State University, B-316 Clinical Sciences Building, East Lansin, MI 48824. James D. Kitchin, III, MD, Associate Professor of Obstetrics-Gynecology, University of

Virginia, School of Medicine, Charlottesville, VA 22901. Ernest I. Kohorn, MD, Professor of Obstetrics-Gynecology, Yale University School of Medicine, 333 Cedar Street, New Haven, CT 06510. Zeev W. Koren, MD, Associate Professor of Obstetrics-Gynecology, Albert Einstein College

of Medicine, 1300 Morris Park Avenue, Bronx, NY 10461. Kermit E. Krantz, MD, Professor and Chairman of Obstetrics-Gynecology, Professor of

Anatomy, Associate to Executive Vice Chancellor for Facilities Development, The University of Kansas Medical Center, Rainbow Boulevard at 39th Street, Kansas City, KS 66103. Stanley Kushinsky, PhD, Director of Biochemical Research, Rees-Stealy Clinic Research

Foundation, 2001 Fourth Avenue, San Diego, CA 92101. Emmet J. Lamb, MD, Associate Professor of Obstetrics-Gynecology, Stanford University

Medical Center, Stanford, CA 94305.

Scientific Abstracts

119

Niels H. Lauersen, MD, Department of Obstetrics-Gynecology, Cornell University Medical College, New York, NY 10021. 
William J. Ledger, MD, Professor of Obstetrics-Gynecology, University of Southern California, School of Medicine, Los Angeles, CA 90033.

William J. LeMaire, MD, Associate Professor of Obstetrics-Gynecology, University of Miami School of Medicine, P.O. Box 875, Biscayne Annex, Miami, FL 33152.

John L. Lewis, jr., MD, Professor of Obstetrics-Gynecology, Cornell University Medical College, Chief, Gynecology Service, Memorial Hospital, 1275 York Avenue, New York, NY 10021.

Ta-Jung Lin, MD, Professor of Obstetrics-Gynecology, Medical College of Georgia, Augusta, GA 30902.

Marshall D. Lindheimer, MD, Professor of Obstetrics-Gynecology and Medicine, University of Chicago, Chicago Lying-in Hospital, 5841 Maryland Avenue, Chicago, IL 60637.

A. Brian Little, MD, Professor of Obstetrics-Gynecology, University Hospitals, 2065 Adel-bert Road, Cleveland, $\mathrm{OH} 44106$.

Lawrence D. Longo, MD, Professor of Obstetrics-Gynecology and Physiology, Loma Linda University, School of Medicine, Loma Linda, CA 92354.

James A. Low, MD, Professor and Head of Obstetrics-Gynecology, Queen's University, Kingston General Hospital, Kingston, Ontario, Canada

Paul MacDonald, MD, Professor and Chairman of Obstetrics-Gynecology, University of Texas, Southwestern Medical School, 5323 Harry Hines Boulevard, Dallas, TX 75235.

Virindra B. Mahesh, PhD, Regents Professor and Chairman of Endocrinology, Medical College of Georgia, Eugene Talmadge Memorial Hospital, Augusta, GA 30902.

Edgar L. Makowski, MD, Professor of Obstetrics-Gynecology, University of Colorado Medical Center, 4200 East 9th Avenue, Denver, CO 80220.

Leon I. Mann, MD, Professor and Chairman of Obstetrics-Gynecology, University of Vermont, College of Medicine, Burlington, VT 05401.

John M. Marsh, PhD, Professor of Biochemistry, University of Miami, School of Medicine, P.O. Box 520875 Biscayne Annex, Miami, FL 33152.

John R. Marshall, MD, Professor of Obstetrics-Gynecology University of California at Los Angeles, Harbor General Hospital, Torrance, CA 90509.

Chester B. Martin, jr., MD, Professor of Obstetrics-Gynecology, Division of Maternal-Fetal Medicine, Los Angeles County-U.S.C. Medical Center, Women's Hospital, 1240 North Mission Road, Room 5K22, Los Angeles, CA 90033.

Luigi Mastroianni, jr., MD, Professor and Chairman of Obstetrics-Gynecology, University of Pennsylvania, 34th and Spruce Streets, Philadelphia, PA 19104.

James H. McClure, MD, Professor of Obstetrics-Gynecology, University of California, Irving Medical Center, 101 City Drive South, Orange, CA 92668.

William J. McGanity, MD, Professor and Chairman of Obstetrics-Gynecology, University of Texas Medical Branch, Galveston, TX 77551.

James A. Merrill, MD, Professor and Head of Obstetrics-Gynecology, University of Oklahoma Medical Center, 800 N.E. 13th Street, Oklahoma City, OK 73104.

Giacomo Meschia, MD, Professor of Physiology, University of Colorado Medical Center, 4200 East Ninth Avenue, Denver, CO 80220.

Girgis Mikhail, MD, Professor and Director of Endocrine Section, Hospital of the University of Pennsylvania, 106 Dulles Building, 34th and Spruce Streets, Philadelphia, PA 19104.

Orlando J. Miller, MD, Professor of Obstetrics-Gynecology, Columbia University, College of Physicians and Surgeons, 630 West 168th Street, New York, NY 10032. 
Daniel R. Mishell, jr., MD, Professor and Associate Chairman, Department of ObstetricsSociety for Gynecologic Investigation

120

Gynecology, University of Southern California, Women's Hospital, Room L1013, 1240 North Mission Road, Los Angeles, CA 90033.

Atef F. Moawad, MD, Associate Professor of Obstetrics-Gynecology, University of Chicago, Chicago Lying-in Hospital, 5841 Maryland Avenue, Chicago, IL 60637.

Gilles R.G. Monif, MD, Associate Professor of Obstetrics-Gynecology, University of Florida College of Medicine, Gainesville, FL 32610.

John A. Morris, MD, Professor and Chief, Division of Reproductive Sciences, Department of Obstetrics-Gynecology, Charles R. Drew Postgraduate Medical School, 12021 South Wilmington Street, Los Angeles, CA 90059.

Robert A. Munsick, MD, PhD, Professor of Obstetrics-Gynecology, Indiana University Medical School, 1100 West Michigan Street, Indianapolis, IN 46202.

Ronald E. Myers, MD, PhD, Chief, Laboratory of Perinatal Physiology, National Institute of Neurological Diseases and Stroke, Auburn Building, Room 106, Bethesda, MD 20014. Frederick Naftolin, MD, DPhil, Professor and Chairman of Obstetrics-Gynecology, McGill University Faculty of Medicine, Obstetrician and Gynecologist-in-Chief, Women's Pavilion, Royal Victoria Hospital, 687 Pine Avenue West, Montreal, Quebec H3A 1A1, Canada.

Robert M. Nakamura, PhD, Associate Professor of Obstetrics-Gynecology, University of Southern California, School of Medicine, Livingston Research Center, 1321 North Mission Road, Los Angeles, CA 90033.

George H. Nelson, PhD, MD, Professor of Obstetrics-Gynecology, Medical College of Georgia, Augusta, GA 30902.

James H. Nelson, jr., MD, Chief of Gynecology and the Vincent Memorial Hospital, Department of Gynecology, Massachusetts General Hospital, Vincent One, Fruit Street, Boston, MA 02114. Robert E.L. Nesbitt, jr., MD, Professor and Chairman of Obstetrics-Gynecology, State University of New York, State University Hospital, 750 East Adams Street, Syracuse, NY 13210.

John B. Nettles, MD, Professor and Head of Obstetrics-Gynecology, University of Oklahoma, College of Medicine, Tulsa Executive Director, Tulsa Obstetrical and Gynecological Education Foundation, 1120 South Utica, Tulsa, OK 74104.

Michael R. Neuman, MD, Associate Professor of Biomedical Engineering, Associate Professor of Electrical Engineering, Research Associate, Department of Reproductive Biology, Department of Obstetrics and Gynecology, Case Western Reserve University, Cleveland, OH 44106.

Robert S. Neuwirth, MD, Professor of Obstetrics-Gynecology, Volumbia University, Director, Obstetrics-Gynecology, St. Luke's Hospital, 1111 Amsterdam Avenue, New York, NY 10025. Miles J. Novy, MD, Associate Professor of Obstetrics-Gynecology, Head, Perinatal Physiology, Oregon Regional Primate Research Center, 505 N.W. 185th Avenue, Beaverton, OR 97005. Julian T. Parer, MD, Department of Obstetrics-Gynecology, University of California at San Francisco, San Francisco, CA 94143.

Albert F. Parlow, PhD, Research Professor of Obstetrics-Gynecology, University of California at Los Angeles, Harbor General Hospital, 1000 West Carson Street, Torrance, CA 90509.

Roland A. Patillo, MD, Associate Professor of Obstetrics-Gynecology, Medical College of Wisconsin, 8700 West Wisconsin Avenue, Milwaukee, WI 53226. 
Carl J. Pauerstein, MD, Professor of Obstetrics-Gynecology and Physiology, University of Texas, Health Science Center, 7703 Floyd Curl Drive, San Antonio, TX 78284.

Scientific Abstracts

121

William Paul, MD, Professor of Obstetrics-Gynecology, University of Toronto, Toronto Western Hospital, Suite 352, 399 Bathurst Street, Toronto, Ontario, Canada. Warren H. Pearse, MD, Executive Director, American College of Obstetricians and Gynecologists, One East Wacker Drive, Chicago, IL 60601. Edward N. Peterson, MD, Associate Professor of ObstetricsGynecology, Office of the Dean,

Scaife Hall, Room M-240, University of Pittsburgh, Pittsburgh, PA 15261. Roy M. Pitkin, MD, Professor of Obstetrics-Gynecology, University of Iowa Hospitals, Iowa

City, IA 52242. Gordon G. Power, MD, Professor of Perinatal Research and Obstetrics-

Gynecology, Loma

Linda University School of Medicine, Barton Road, Loma Linda, CA 92354. Harry Prystowsky, MD, Provost and Dean, The Milton S. Hershey Medical Center, Pennsylvania State University, 500 University Drive, Hershey, PA 17033. Edward J. Quilligan, MD, Professor and Chairman of Obstetrics-Gynecology, University of

Southern California, 1200 Mission Road, Los Angeles, CA 90033. Robert Resnik, MD, 5303

Block Street, San Diego, CA 92122.

W. Ann Reynolds, PhD, Professor of Anatomy, Research Professor of Obstetrics-Gynecology, Department of Anatomy, University of Illinois, 1853 West Polk, Chicago,

IL 60612. Ralph M. Richart, MD, Associate Professor of Obstetrics-Gynecology, Columbia University,

College of Physicians and Surgeons, 630 West 168th Street, New York, NY 10032. John W. Roddick, jr., MD, Professor and Chairman of Obstetrics-Gynecology, Southern

Illinois University, School of Medicine, Springfield, IL 62708. Jacques F. Roux, MD, PhD,

Professor of Obstetrics-Gynecology, University of Montreal,

Montreal, Quebec, Canada. Kenneth J. Ryan, MD, Chief-of-Staff, Boston Hospital for Women,

221 Longwood Avenue,

Boston, MA 02115. Hilton A. Salhanick, MD, PhD, Professor of Obstetrics-Gynecology,

Harvard Medical School,

Center for Population Studies, 665 Huntington Avenue, Boston, MA 02115. Naquib A. Samaan, $\mathrm{MD}, \mathrm{PhD}$, Professor of Medicine and Biomedical Science, University of

Texas, Endocrine Section, M.D. Anderson Hospital, Houston, TX 77025. Eugene C. Sandberg, MD, Associate Professor of Obstetrics-Gynecology, Stanford University

Medical Center, 300 Pasteur Drive, Stanford, CA 94305. Gloria E. Sarto, MD, PhD, Professor of Obstetrics-Gynecology, University of Wisconsin,

Center for the Health Sciences, 1300 University Avenue, Madison, WI 53706. John J. Schruefer, MD, Professor of Obstetrics-Gynecology, Georgetown University, School of Medicine, Washington, DC 20007. Harold Schulman, MD, Professor and Chairman of Obstetrics-Gynecology, Albert Einstein

College of Medicine, Bronx Municipal Hospital Center, Room 709, Jacobi, Pelham

Parkway South and Eastchester Road, Bronx, NY 10461. Joseph D. Schulman, MD, National

Institutes of Health, NICHD Building, Room 13N258,

Bethesda, MD 20014. Gebhard F.B. Schumacher, MD, Professor and Chief, Section of

Reproductive Biology, 
Department of Obstetrics-Gynecology, Laboratory of Reproductive Biochemistry and Immunology, The University of Chicago, Chicago Lying-in Hospital, 5841 Maryland Avenue, Chicago, IL 60637. Neena B. Schwartz, PhD, Department of Biological Sciences, Northwestern University, O.T.

Hogan Hall, 2153 Sheridan Road, Evanston, IL 60201. John J. Sciarra, MD, PhD, Professor and Chairman of Obstetrics-Gynecology, Northwestern

University Medical School, Prentice Women's Hospital, 333 East Superior Street, Room 490, Chicago, IL 60611.

Society for Gynecologic Investigation

122

William A. Scoggin, MD, Professor and Chairman of Obstetrics-Gynecology, Medical College of Georgia, Augusta, GA 30902. Antonio Scommegna, MD, Chairman of ObstetricsGynecology, Michael Reese Hospital and

Medical Center, 29th Street and Ellis Avenue, Chicago, IL 60616. Daniel E. Scott, MD, Chairman and Chief of Obstetrics-Gynecology, Presbyterian Hospital

of Dallas, 8200 Walnut Hill Lane, Dallas, TX 75231. James R. Scott, MD, Department of Obstetrics-Gynecology, University of Iowa Hospitals,

Iowa City, IA 52242. A. Elmore Seeds, MD, Professor and Chairman of Obstetrics-Gynecology, University of

Cincinnati Medical Center, College of Medicine, 231 Bethesda Avenue, Cincinnati,

$\mathrm{OH}$ 45267. Sol M. Shnider, MD, Professor of Obstetrics-Gynecology and Anaesthesia, Vice

Chairman of

Anesthesia, University of California at San Francisco, San Francisco, CA 94143. Pentti K.

Siiteri, PhD, Professor of Obstetrics-Gynecology, University of California, San

Francisco Medical Center, San Francisco, CA 94143. Samuel Solomon, PhD, Professor of

Biochemistry and Experimental Medicine, Royal

Victoria Hospital, 687 Pine Avenue, West Montreal 112, P.Q., Canada. A. Louis Southren, MD, Professor of Medicine, Chief of Endocrinology, Department of

Medicine/Endocrinology, New York Medical College, 1249 Fifth Avenue, New York, NY 10029. William N. Spellacy, MD, Professor and Chairman of Obstetrics-Gynecology, University of

Florida, College of Medicine, Gainesville, FL 32610. Leon Speroff, MD, Chairman of Obstetrics-Gynecology, University of Oregon, School of

Medicine, 3181 S.W. Sam Jackson Park Road, Portland, OR 97201. Morton A. Stenchever, MD, Professor and Head of Obstetrics-Gynecology, University of

Utah Medical Center, 50 North Medical Drive, Salt Lake City, UT 84112. Vincent G. Stenger, MD, Professor and Chairman of Obstetrics-Gynecology, Pennsylvania

State University, College of Medicine, Milton S. Hershey Medical Center, Hershey, PA 17033. Vernon C. Stevens, PhD, Department of Obstetrics-Gynecology, Ohio State University

Hospital, 410 West Tenth Avenue, Columbus, OH 43210. Sergio C. Stone, MD, Department of Obstetrics-Gynecology, Louisiana State University

School of Medicine, 1542 Tulane Avenue, New Orleans, LA 70112. Joseph R. Swartwout, MD, Associate Professor of Obstetrics-Gynecology, University of

Chicago, Chicago Lying-in Hospital, Chicago, IL 60637. Luther M. Talbert, MD, Professor of Obstetrics-Gynecology, University of North Carolina, 
School of Medicine, Chapel Hill, NC 27515. O. Eduardo Talledo, MD, Professor of ObstetricsGynecology and Section Chief of Gynecol-

ogy and Gynecological Oncology, Department of Obstetrics-Gynecology, Medical College of Georgia, Augusta, GA 30902. Hans-Dieter Taubert, MD, J.W. Goethe University, Frankfurt am Main, FRG. Henry A. Thiede, MD, Professor and Chairman of Obstetrics-Gynecology, University of

Rochester, School of Medicine and Dentistry, 601 Elmwood Avenue, Rochester, NY 14642. John D. Townsley, PhD, Chief, Perinatal Biochemistry Section, Pregnancy Research Branch,

NIH Clinical Center, Room 5B08, Building 10, Bethesda, MD 20014. Donald R. Tredway, MD, $\mathrm{PhD}$, Clinical Investigation Center, Naval Regional Medical Center,

850 Mountain Boulevard, Oakland, CA 94627. Dan Tulchinsky, MD, Associate Professor of Obstetrics-Gynecology, Harvard Medical

School, Boston Hospital for Women, 221 Longwood Avenue, Boston, MA 02115.

Scientific Abstracts

123

J. Howard Turner, ScD, Associate Research Professor of Obstetrics-Gynecology, Professor of Biostatistics, University of Pittsburgh, Magee-Women's Hospital, Pittsburgh,

PA 15213. John E. Tyson, MD, Associate Professor of Obstetrics-Gynecology, Johns Hopkins Hospital,

601 N. Broadway, Baltimore, MD 21205. Kent Ueland, MD, Professor of Obstetrics-

Gynecology, University of Washington Hospital,

RG-20, Seattle, WA 98105. Carlo Valenti, MD, via del Tritone, 125, 00187 Roma, Italy.

Raymond L. Vande Wiele, MD, Professor and Chairman of Obstetrics-Gynecology, Columbia

University, College of Physicians and Surgeons, 620 West 168th Street, New York,

NY 10032. Helmuth Vorherr, MD, Professor of Obstetrics-Gynecology and Pharmacology,

University of

New Mexico, 915 Stanford N.E., Albuquerque, NM 87131. Edward E. Wallach, MD, Professor of Obstetrics-Gynecology, University of Pennsylvania,

School of Medicine, Chairman, Department of Obstetrics-Gynecology, Pennsylvania

Hospital, Eighth and Spruce Streets, Philadelphia, PA 19107. James C. Warren, MD, PhD,

Professor and Chairman of Obstetrics-Gynecology, Washington

University, 4911 Barnes Hospital Plaza, St. Louis, MO 63110. Gerson Weiss, MD, Department of Obstetrics-Gynecology, New York University Medical

Center, 566 First Avenue, New York, NY 10016. Anne C. Wentz, MD, Department of

Obstetrics-Gynecology, Johns Hopkins University

School of Medicine, Baltimore, MD 21205. Peggy J. Whalley, MD, Professor of ObstetricsGynecology, University of Texas, Southwestern Medical School, 5323 Harry Hines Boulevard, Dallas, TX 75235. Walter G. Wiest, PhD, Professor of Biochemistry in Obstetrics-Gynecology, Washington

University, 4911 Barnes Hospital Plaza, St. Louis, MO 63110. Charles A. Woolever, MD,

Professor of Obstetrics-Gynecology, University of Toronto, St.

Michael's Hospital, Toronto, Ontario, Canada. Ralph M. Wynn, MD, Professor and Head of Obstetrics-Gynecology, The Abraham Lincoln

School of Medicine, University of Illinois at The Medical Center, 840 South Wood 
Street, Chicago, IL 60612. Michael E. Yannone, MD, Professor of Obstetrics-Gynecology, University of North Dakota,

School of Medicine, Grand Forks, ND 58202. Samuel S.C. Yen, MD, Professor and Chairman, Department of Reproductive Medicine,

University of California, San Diego School of Medicine, Department of Reproductive

Medicine C-015, La Jolla, CA 92093. Arturo Zarate, MD, Professor of Endocrinology, Hospital

Gineco-Obstetricia, No. Uno,

Gabriel Mancera 222, Mexico, 12, D.F. Frederick P. Zuspan, MD, Professor and Chairman of

Obstetrics-Gynecology, The Ohio

State University, 410 West 10th Street, Columbus, OH 43210.

Emeritus Members

Nicholas S. Assali, MD, Professor of Obstetrics-Gynecology and Physiology, University of

California at Los Angeles, Center for the Health Sciences, Los Angeles, CA 90024.

Paul D. Bruns, MD, Professor and Chairman of Obstetrics-Gynecology, Georgetown University, University Hospital, Washington, DC 20007.

Society for Gynecologic Investigation

124

Richard L. Burt, MD, PhD, Professor of Obstetrics-Gynecology, Wake Forest University,

Bowman Gray School of Medicine, Winston-Salem, NC 27103.

Roberto Caldeyro-Barcia, MD, Professor and Director, Centro Latinoamericano de Perinata-

logía y Desarrollo Humano (OPS/OMS), Cassilla de correo 627, Montevideo, Uruguay.

Arpad I. Csapo, MD, Professor of Obstetrics-Gynecology, Washington University, 4911 Barnes

Hospital Plaza, St. Louis, MO 63110.

David N. Danforth, PhD, MD, Thomas J. Watkins Professor of Obstetrics-Gynecology,

Northwestern University Medical School, 636 Church Street, Evanston, IL 60201.

William J. Dignam, MD, Professor of Obstetrics-Gynecology, University of California at Los

Angeles, Center for the Health Sciences, Los Angeles, CA 90024.

Gordon W. Douglas, MD, Professor and Chairman of Obstetrics-Gynecology, New York

University, 550 First Avenue, New York, NY 10016.

Saul B. Gusberg, MD, Professor and Chairman of Obstetrics-Gynecology, Mt. Sinai School of

Medicine of The City University of New York, Mt. Sinai Hospital, New York, NY 10029.

Arthur L. Haskins, jr., MD, Professor and Chairman of Obstetrics-Gynecology, University of

Maryland, University Hospital, Baltimore, MD, 21201.

T. Terry Hayashi, MD, Professor and Chairman of Obstetrics-Gynecology, University of

Pittsburgh, School of Medicine, Magee Women's Hospital, Pittsburgh, PA 15213.

Charles H. Hendricks, MD, Professor and Chairman of Obstetrics-Gynecology, University of

North Carolina, School of Medicine, Chapel Hill, NC 27515.

Roy G. Holly, MD, Associate Chairman of Obstetrics-Gynecology, University of Wisconsin,

Madison, Medical Director of Planned Parenthood Association of Wisconsin, Chief of

Obstetrics-Gynecology, Mt. Sinai Medical Center, 950 North 12th Street, Milwaukee, WI 53233.

Edward H.G. Hon, MD, Dore Professor of Obstetrics-Gynecology, Chief, Perinatal Research,

Department of Obstetrics, Perinatal Medicine, University of Southern California, Women's

Hospital, Room 5K-40, 1240 North Mission Road, Los Angeles, CA 90033.

Irwin H. Kaiser, MD, Professor of Obstetrics-Gynecology, Albert Einstein College of Medicine, Bronx Municipal Hospital Center, Bronx, NY 10461. 
Schuyler G. Kohl, MD, PhD, Professor and Acting Chairman of Obstetrics-Gynecology, State University of New York, Downstate Medical Center, Brooklyn, NY 11203.

Mortimer Levitz, PhD, Professor of Research in Obstetrics-Gynecology, New York University Medical Center, 550 First Avenue, New York, NY 10016.

John G. Masterson, MD, Professor of Obstetrics-Gynecology, Loyola University, Stritch School of Medicine, 2160 South First Avenue, May wood, IL 60153.

Charles P. McCartney, MD, Clinical Professor of Obstetrics-Gynecology, University of Illinois, P.O. Box 605, Palos Heights, IL 60463.

J. George Moore, MD, Professor and Chairman of Obstetrics-Gynecology, University of California at Los Angeles, Center for the Health Sciences, Los Angeles, CA 90024.

Robert W. Noyes, MD, Clinical Professor of Obstetrics-Gynecology, Stanford University, Director of Clinical Services and Research, Planned Parenthood Association of Santa Clara County, Inc., 17 North Pedro, San Jose, CA 95110.

Ben M. Peckham, MD, PhD, Professor and Chairman of Obstetrics-Gynecology, University of Wisconsin, 1300 University Avenue, Madison, WI 53706.

E. Jurgen Plotz, MD, Professor and Chairman of Obstetrics-Gynecology, University of Bonn, Venusberg, FRG.

Jack A. Pritchard, MD, Gillette Professor of Obstetrics-Gynecology, University of Texas, Southwestern Medical School, 5323 Harry Hines Boulevard, Dallas, TX 75235.

Scientific Abstracts

125

Seymour L. Romney, MD, Professor of Obstetrics-Gynecology, Albert Einstein College of Medicine, 1300 Morris Park Avenue, Bronx, NY 10461. Joseph Seitchik, MD, Professor and Chairman of Obstetrics-Gynecology, University of

Texas, Health Science Center, 7703 Floyd Curl Drive, San Antonio, TX 78229. Alfred I.

Sherman, MD, Professor of Obstetrics-Gynecology, Wayne State University, Sinai

Hospital of Detroit, Detroit, MI 48235. Ethan A.H. Sims, MD, Professor of Medicine, University of Vermont, College of Medicine,

Burlington, VT 05401. Howard J. Tatum, MD, PhD, Associate Director, Bio-Medical Division, The Population

Council, Rockefeller University, York Avenue at 66th Street, New York, NY 10021. Melvin L. Taymor, MD, Associate Professor of Gynecology, Harvard Medical School, Peter Bent Brigham Hospital, Boston, MA 02115. Vincent Tricomi, MD, Professor of ObstetricsGynecology, Associate Dean, Brooklyn-Cumberland Medical Center, The Brooklyn Hospital, 121 DeKalb Avenue, Brooklyn,

NY 11201. Alois Vasicka, MD, Professor of Obstetrics-Gynecology, State University of New York,

Maimonides Hospital, Coney Island Division, Ocean and Shore Parkways, Brooklyn, NY 11235. Gilbert J. Vosburgh, MD, Associate Professor of Obstetrics-Gynecology, Columbia University, Columbia-Presbyterian Medical Center, 622 West 168th Street, New York, NY 10032. J. Robert Willson, MD, Professor and Chairman of Obstetrics-Gynecology, University of

Michigan Medical Center, Ann Arbor, MI 48104. A. Stark Wolkoff, MD, Professor of Obstetrics-Gynecology, University of Kansas Medical

Center, Rainbow Boulevard at 39th Street, Kansas City, KS 66103.

Honorary Members 
Willard M. Allen, MD, Professor of Obstetrics-Gynecology, University of Maryland, Baltimore, MD 21201.

Allan C. Barnes, MD, Vice President, The Rockefeller Foundation, 1133 Avenue of the Americas, New York, NY 10036.

Donald H. Barron, PhD, J. Wayne Reitz Professor of Reproductive Biology and Medicine, University of Florida, J. Hillis Miller Health Center, Gainesville, FL 32601.

Roy W. Bonsnes, PhD, Associate Professor of Biochemistry in Obstetrics and Gynecology, New York Hospital-Cornell Medical Center, 525 East 68th Street, New York, NY 10021.

James T. Bradbury, ScD, 1020 East Olive, Bozeman, MT 59715.

Mary E. Carsten, PhD, Professor in Residence, Department of Obstetrics-Gynecology, University of California at Los Angeles, School of Medicine, Los Angeles, CA 90024.

Leon C. Chesley, PhD, Professor of Obstetrics-Gynecology, State University of New York, Downstate Medical Center, 450 Clarkson Avenue, Brooklyn, NY 11203.

Edwin E. Daniel, PhD, Professor of Pharmacology, University of Alberta, Edmonton, Alta., Canada.

M. Edward Davis, MD, Professor Emeritus of Obstetrics-Gynecology, University of Chicago, 800 Oak Street, Apartment 2-C, Winnetka, IL 60093.

Russell R. de Alvarez, MD, Professor of Obstetrics-Gynecology, Temple University, 3401 North Broad Street, Philadelphia, PA 19140.

Ronald R. Greene, MD, 2730 Bonita Street, Lemon Grove, CA 92045.

Society for Gynecologic Investigation

126

Louis M. Hellman, MD, Deputy Assistant Secretary, US Department of Health, Education and Welfare, Population Affairs, 330 Independence, Washington, DC 20003. Roy M. Hertz, MD, $\mathrm{PhD}$, Departments of Pharmacology and Obstetrics-Gynecology, George

Washington University Medical Center, Ross Basic Science Building, 2300 Eye Street,

N.W., Washington, DC 20037. H. Close Hesseltine, MD, Mary Campau Ryerson Professor

Emeritus, Department of Obstetrics-Gynecology, The University of Chicago, 5807 South

Dorchester Avenue, Chicago,

IL 60637. William C. Keettel, MD, Professor and Chairman of Obstetrics-Gynecology,

University of

Iowa Hospitals, Iowa City, IA 52240. Curtis J. Lund, MD, Professor Emeritus of ObstetricsGynecology, Box 395, University of

Minnesota Hospitals, Minneapolis, MN 55455. Charles E. McLennan, MD, PhD, Professor of

Obstetrics-Gynecology, Stanford University

Medical Center, 300 Pasteur Drive, Stanford, CA 94305. James Metcalfe, MD, Professor of

Medicine, University of Oregon, 3181 S.W. Sam Jackson

Park Road, Portland, OR 97201. Ernest W. Page, MD, Professor and Chairman, Department of Obstetrics-Gynecology,

C.M.D.N.J.-Rutgers Medical School, Piscataway, NJ 08854. Elizabeth M. Ramsey, MD, Mamie

A. Jessup Visiting Professor of Obstetrics-Gynecology,

University of Virginia, 3420 Que Street, N.W., Washington, DC 20007. S.R.M. Reynolds, PhD,

Professor Emeritus of Anatomy, University of Illinois, 933 Old

Hickory Road, Lancaster, PA 17601. Abraham M. Rudolph, MD, Professor of Pediatrics and

Obstetrics-Gynecology, 1403 HSE,

University of California at San Francisco, Cardiovascular Research Institute, San 
Francisco, CA 94143. Hans H. Simmer, MD, Professor and Chairman, Department of Medical History, University

of Erlangen, Bismarckstrasse 6, 852 Erlangen, FRG. Somers H. Sturgis, MD, Clinical Professor of Gynecology, Harvard Medical School, Peter

B. Bent Brigham Hospital

Boston

MA 02115. Claude A. Villee

jr.

$\mathrm{PhD}$

Andelot Professor of Biological Chemistry

Harvard Medical

School

25 Shattuck Street

Boston

MA 02115. 